\title{
ก NWU \\ The association of von Willebrand factor and its cleaving protease (ADAMTS13) with health behaviours in young black and white adults: The African-PREDICT study
}

\section{NH Navise \\ () orcid.org/0000-0002-1377-7383}

Dissertation submitted in fulfilment of the requirements for the degree Master of Health Science in Cardiovascular Physiology at the North-West University

Supervisor: $\quad$ Prof AE Schutte

Co-Supervisor: Dr L Lammertyn

Co-Supervisor: $\quad$ Dr GG Mokwatsi

Examination: November 2019

Student number: 31870864 


\section{Table of Contents}

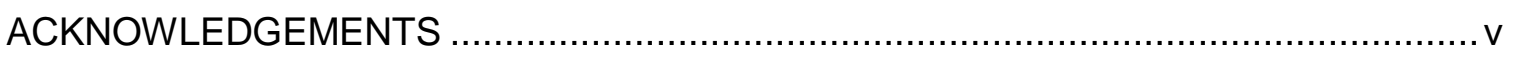

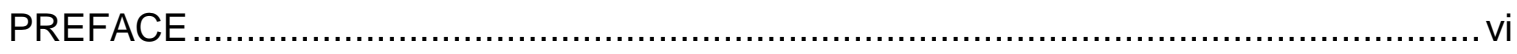

CONTRIBUTIONS OF AUTHORS .............................................................. vii

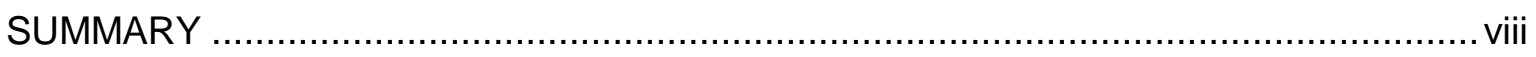

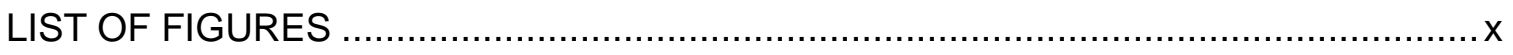

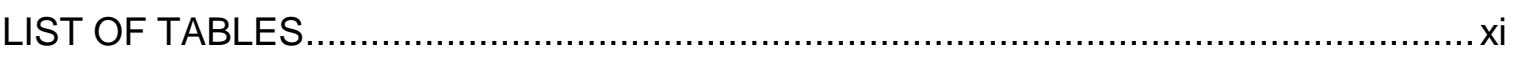

LIST OF ABBREVIATIONS .............................................................................

Chapter 1: Literature review, motivation, aim, objectives and hypotheses

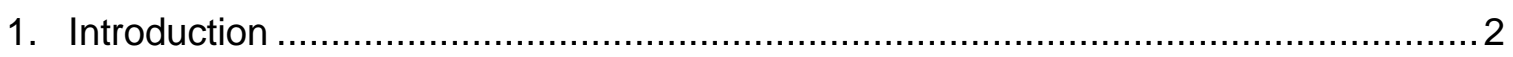

2. Von Willebrand factor and its cleaving protease, ADAMTS13 …........................

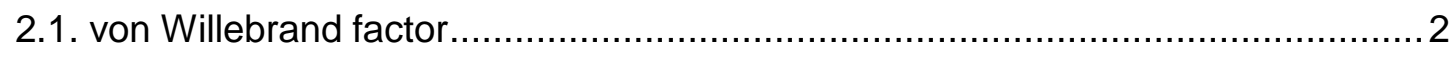

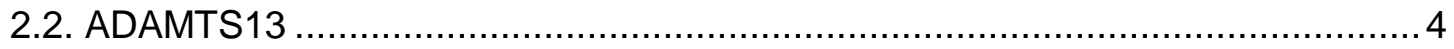

3. Health implications related to VWF and ADAMTS13 plasma levels ........................ 5

4. Factors influencing VWF and ADAMTS13 plasma levels .................................... 6

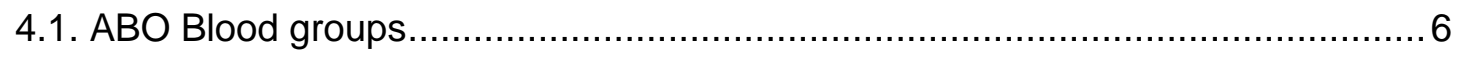

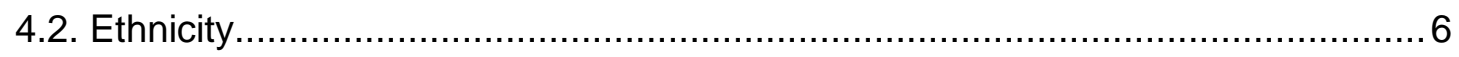

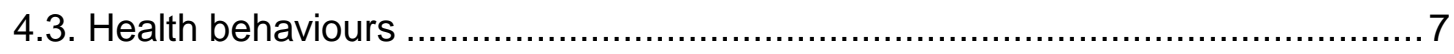

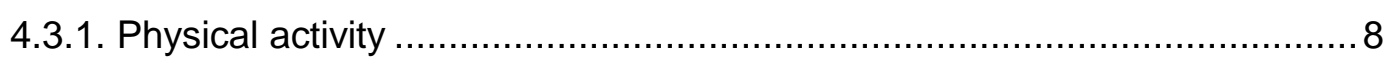

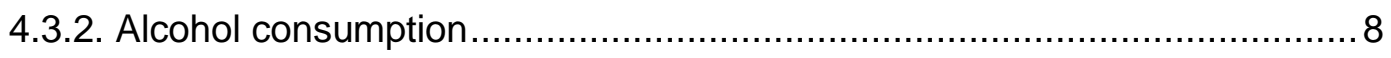

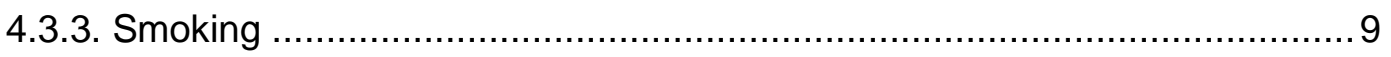

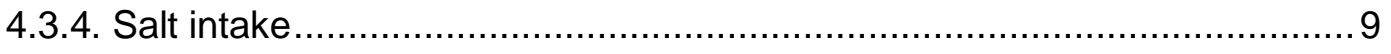

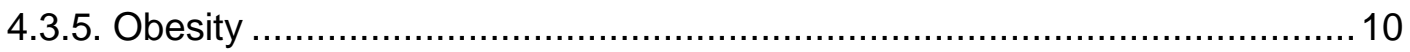

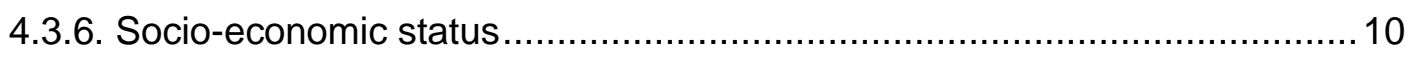


5. Problem Statement and Motivation

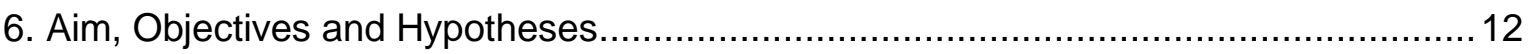

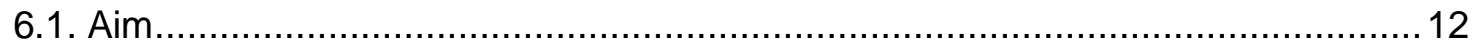

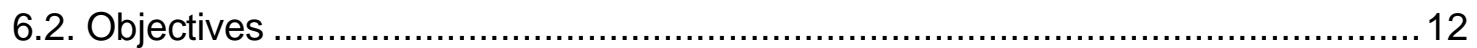

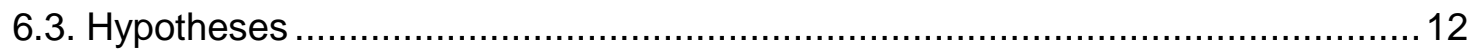

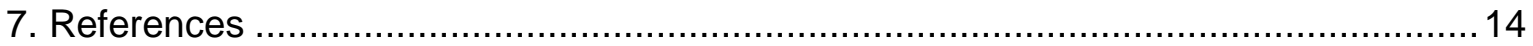

\section{Chapter 2: Methodology}

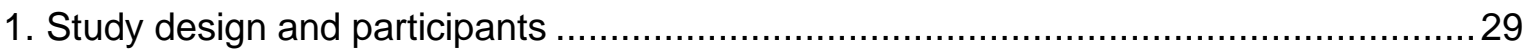

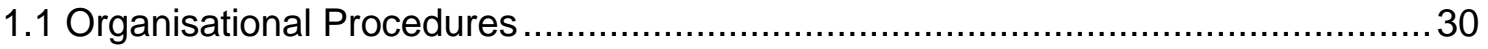

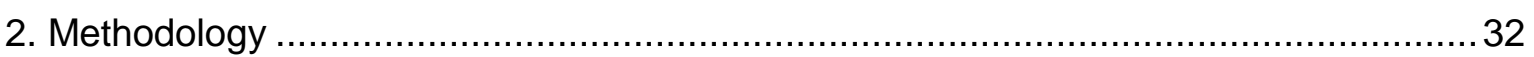

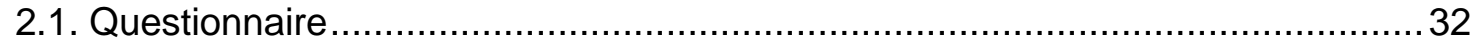

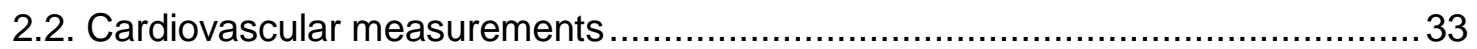

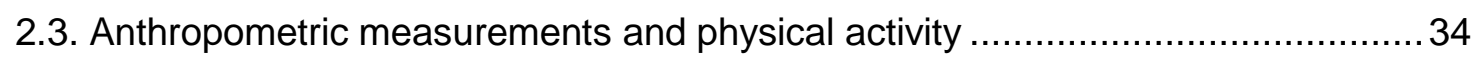

2.4. Biological sampling and biochemical measurements...................................... 35

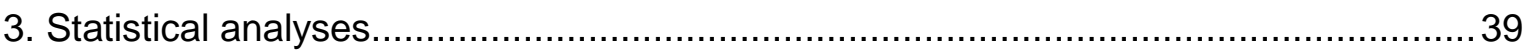

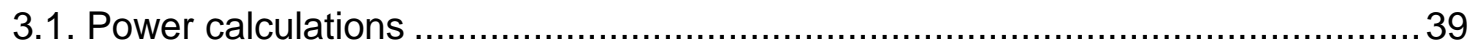

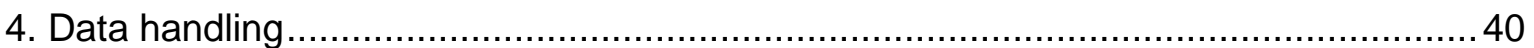

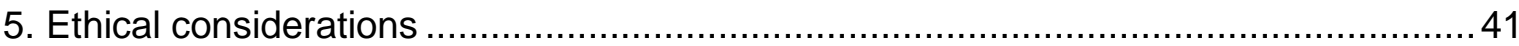

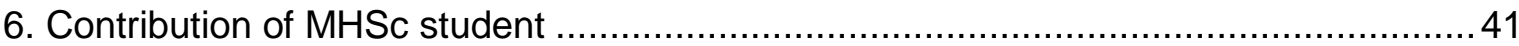

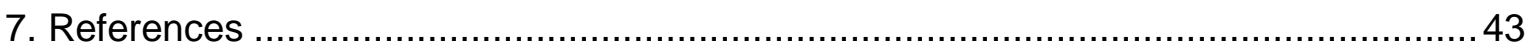

\section{Chapter 3: Manuscript}

Author Instructions 46

The association of von Willebrand factor and its cleaving protease (ADAMTS13) with health behaviours in young black and white adults: The African-PREDICT study 
Abstract

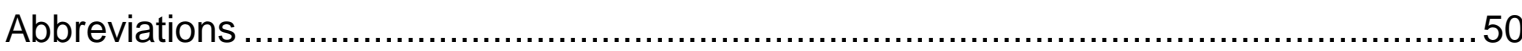

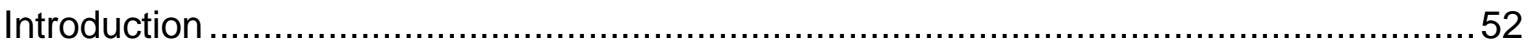

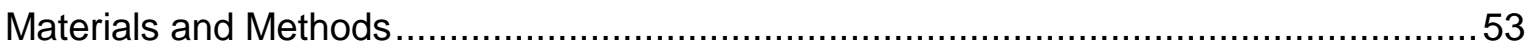

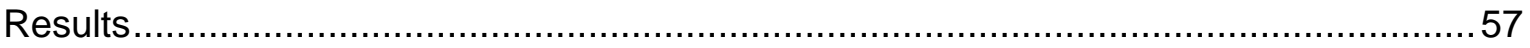

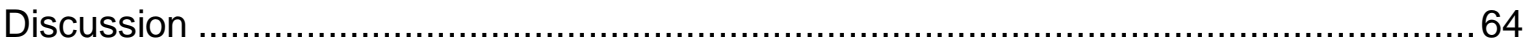

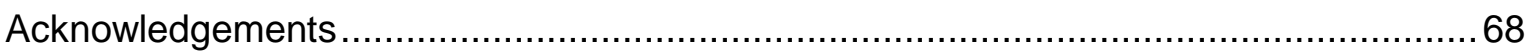

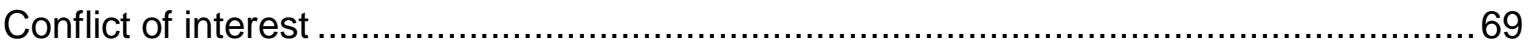

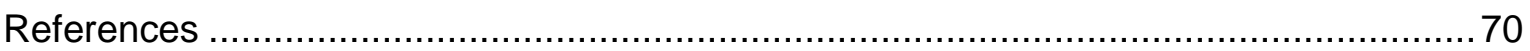

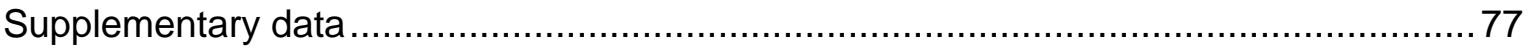

\section{Chapter 4: Summary of main findings and conclusion}

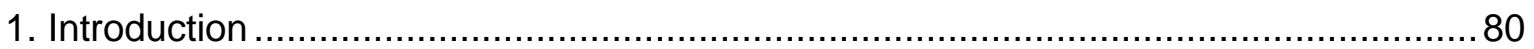

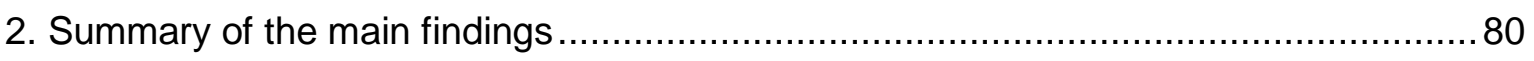

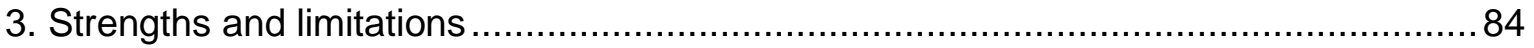

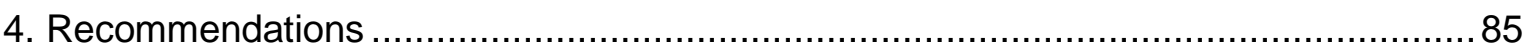

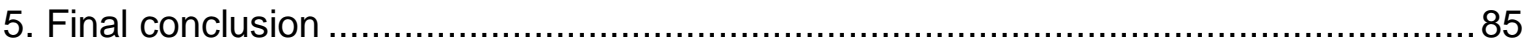

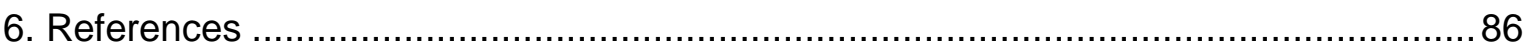

\section{Appendices}

Approval by the Health Research Ethics Committee ................................................. 90

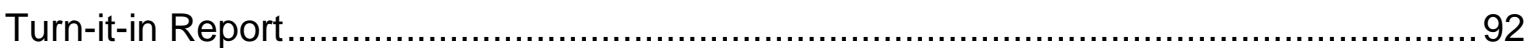

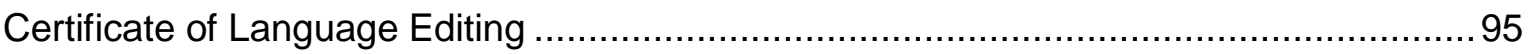




\section{ACKNOWLEDGEMENTS}

I would like to give sincerest gratitude to the following people:

- Prof. AE Schutte, Dr. L Lammertyn, Dr. GG Mokwatsi for their supervision, time, support, guidance, valuable intellectual input, helpful feedback and constructive criticism. Lastly, as a new student I am grateful to them for welcoming me with open arms and for being such great inspiration.

- All the participants who participated in the African Prospective study on the Early Detection and Identification of Cardiovascular Disease and Hypertension (AfricanPREDICT) for their voluntary participation. Without them the study would not be possible.

- The Hypertension in Africa Research Team (HART) staff and students for their hard work and dedication.

- The National Research Foundation (NRF) for the financial assistance. Without their scholarship enrolling for this degree would not have been possible.

- My mother and sister for all their sacrifices, support and unconditional love.

- My grandparents for their support and never ending prayers.

- My friends for their support and encouragement. 


\section{PREFACE}

This dissertation (The association of von Willebrand factor and its cleaving protease (ADAMTS13) with health behaviours in young black and white adults: The African-PREDICT study) is compiled according to the requirements for the degree Master of Health Sciences in Cardiovascular Physiology at the Potchefstroom Campus of the North-West University. The dissertation is compiled in the article format as described and recommended by the NorthWest University. Following this format, the chapter outline is as follows:

Chapter 1: Literature review, motivation, aim, objectives and hypotheses

Chapter 2: Methodology

Chapter 3: Manuscript

Chapter 4: Summary of main findings and conclusion

The manuscript is prepared for submission to the journal, Thrombosis Research. There are no strict requirements on reference formatting at submission for this journal, therefore Vancouver style was used for all the chapters of the dissertation. 


\section{CONTRIBUTIONS OF AUTHORS}

\section{Ms. NH Navise}

Responsible for conducting the literature search, compiling the research proposal, completing the ethics application, performing all statistical analyses and writing the complete dissertation, including the manuscript for publication. The candidate was also responsible for the collection, processing and analysing of blood and urine samples in the laboratory. She also performed cardiovascular measurements for the African-PREDICT study.

\section{Prof. AE Schutte}

As the study supervisor, she supervised and provided intellectual input in the writing of the study proposal, ethics application, manuscript, dissertation and interpretation of results. She provided guidance regarding statistical analysis, initial planning and design of the manuscript.

\section{Dr. L Lammertyn}

She co-supervised the study. She supervised and provided intellectual input in the writing of the study proposal, ethics application, manuscript, dissertation and interpretation of results. She provided guidance and helped with the statistical analysis. She also provided her expertise on the haemostatic markers.

\section{Dr. GG Mokwatsi}

She co-supervised the study. She supervised and provided intellectual input in the writing of the study proposal, ethics application, manuscript, dissertation and interpretation of results. She provided guidance and expertise with the SPSS software and helped with the statistical analysis.

Below is a statement from the co-authors confirming their individual contribution to the study and their permission that the manuscript may form part of this dissertation.

Hereby, I declare that I approved the aforementioned manuscript and that my role in this study as stated above is representative of my actual contribution.

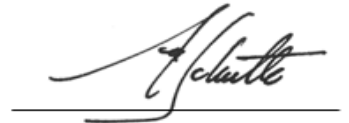

Prof. AE Schutte

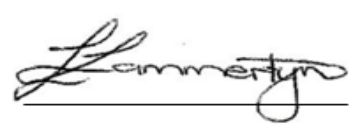

Dr. L Lammertyn

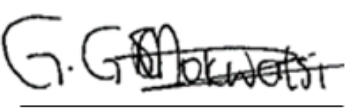

Dr. GG Mokwatsi 


\section{SUMMARY}

\section{Motivation}

Stroke is the second leading cause of death worldwide. In South Africa, the stroke incidence and mortality rate increased significantly in the last 30 years. Elevated plasma levels of the multimeric glycoprotein, von Willebrand factor (VWF) are associated with an increased risk of stroke and other cardiovascular diseases. vWF is responsible for inducing platelet adhesion and aggregation at sites of vascular injury, and for the protection of the blood-clotting protein, Factor VIII from proteolysis. VWF is regulated by ADAMTS13 (A Disintegrin And Metalloproteinase with a ThromboSpondin type 1 motif, member 13) that cleaves vWF into smaller, less reactive molecules.

Previous reports suggest that modifiable lifestyle factors such as physical activity, diet and smoking can contribute to the variation in plasma levels of haemostatic markers. Taking into account the shift towards unhealthy lifestyles in the youth, we investigated the associations between VWF and ADAMTS13 with health behaviours, namely physical activity, alcohol consumption, smoking, obesity, salt intake, and socio-economic status in young black and white adults from South Africa.

\section{Methods}

This study made use of the baseline data of the African-PREDICT study. We included 602 black and 594 white young adults aged 20-30 years. General Health and Demographic Questionnaires were used to report information on socio-economic status (SES), tobacco use, alcohol intake, and contraceptive use. Anthropometric measurements including weight, height and waist circumference were taken, and body mass index (BMI) was calculated. To determine physical activity, accelerometry was used by means of an ActiHeart monitor. Clinic and 24-hour blood pressure measurements were conducted using standard methods. Fasted citrated blood samples were used for the analysis of VWF:Ag and serum samples were used to measure ADAMTS13, cotinine and gamma-glutamyl transferase (GGT). Twenty four-hour urine samples were used to estimate daily salt intake.

\section{Results}

Black adults had higher vWF:Ag and lower ADAMTS13 levels compared to whites (all $p<0.001)$. Multiple regression analyses were carried out in the total group and then within each ethnic group. In the total group, vWF:Ag associated positively with BMI $(\beta=0.09$; $p=0.037)$, while ADAMTS13 associated negatively with $B M I(\beta=-0.10 ; p=0.016)$ and cotinine $(\beta=-0.09 ; p=0.029)$; and positively with GGT $(\beta=0.14 ; p=0.002)$. The vWF:Ag associated 
negatively with black ethnicity $(\beta=-0.25 ; p<0.001)$ while ADAMTS13 associated positively with white ethnicity $(\beta=0.23 ; p<0.001)$. When exploring within each ethnic group, vWF:Ag associated positively with estimated salt intake $(\beta=0.12 ; p=0.043)$ only in the black group, and with BMI $(\beta=0.14 ; p=0.023)$ only in the white group. Whereas, ADAMTS13 associated positively with GGT $(\beta=0.22 ; p=0.003)$ and negatively with cotinine $(\beta-0.14 ; p=0.041)$ in the white group.

\section{Conclusion}

We found ethnic-specific associations between VWF and ADAMTS13 with obesity, salt intake, and smoking. Black individuals may have an increased thrombotic risk than whites, suggested by higher VWF:Ag and lower ADAMTS13 levels. Our findings suggest that in this young healthy population lifestyle factors already play a role in determining cardiovascular risk, thereby confirming the importance of maintaining a healthy lifestyle throughout ones' lifespan. 


\section{LIST OF FIGURES}

\section{Chapter 1}

Figure 1: $\quad$ Schematic diagram of von Willebrand factor showing vWF multimers, dimer and monomer with its functional domains and major binding sites 3

Figure 2: Schematic diagram of ADAMTS13, showing its structural domains and binding sites 5

\section{Chapter 2}

Figure 1: $\quad$ Map of South Africa indicating the city of Potchefstroom in the North-West Province and surrounding areas in which recruitment was conducted......29

Figure 2: $\quad$ Correct posture for blood pressure measurements............................... 33

Figure 3: $\quad$ Anthropometric measurements for the African-PREDICT study .................35

Figure 4: $\quad$ Preparation of the African-PREDICT study blood and spot urine samples39

\section{Chapter 3}

Figure 1: Linear regression analyses between vWF:Ag and ADAMTS13 levels in the total group. 59

Figure 2: $\quad$ Linear regression analyses in the total group between (a) vWF:Ag and SES score and GGT; and (b) ADAMTS13 and SES score and BMI 60 


\section{LIST OF TABLES}

\section{Chapter 2}

Table 1: Detailed eligibility criteria and justification for the African-PREDICT study

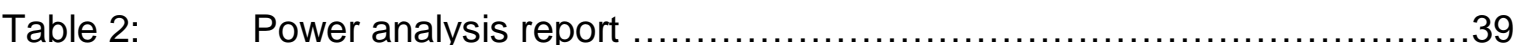

\section{Chapter 3}

Table 1: $\quad$ Characteristics of the study population .58

Table 2: $\quad$ Multiple regression analysis of VWF:Ag and ADAMTS13 with health behaviours in the total group 61

Table 3: $\quad$ Multiple regression analysis of VWF:Ag and ADAMTS13 with health behaviours 63

Table S1: $\quad$ Single linear regression analysis of VWF:Ag and ADAMTS13 with health behaviours 77

Table S2: Analysis of covariance of VWF:Ag and ADAMTS13 levels according to hormonal contraceptive use in all women and separately in black and white women 78 


\section{LIST OF ABBREVIATIONS}

ABPM

ADAMTS13

AEE

African-PREDICT

$\mathrm{Ag}$

$\mathrm{BMI}$

BP

$\mathrm{cm}$

CVD

DBP

$\mathrm{dL}$

EDTA

FVIII

g

GDF

GGT

GPIba

HbAlc

HDL-C

HIV

HRP

hs-CRP
Ambulatory blood pressure monitoring

A Disintegrin And Metalloproteinase with a ThromboSpondin type 1 motif, member 13

Activity energy expenditure

African Prospective study on the Early Detection and Identification of Cardiovascular Disease and Hypertension

Antigen

Body mass index

Blood pressure

Centimetre

Cardiovascular disease

Diastolic blood pressure

Decilitre

Ethylenediaminetetraacetic

Factor VIII

Gram

Growth differentiation factor

Gamma-glutamyltransferase

Glycoprotein Iba

Haemoglobin Alc

High-density lipoprotein-cholesterol

Human immunodeficiency virus

Horseradish peroxidase

High-sensitivity C-reactive protein 
International unit

$\mathrm{KCal} / \mathrm{kg} \quad$ Kilocalorie per kilogram

$\mathrm{Kg}$

Kilogram

LDL-C

Low-density lipoprotein-cholesterol

m

Meter

MHSc

Master of Health Science

mg

Milligram

$\mathrm{ml}$

Millilitre

$\mathrm{mmHg}$

Millimetre of mercury

$\mathrm{mmol} / \mathrm{L}$

Millimole per liter

MPO

Myeloperoxidase

n

Number of participants

$\mathrm{NaCl}$

Sodium chloride

$\mathrm{NaF}$

Sodium fluoride

NAFLD

Non-alcoholic fatty liver disease

$\mathrm{ng} / \mathrm{ml}$

Nanogram per millilitre

$\mathrm{nM}$

Nanomolar

REDCap

Research Electronic Data Capture

SAMRC

South African Medical Research Council

SARChl

South African Research Chairs Initiative

SASCO

South African Standard Classification of Occupation

SBP

Systolic blood pressure

sCAM

Soluble cell adhesion molecule

SES

Socio-economic status 
SVCAM

TC

TTP

U

VWD

vWF

WC
Soluble vascular cell adhesion molecule

Total cholesterol

Thrombotic thrombocytopenic purpura

Units

von Willebrand Disease

von Willebrand factor

Waist circumference 


\section{Chapter 1}

Literature review, motivation, aims, objectives and hypotheses 


\section{Introduction}

Thrombotic events, such as stroke, are one of the leading causes of morbidity and mortality in both developed and developing countries $(1,2)$. Over the last three decades, ischaemic and haemorrhagic stroke incidence has more than doubled in low- and middle-income countries (3). Studies conducted in rural South Africa reported a high prevalence of stroke $(4,5)$, with Maredza et al. reporting an increase in stroke mortality rate of 114 per 100000 person-years during 2007-2011 compared to 87 per 100000 person-years from 1990-1994 (4). Von Willebrand Factor (vWF) is a primary protein secreted during the early stages of the haemostatic process and plays an important role in thrombus formation. Prior studies indicated that high levels of VWF are linked to an increased risk of thrombosis and thrombotic events $(6,7)$. Plasma levels of vWF are regulated by ADAMTS13 (A Disintegrin And Metalloproteinase with a ThromboSpondin type 1 motif, member 13) (8). High vWF and low ADAMTS13 levels have been associated with an increased risk of cardiovascular mortality (9).

\section{Von Willebrand factor and its cleaving protease, ADAMTS13}

\subsection{Von Willebrand factor}

Von Willebrand Factor is a large multimeric glycoprotein that is largely synthesised by endothelial cells and platelets (10), and is found in blood and sub-endothelial connective tissue (11). Newly synthesised vWF multimers are stored in Weibel-Palade bodies of endothelial cells and $\alpha$-granules of platelets, and are secreted as a series of ultra-large multimers in response to vascular injury $(12-14)$. The normal concentration range of circulating plasma vWF is 50-200 IU per dL (15). The vWF plays an important role in primary haemostasis by inducing platelet adhesion and aggregation at sites of vascular injury, and it serves as a carrier for the blood-clotting protein, factor VIII (FVIII) $(14,16,17)$. The size and structure of vWF multimers in the circulation correlates with its prothrombotic activity, where the higher molecular weight multimers indicate a stronger activity whereas a lower molecular 
weight multimers have reduced haemostatic potential (18). As plasma levels of vWF increase in high shear stresses and when the endothelium is damaged, it is considered to be a good marker for endothelial dysfunction (19).

The large multimeric protein, vWF, is composed of over 80 identical subunits with a molecular mass of $250 \mathrm{kDa}$, each consisting of 2050 amino acid residues and up to 22 carbohydrates chains, making up different domains with specific functions (20) (Figure 1). There are four repeated domains (domain A, B, C and D) making up each of the vWF subunits arranged in the sequence: D1-D2-D'-D3-A1-A2-A3-D4-B1-B2-B3-C1-C2-CK (20).

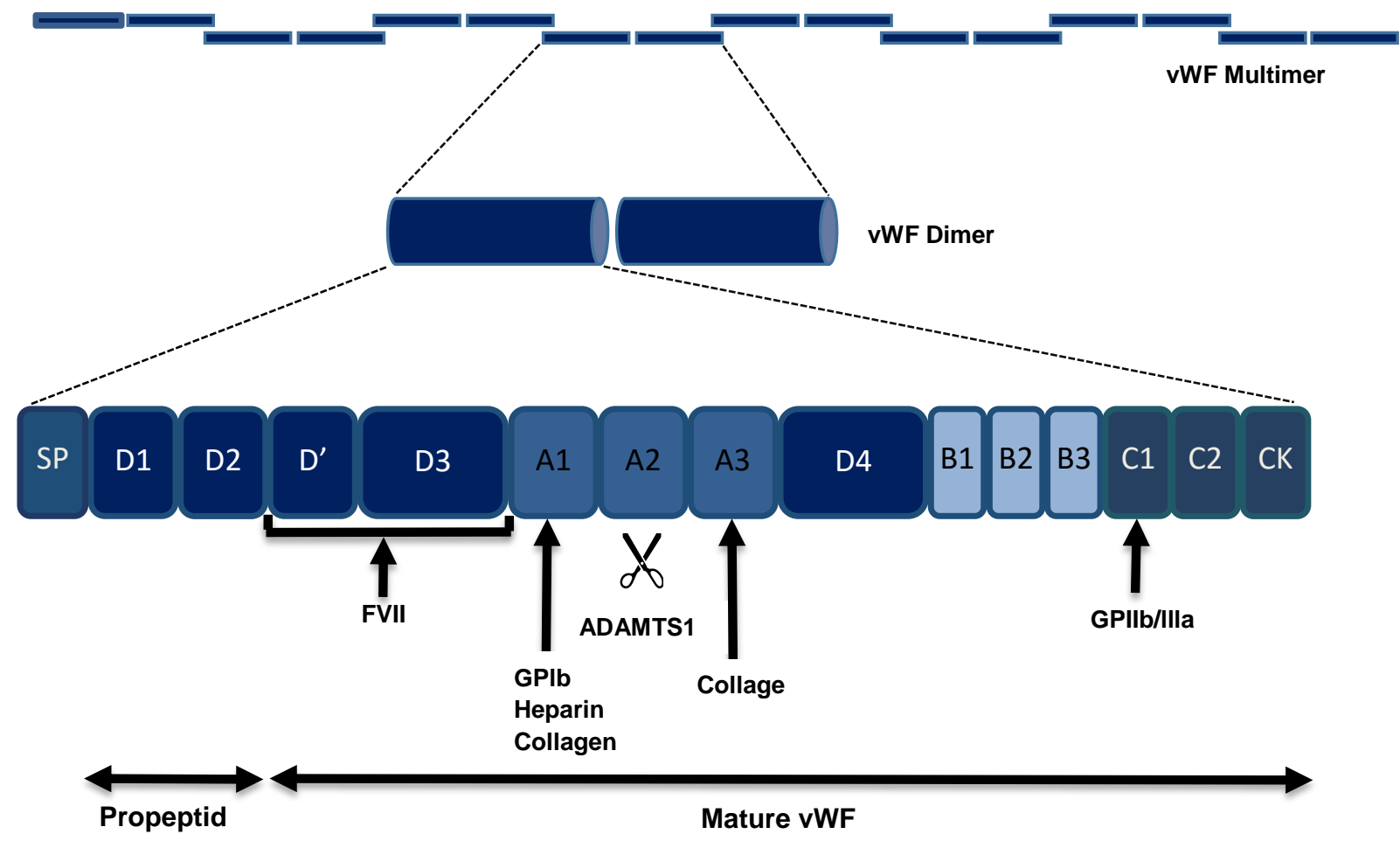

Figure 1: Schematic diagram of von Willebrand factor showing vWF multimers, dimer and monomer with its functional domains and major binding sites. Adapted from De Meyer el al (21).

Domains D1 and D2 constitute the amino-terminal pro-polypeptide and the rest of the domains constitute the mature peptide which is generated upon proteolytic processing (22). The VWF D'D3 domain binds to FVIII (23) protecting it from proteolysis, and therefore, 
maintaining its survival in the circulation, as FVIII is rapidly removed from the circulation in the absence of VWF (24). The A1 domain binds to platelet glycoprotein Iba (GPIba) receptor, heparin, as well as collagen which also binds to the A3 domain (25). In response to an increase in shear stress, the $\mathrm{A} 2$ domain undergoes translation and exposes the cleaving site of VWF for its cleaving protease ADAMTS13 (26). This glycoprotein is regulated by the protease, ADAMTS13, a metalloprotease belonging to the ADAMTS family (8). The highly thrombogenic ultra-large vWF multimers are cleaved by ADAMTS13 into smaller, less reactive molecules $(8,27)$.

\subsection{ADAMTS13 (A Disintegrin And Metalloproteinase with a ThromboSpondin type 1 motif, member 13)}

The ADAMTS13 is a plasma enzyme that is predominantly expressed in the liver and is produced by hepatic stellate cells (28), endothelial cells (29) and platelets upon activation (30). It is secreted into the circulation as an active enzyme and circulates at a plasma concentration of approximately $5 \mathrm{nM}(31,32)$. The major role of ADAMTS13 is to cleave the highly reactive large vWF multimers into smaller less reactive ones (33). By regulation of vWF, ADAMTS13 helps to maintain the delicate balance between bleeding and thrombosis (34).

The structure of ADAMTS13 is similar to that of the other members of the ADAMTS family of metalloprotease (35). The complete amino-acid sequence of ADAMTS13 consists of a signal peptide $(\mathrm{S})$, a propeptide $(\mathrm{P})$, a metalloprotease domain $(\mathrm{M})$, a disintegrin-like domain (Dis), a first thrombospondin-1 repeat (TSP1), a cysteine-rich domain (Cys-R), an ADAMTS spacer (Spa), the 7 additional TSP1 repeats and 2 CUB domains $(27,36)$ (Figure 2). 


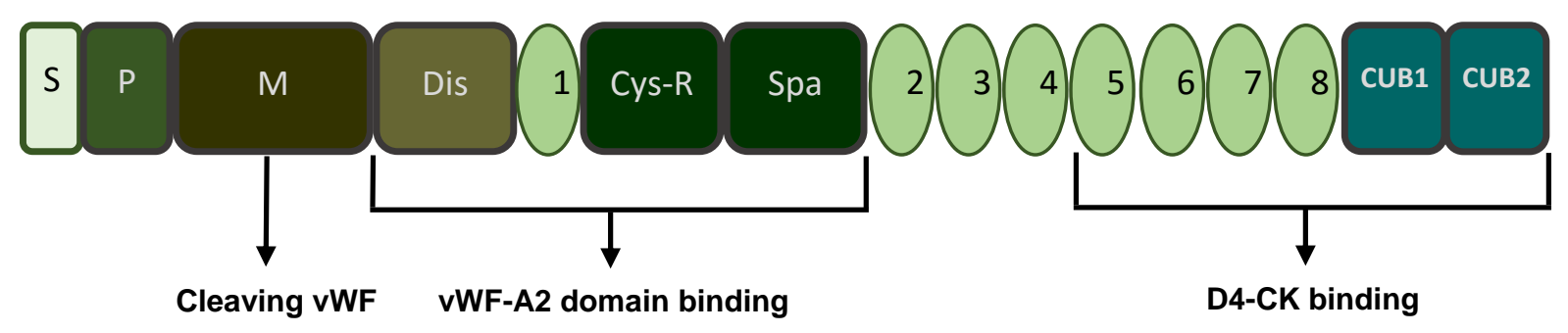

Figure 2: Schematic diagram of ADAMTS13, showing its structural domains and binding sites. Adapted from Lancellotti et al. (27).

Data obtained from a study on the structure of ADAMTS13 suggest that several structural domains of this protein play a role in the complex and regulated interaction with vWF (37). De Groot et al. proposed that the tight binding of ADAMTS13 and VWF is provided by the cysteine rich and spacer domain interaction with vWF A2 domain (38). However, this interaction is not enough for proteolysis to occur, and therefore, weaker binding between the disintegrin-like domain of ADAMTS13 with vWF assists with positioning the Ty1650-Met1606 bond into the active-site cleft resulting in the cleavage of VWF (38).

\section{Health implications related to VWF and ADAMTS13 plasma levels}

Imbalances in VWF and ADAMTS13 plasma levels were reported to have adverse clinical implications (39). Deficiency in vWF causes the most common bleeding disorder called von Willebrand Disease (40) which result in excessive bleeding (41), whereas, high plasma levels of vWF result in thrombotic events, such as ischaemic stroke and atherosclerosis (42). Deficiency in ADAMTS13 causes thrombotic thrombocytopenic purpura (TTP) (43), a thrombotic disorder characterised by a very low blood platelet count, microangiopathic haemolytic anaemia, and thrombocytopenia (44). A number of studies have highlighted the relationship between the plasma levels of these two proteins and their association with several cardiovascular diseases (CVD) (39, 45-47). High vWF and low ADAMTS13 plasma levels were found to be associated with an increased risk of CVD including coronary heart disease, myocardial infarction and ischemic stroke $(9,45,48)$. Elevated vWF levels in the 
presence of very low ADAMTS13 levels were found to accelerate the formation of platelet thrombi under high fluid shear stress (49).

\section{Factors influencing vWF and ADAMTS13 plasma levels}

\subsection{ABO Blood groups}

The levels of vWF are known to differ between the ABO blood groups (50), with individuals in the blood group non-O (A, B and $A B)$ generally having higher levels of vWF compared to individuals with blood group-O (50-53). Probable mechanisms have been proposed through which blood groups influence vWF levels. One of the mechanisms is the survival and half-life of VWF which depends on its clearance in the circulation (54). In individuals with blood group-O, vWF was found to have a shorter survival with decreased half-life and a higher clearance which was attributed to the varying carbohydrate structure of plasma glycoproteins compared to the non-O group (54). The ABO blood groups were further shown to influence vWF directly through its functional effect of the ABO locus (55). The ABO antigen mediate its effect The ADAMTS13 plasma levels were also found to be depended on blood group, and in contrast to vWF, individuals with blood group-O were found to have higher plasma levels of ADAMTS13 compared to the non-O group (56). The rate at which ADAMTS13 cleaves VWF was also found to be greater in blood group-O compared to group non-O (57). According to these findings, individuals with blood group-O had higher ADAMTS13 activity, proposing another mechanism by which $\mathrm{ABO}$ blood groups influenced plasma levels of vWF. Despite this evidence, studies focusing on ADAMTS13 did not observe differences between the $\mathrm{ABO}$ blood groups and plasma levels of $\operatorname{ADAMTS13}(51,58)$, however, these studies focused on the plasma levels and not the activity of ADAMTS13.

\subsection{Ethnicity}

Variation in vWF levels is also seen in different ethnic groups, with black populations having higher levels of this protein (59-63). Miller et al. found black women to have significantly 
higher FVIII and vWF levels with consequently, a lower ADAMTS13 activity when compared to white women (59). These results are consistent with those of a South African-based study in which a significant difference was found in VWF and FVIII levels between black and white women, with black women having higher VWF and FVIII levels. In the same study, vWF and FVIII levels were also significantly higher in black women when compared to Indian women, but no difference was found between Indian and white women (60). In all the ethnic groups, individuals with blood group-O showed significantly lower levels of FVIII and VWF, and this correlates with the increased risk of bleeding disorders seen in individuals with blood group$\mathrm{O}$, and their reduced incidence of thrombosis (64).

\subsection{Health behaviours}

It is well known that lifestyle behaviour plays an important role on health outcomes, in which healthy lifestyle behaviours may improve health and prolonged life expectancy while unhealthy lifestyle choices may have an adverse effect (65). Lifestyle behaviours such as smoking were found to increase the concentrations of VWF and decrease those of ADAMTS13 $(66,67)$. In South Africa, there is a significant gap in socio-economic status (SES) between black and white populations, with a majority of black individuals falling within a low SES and whites in the high SES $(68,69)$. Previous studies have suggested that black individuals are more likely to drink and abuse alcohol (70), live a sedentary lifestyle $(71,72)$ and have a higher prevalence of obesity $(73,74)$ compared to white individuals. Black men were also reported to have a higher prevalence of smoking compared to white men $(75,76)$, and a majority of older black women (aged 35 - 65 years) were reported to consume more salt as compared to white women (77). These health behaviours are briefly described below in relation to their association with VWF and ADAMTS13, and to the best of our knowledge, there is no information available on the association of ADAMTS13 with physical activity, alcohol consumption, salt intake and SES. 


\subsubsection{Physical activity}

Regular physical activity is known to decrease blood pressure, lower fat mass, and improve body fat distribution $(78,79)$. Studies have demonstrated a strong relationship between an increase in physical activity and reduction in cardiovascular risk (80-82). A study investigating the effects of strenuous exercise on haemostasis found strenuous exercise to increase endothelial activation leading to an increase in vWF plasma levels (83). This study, together with other cross-sectional studies reported that excessive physical activity has a pro-thrombotic effect by increasing plasma levels of FVIII and VWF, platelet reactivity, and activation of the immune system (84-87). Other studies have yielded conflicting results, and this may have been due to variation in the methodology used, type of exercise, intensity, duration and the population studied. In a British study including elderly men aged 60-70 years, physical activity was found to be inversely associated with vWF levels (88). Physical activity can thus, either produce favourable or detrimental health outcomes depending on the aforementioned factors. In a study including 105 healthy individuals aged 18-35 years, both VWF:Ag and ADAMTS13 levels were found to increase after exhaustive physical activity (89). These findings confirmed findings from a previous study in individuals with type 1 and type $2 B$ von Willebrand disease (90) in which vWF levels were reported to increase after physical activity in both the control and type $2 \mathrm{~B}$ von Willebrand disease group, and ADAMTS13 only increased in the type 2B group.

\subsubsection{Alcohol consumption}

Similar to physical activity, the effect of alcohol consumption on health outcome is not uniform across diseases. Much focus has been placed on the distribution of drinking patterns (quantity per occasion and frequency) as this can determine the level of harm within a population (91). For example, moderate alcohol consumption (2 drinks or less per day) is associated with lower risk of myocardial infarction and cardiovascular mortality compared to teetotalism (92-94). However, excessive alcohol consumption or heavy drinking (3 or more 
drinks per day) increases cardiovascular risks, including stroke (94). In a study, self-reported moderate alcohol intake was shown to slightly decrease vWF levels, in which 2-6 glasses of drinks per week resulted in the highest decrease (95). Levels were also lower in drinkers compared to individuals who do not drink.

\subsubsection{Smoking}

Smoking is one of the major causes of cardiovascular diseases including stroke, coronary heart disease, peripheral vascular disease, and aortic aneurysm $(96,97)$. It has also been associated with atherosclerosis by compromising the integrity of the vascular wall, contributing to endothelial dysfunction $(98,99)$. In an older population, men who smoke, with a mean age and range of 36.5 (20-75) years were found to have significantly higher vWF compared to non-smokers (100). However, in the same study, no significant difference in vWF levels was found between women who smoked and non-smokers. It was postulated that this may have been due to a low cigarette consumption rate in women compared to men, and the small number of women who smoked in the study. In a study among Arab males, acute smokers who were asked to smoke one cigarette immediately before blood collection, were reported to have significantly higher levels of both vWF and ADAMTS13 plasma levels and activity compared to smokers (at rest) who refrained from smoking for 8 hours. Smokers at rest also had lower vWF and ADAMTS13 activities compare to nonsmokers (67). In two young populations aged 14-35 and 18-28 years, ADAMTS13 plasma levels were found to be significantly lower in smokers compared to non-smokers in both groups, despite the smaller fraction of smokers in the first group (101).

\subsubsection{Salt intake}

High salt intake is one of major determinants of high blood pressure, and it is associated with unfavourable health outcomes including cardiovascular mortality (102). Changes in salt intake are associated with corresponding changes in blood pressure (103). The risk of cardiovascular diseases increases with an increase in blood pressure (104), and therefore it 
is important to control salt intake. A dietary salt consumption of no more than $5 \mathrm{~g} /$ day was suggested by the World Health Organization in an effort to alleviate the risks of CVD including haemorrhagic stroke (105). In 2010, 1.65 million global annual deaths resulting from cardiovascular complications were attributed to excessive dietary salt intake (102). Black individuals were found to be more salt sensitive when compared to white individuals (106). A positive relationship was shown between increased sodium intake and VWF levels (6). Sodium was reported to increase the production and secretion of vWF by the endothelial cells, leading to elevated vWF plasma levels (6).

\subsubsection{Obesity}

The prevalence of obesity is widely increasing, making it a major global health problem (107). Obesity is associated with glucose intolerance, type 2 diabetes, hypertension and other cardiovascular diseases $(108,109)$. In a study by Garcia et al. (110) investigating factors associated with platelet activation in obese children, vWF plasma levels were found to be elevated in obese children compared to non-obese children. Plasma levels of ADAMTS13 have been suggested to be low in obese individuals, and obesity independent of race and sex, was found to be a risk factor for the development of TTP (111). In a study investigating the changes induced by weight loss after bariatric surgery or medical therapy (diet and physical activity) in obese individuals, weight loss was shown to improve the inflammatory and haemostatic profile by significantly reducing anti-ADAMTS13 autoantibodies and thrombospondin-1 (112).

\subsubsection{Socio-economic status}

Socio-economic status is interrelated with all the other aforementioned lifestyle factors (69, 113 , 114), with socio-economically disadvantaged individuals being more likely to experience heavier drinking patterns, to smoke, and to have a poor diet while living a sedentary lifestyle $(69,113,115)$. Individuals at the top of the SES hierarchy, defined by high income, having educational qualification, and a good occupation are more likely to have a 
healthy diet, drink less and exercise regularly (116-118). In a United State-based study, men with more years of education, smoked less compared to those with minimal education (119). However, in a study done on university students, undergraduates with a high SES were found to be more likely to smoke marijuana or use varied drugs and frequently consume alcohol to cope with academic stress (120). Men in lower SES were found to have higher haemostatic markers including vWF compared to men in higher social class groups (121). To the best of our knowledge, there is no information available on the association between SES and ADAMTS13.

\section{Problem statement and motivation}

Lifestyle risk factors such as smoking, alcohol consumption, high salt intake, obesity and physical activity have adverse effects on health outcomes. These lifestyle factors were reported to be risk factors for CVD via several mechanisms, including changes in haemostasis $(6,122)$. Plasma concentrations of VWF and ADAMTS13 have significant clinical implications. Elevated levels of vWF accompanied by low levels of ADAMTS13 have been associated with ischemic stroke and myocardial infarction $(39,123,124)$. Lifestyle risk factors have been suggested to contribute to the variation in plasma levels of haemostatic factors including vWF in older men $(121,125)$, however, limited information is available on the role of these lifestyle factors on VWF and ADAMTS13 in healthy young people. The transition from healthy dietary intake and physical activity to a higher salt/fat/sugar intake and sedentary lifestyle, driven by urbanisation is alarming $(126,127)$. Taking into account this rapid transition and lifestyle deterioration, it would be important to investigate the associations between the aforementioned health behaviours and haemostatic biomarkers, known to predict cardiovascular outcome, namely plasma VWF and ADAMTS13. It is important to investigate these factors in young people, in whom interventions in lifestyle can be instigated to address and prevent future CVD development. Furthermore, based on previous evidence, black populations have a higher risk for hypertension and stroke (128) and generally have higher plasma levels of FVIII and VWF (59). Therefore, it would be 
important to determine the associations between VWF and ADAMTS13 with health behaviours, particularly in this vulnerable population.

\section{Aim, Objectives and Hypotheses}

\subsection{Aim}

The aim of this study was to determine whether circulating vWF antigen and ADAMTS13 concentrations are associated with lifestyle behaviours namely physical activity, alcohol consumption, smoking, obesity, salt intake, and socio-economic status in young black and white adults participating in the African-PREDICT study.

\subsection{Objectives}

The objectives of this study are:

- To compare the circulating VWF antigen and ADAMTS13 concentrations, as well as health behaviours between black and white participants.

- To determine if associations exist between circulating vWF antigen and ADAMTS13 concentrations and health behaviours including physical activity, alcohol consumption, smoking, obesity, salt intake as well as socio-economic status.

\subsection{Hypotheses}

Based on the literature the following hypotheses were formulated:

- VWF:Ag will be higher and ADAMTS13 will be lower in black individuals compared to whites.

- Black participants will have higher levels of smoking, alcohol consumption, salt intake, obesity, and lower levels of physical activity and SES compared to white participants.

- VWF:Ag will be positively and ADAMTS13 will be negatively associated with: 
- Smoking

- Obesity

- Alcohol consumption

- Salt intake

- VWF:Ag will be negatively and ADAMTS13 will be positively associated with:

- Physical activity

- SES 


\section{References}

1. Kim AS, Johnston SC. Temporal and Geographic Trends in the Global Stroke Epidemic. Stroke. 2013;44(6 suppl 1):s123-s25.

2. Roth GA, Johnson C, Abajobir A, Abd-Allah F, Abera SF, Abyu G, et al. Global, Regional, and National Burden of Cardiovascular Diseases for 10 Causes, 1990 to 2015. J Am Coll Cardiol. 2017;70(1):1-25.

3. Feigin VL, Forouzanfar MH, Krishnamurthi R, Mensah GA, Connor M, Bennett DA, et al. Global and Regional Burden of Stroke During 1990-2010: Findings from the Global Burden of Disease Study 2010. Lancet. 2014;383(9913):245-55.

4. Maredza M, Bertram MY, Tollman SM. Disease Burden of Stroke in Rural South Africa: An Estimate of Incidence, Mortality and Disability Adjusted Life Years. BMC Neurol. 2015;15(1), DOI: 10.1186/s12883-015-0311-7.

5. Connor M, Thorogood M, Casserly B, Dobson C, Warlow CJS. Prevalence of Stroke Survivors in Rural South Africa: Results from the Southern Africa Stroke Prevention Initiative (SASPI) Agincourt Field Site. Stroke. 2004;35(3):627-32.

6. Dmitrieva NI, Burg MB. Secretion of Von Willebrand Factor by Endothelial Cells Links Sodium to Hypercoagulability and Thrombosis. Proc Natl Acad Sci U S A. 2014;111(17):6485-90.

7. Shahidi M. Thrombosis and Von Willebrand Factor. Adv Exp Med Biol. 2017;906:285-306.

8. Kelwick R, Desanlis I, Wheeler GN, Edwards DR. The Adamts (a Disintegrin and Metalloproteinase with Thrombospondin Motifs) Family. Genome Biol. $2015 ; 16(1): 113$.

9. Sonneveld MA, Franco OH, Ikram MA, Hofman A, Kavousi M, de Maat MP, et al. Von Willebrand Factor, Adamts13, and the Risk of Mortality: The Rotterdam Study. Arterioscler Thromb Vasc Biol. 2016;36(12):2446-51. 
10. Sumpio BE, Riley JT, Dardik A. Cells in Focus: Endothelial Cell. Int J Biochem Cell Biol. 2002;34(12):1508-12.

11. Sadler JE. Biochemistry and Genetics of Von Willebrand Factor. Annu Rev Biochem. 1998;67:395-424.

12. Cramer EM, Meyer D, Le Menn R, Breton-Gorius J. Eccentric Localization of Von Willebrand Factor in an Internal Structure of Platelet Alpha-Granule Resembling That of Weibel-Palade Bodies. Blood. 1985;66(3):710-13.

13. Wagner DD, haemostasis. The Weibel-Palade Body: The Storage Granule for Von Willebrand Factor and P-Selectin. Thromb Haemost. 1993;70(1):105-10.

14. Lenting PJ, Denis CV. Platelet Von Willebrand Factor: Sweet Resistance. Blood. 2013;122(25):4006-07.

15. Bharati KP, Prashanth UR. Von Willebrand Disease: An Overview. Indian J Pharm Sci. $2011 ; 73(1): 7-16$.

16. Sonneveld MA, de Maat MP, Leebeek FW. Von Willebrand Factor and ADAMTS13 in Arterial Thrombosis: A Systematic Review and Meta-Analysis. Blood Rev. 2014;28(4):167-78.

17. Ruggeri ZM. The Role of Von Willebrand Factor in Thrombus Formation. Thromb Res. 2007;120(Suppl 1):S5-S9.

18. Yee A, Kretz CA. Von Willebrand Factor: Form for Function. Semin Thromb Hemo. $2014 ; 40(1): 17-27$.

19. Wiseman S, Marlborough F, Doubal F, Webb DJ, Wardlaw J. Blood Markers of Coagulation, Fibrinolysis, Endothelial Dysfunction and Inflammation in Lacunar Stroke Versus Non-Lacunar Stroke and Non-Stroke: Systematic Review and MetaAnalysis. Cerebrovasc Dis. 2014;37(1):64-75.

20. Ruggeri ZM, Ware J. The Structure and Function of Von Willebrand Factor. Thromb Haemost. 1992;68(6):594-99.

21. De Meyer SF, Stoll G, Wagner DD, Kleinschnitz C. Von Willebrand Factor: An Emerging Target in Stroke Therapy. Stroke. 2012;43(2):599-606. 
22. Meyer D, Girma J-P. Von Willebrand Factor: Structure and Function. Thromb Haemost. 1993;70(1):99-104.

23. Mendolicchio GL, Ruggeri ZM. New Perspectives on Von Willebrand Factor Functions in Hemostasis and Thrombosis. Semin Hematol. 2005;42(1):5-14.

24. Vlot AJ, Koppelman SJ, Bouma BN, Sixma JJ. Factor Viii and Von Willebrand Factor. Thromb Haemost. 1998;79(3):456-65.

25. Ulrichts H, Udvardy M, Lenting PJ, Pareyn I, Vandeputte N, Vanhoorelbeke K, et al. Shielding of the A1 Domain by the D' D3 Domains of Von Willebrand Factor Modulates Its Interaction with Platelet Glycoprotein Ib-Ix-V. J Biol Chem. 2006;281(8):4699-707.

26. Baldauf C, Schneppenheim R, Stacklies W, Obser T, Pieconka A, Schneppenheim S, et al. Shear-Induced Unfolding Activates Von Willebrand Factor A2 Domain for Proteolysis. J Thromb Haemost. 2009;7(12):2096-105.

27. Lancellotti S, Basso M, De Cristofaro R. Proteolytic Processing of Von Willebrand Factor by ADAMTS13 and Leukocyte Proteases. Mediterr J Hematol Infect Dis. 2013;5(1), DOI: 10.4084/MJHID.2013.058.

28. Uemura M, Tatsumi K, Matsumoto M, Fujimoto M, Matsuyama $T$, Ishikawa $M$, et al. Localization of ADAMST13 to the Stellate Cells of Human Liver. Blood. 2005;106(3):922-24 .

29. Wang A, Duan Q, Wu J, Liu X, Sun Z. The Expression of ADAMTS13 in Human Microvascular Endothelial Cells. Blood Coagul Fibrinolysis. 2016;27(4):464-66.

30. Suzuki M, Murata M, Matsubara $\mathrm{Y}$, Uchida $\mathrm{T}$, Ishihara $\mathrm{H}$, Shibano $\mathrm{T}$, et al. Detection of Von Willebrand Factor-Cleaving Protease (Adamts-13) in Human Platelets. Biochem Biophys Res Commun. 2004;313(1):212-16.

31. Majerus EM, Zheng X, Tuley EA, Sadler JE. Cleavage of the ADAMTS13 Propeptide Is Not Required for Protease Activity. J Biol Chem. 2003;278(47):46643-48.

32. Rieger M, Ferrari S, Hovinga JAK, Konetschny C, Herzog A, Koller L, et al. Relation between ADAMTS13 Activity and ADAMTS13 Antigen Levels in Healthy Donors and 
Patients with Thrombotic Microangiopathies (Tma). Thromb Haemost. 2006;95(2):212-20.

33. Dong J-f, Moake JL, Nolasco L, Bernardo A, Arceneaux W, Shrimpton CN, et al. Adamts-13 Rapidly Cleaves Newly Secreted Ultralarge Von Willebrand Factor Multimers on the Endothelial Surface under Flowing Conditions. Blood. 2002;100(12):4033-39.

34. Huisman B, Hoore M, Gompper G, Fedosov DA. Modeling the Cleavage of Von Willebrand Factor by ADAMTS13 Protease in Shear Flow. Med Eng Phys. 2017;48:14-22.

35. Zheng X, Chung D, Takayama TK, Majerus EM, Sadler JE, Fujikawa K. Structure of Von Willebrand Factor-Cleaving Protease (ADAMTS13), a Metalloprotease Involved in Thrombotic Thrombocytopenic Purpura. J Biol Chem. 2001;276(44):41059-63.

36. Zheng XL. Structure-Function and Regulation of ADAMTS-13 Protease. J Thromb Haemost. 2013;11:11-23.

37. Majerus EM, Anderson PJ, Sadler JE. Binding of ADAMTS13 to Von Willebrand Factor. J Biol Chem. 2005;280(23):21773-78.

38. de Groot R, Bardhan A, Ramroop N, Lane DA, Crawley JT. Essential Role of the Disintegrin-Like Domain in ADAMTS13 Function. Blood. 2009;113(22):5609-16.

39. Andersson HM, Siegerink B, Luken BM, Crawley JT, Algra A, Lane DA, et al. High VWF, Low ADAMTS13, and Oral Contraceptives Increase the Risk of Ischemic Stroke and Myocardial Infarction in Young Women. Blood. 2012;119(6):1555-60.

40. Vischer U. Von Willebrand Factor, Endothelial Dysfunction, and Cardiovascular Disease. J Thromb Haemost. 2006;4(6):1186-93.

41. Sadler J, Mannucci P, Berntorp E, Bochkov N, Boulyjenkov V, Ginsburg D, et al. Impact, Diagnosis and Treatment of Von Willebrand Disease. Thromb Haemost. 2000;84(2):160-74. 
42. Sonneveld MAH, van Dijk AC, van den Herik EG, van Loon JE, de Lau LML, van der Lugt A, et al. Relationship of Von Willebrand Factor with Carotid Artery and Aortic Arch Calcification in Ischemic Stroke Patients. Atherosclerosis. 2013;230(2):210-15.

43. Sadler JE. What's New in the Diagnosis and Pathophysiology of Thrombotic Thrombocytopenic Purpura. Hematology Am Soc Hematol Educ Program. $2015 ; 2015(1): 631-36$.

44. Sadler JE. Pathophysiology of Thrombotic Thrombocytopenic Purpura. Blood. 2017;130(10):1181-88.

45. Sonneveld MA, Franco OH, Ikram MA, Hofman A, Kavousi M, de Maat MP, et al. Von Willebrand Factor, ADAMTS13, and the Risk of Mortality: The Rotterdam Study. Arteriosclerosis, thrombosis, and vascular biology. 2016; 36(12):2446-2451.

46. Soares R, Bydlowski S, Nascimento N, Thomaz A, Bastos E, Lopes A. Plasmatic Adamts-13 Metalloprotease and Von Willebrand Factor in Children with Cyanotic Congenital Heart Disease. Braz J Med Biol Res. 2013;46(4):375-81.

47. Willeit P, Thompson A, Aspelund T, Rumley A, Eiriksdottir G, Lowe G, et al. Hemostatic Factors and Risk of Coronary Heart Disease in General Populations: New Prospective Study and Updated Meta-Analyses. PloS one. 2013;8(2):e55175, DOI: 10.1371/journal.pone.0055175.

48. Maino A, Siegerink B, Lotta L, Crawley J, le Cessie S, Leebeek F, et al. Plasma ADAMTS-13 Levels and the Risk of Myocardial Infarction: An Individual Patient Data Meta-Analysis. J Thromb Haemost. 2015;13(8):1396-404.

49. Yagi H, Yamaguchi N, Shida Y, Sugimoto M, Tubaki K, Fujimura Y, et al. Highly Elevated Plasma Level of Von Willebrand Factor Accelerates the Formation of Platelet Thrombus under High Shear Stress in Plasma with Deficient ADAMTS13 Activity. Thromb Res. 2017;159:91-95.

50. Song J, Chen F, Campos M, Bolgiano D, Houck K, Chambless LE, et al. Quantitative Influence of ABO Blood Groups on Factor VIII and Its Ratio to Von Willebrand Factor, 
Novel Observations from an Aric Study of 11,673 Subjects. PloS one. 2015;10(8):e0132626, DOI: 10.1371/journal.pone.0132626.

51. Wang Z, Dou M, Du X, Ma L, Sun P, Cao H, et al. Influences of Abo Blood Group, Age and Gender on Plasma Coagulation Factor VIII, Fibrinogen, Von Willebrand Factor and ADAMTS13 Levels in a Chinese Population. PeerJ. 2017;5, DOI: 10.7717/peerj.3156.

52. Asuquo JI, Okafor IM, Usanga EA, Idongesit I. Von Willebrand Factor Antigen Levels in Different $\mathrm{ABO}$ Blood Groups in a Nigerian Population. Int $\mathrm{J}$ Biomed Lab Sci. $2014 ; 1: 24-28$.

53. Liu X, Chen X, Yang J, Guo R. Association of Abo Blood Groups with Von Willebrand Factor, Factor VIII and ADAMTS-13 in Patients with Lung Cancer. Oncol Lett. 2017;14(3):3787-94 .

54. Gallinaro L, Cattini MG, Sztukowska M, Padrini R, Sartorello F, Pontara E, et al. A Shorter Von Willebrand Factor Survival in O Blood Group Subjects Explains How ABO Determinants Influence Plasma Von Willebrand Factor. Blood. 2008;111(7):3540-45.

55. Souto JC, Almasy L, Muniz-Diaz E, Soria JM, Borrell M, Bayén L, et al. Functional Effects of the ABO Locus Polymorphism on Plasma Levels of Von Willebrand Factor, Factor VIII, and Activated Partial Thromboplastin Time. Arterioscler Thromb Vasc Biol. 2000;20(8):2024-28.

56. Mannucci PM, Capoferri C, Canciani MTJBjoh. Plasma Levels of Von Willebrand Factor Regulate ADAMTS-13, Its Major Cleaving Protease. $\mathrm{Br} \mathrm{J}$ Haematol. 2004;126(2):213-18.

57. Franchini M, Mannucci PM. ABO Blood Group and Thrombotic Vascular Disease. Thromb Haemost. 2014;112(12):1103-09.

58. Chion CK, Doggen CJ, Crawley JT, Lane DA, Rosendaal FR. ADAMTS13 and Von Willebrand Factor and the Risk of Myocardial Infarction in Men. Blood. 2007;109(5):1998-2000. 
59. Miller CH, Dilley A, Richardson L, Hooper WC, Evatt BL. Population Differences in Von Willebrand Factor Levels Affect the Diagnosis of Von Willebrand Disease in African-American Women. Am J Hematol. 2001;67(2):125-29.

60. Sukhu K, Poovalingam V, Mahomed R, Giangrande PF. Ethnic Variation in Von Willebrand Factor Levels Can Influence the Diagnosis of Von Willebrand Disease. Clin Lab Haematol. 2003;25(4):247-49.

61. Miller C, Haff E, Platt S, Rawlins P, Drews C, Dilley A, et al. Measurement of Von Willebrand Factor Activity: Relative Effects of ABO Blood Type and Race. J Thromb Haemost. 2003;1(10):2191-97.

62. Scheepers JDW, Malan L, De Kock A, Malan NT, Cockeran M, von Känel R. Ethnic Disparity in Defensive Coping Endothelial Responses: The SABPA Study. Physiol Behav. 2015;147:306-12.

63. Payne $\mathrm{AB}$, Miller $\mathrm{CH}$, Hooper WC, Lally $\mathrm{C}$, Austin HD. High Factor Viii, Von Willebrand Factor, and Fibrinogen Levels and Risk of Venous Thromboembolism in Blacks and Whites. Ethn Dis. 2014;24(2):169-74.

64. O'donnell J, Laffan M. The Relationship between ABO Histo-Blood Group, Factor VIII and Von Willebrand Factor. Transfus Med. 2001;11(4):343-51.

65. Byrne DW, Rolando LA, Aliyu MH, McGown PW, Connor LR, Awalt BM, et al. Modifiable Healthy Lifestyle Behaviors: 10-Year Health Outcomes from a Health Promotion Program. Am J Prev Med. 2016;51(6):1027-37.

66. von Känel R, Meister-Langraf RE, Schmid J-P, Barth J, Znoj H, Schnyder U, et al. Low Self-Rated Health Is Related to Blood Hypercoagulability in Patients Admitted with Acute Myocardial Infarction. Thromb Haemost. 2018;118(1):54-62.

67. Al-Awadhi AM, Jadaon MM, Alsayegh FA, AI-Sharrah SK. Smoking, Von Willebrand Factor and ADAMTS-13 in Healthy Males. Scand J Clin Lab Invest. 2012;72(8):61418. 
68. Leibbrandt M, Wegner E, Finn A. The Policies for Reducing Income Inequality and Poverty in South Africa. A Southern Africa Labour and Development Research Unit Working Paper Number 64. 2011. Cape Town: SALDRU, University of Cape Town.

69. Nandi A, Glymour MM, Subramanian S. Association among Socioeconomic Status, Health Behaviors, and All-Cause Mortality in the United States. Epidemiology. $2014 ; 25(2): 170-77$.

70. Ellithorpe ME, Bleakley A, Hennessy M, Weitz I, Jamieson P, Khurana A. Differences in the Portrayal of Health Risk Behaviors by Black and White Characters in Popular Films. J Health Commun. 2017;22(6):451-58.

71. Micklesfield LK, Pedro TM, Kahn K, Kinsman J, Pettifor JM, Tollman S, et al. Physical Activity and Sedentary Behavior among Adolescents in Rural South Africa: Levels, Patterns and Correlates. BMC Public Health. 2014;14(1), DOI: 10.1186/4712458-14-40.

72. McVeigh J, Meiring R. Physical Activity and Sedentary Behavior in an Ethnically Diverse Group of South African School Children. J Sports Sci Med. 2014;13(2):37178.

73. Micklesfield LK, Lambert EV, Hume DJ, Chantler S, Pienaar PR, Dickie K, et al. Socio-Cultural, Environmental and Behavioural Determinants of Obesity in Black South African Women. Cardiovasc J Afr. 2013;24(9-10):369-75.

74. Peer N, Lombard C, Steyn K, Gwebushe N, Levitt N. Differing Patterns of Overweight and Obesity among Black Men and Women in Cape Town: The Cribsa Study. PloS One. 2014;9(9):e107471, DOI: 10.1371/journal.pone.0107471.

75. Sitas F, Egger S, Bradshaw D, Groenewald P, Laubscher R, Kielkowski D, et al. Differences among the Coloured, White, Black, and Other South African Populations in Smoking-Attributed Mortality at Ages 35-74 Years: A Case-Control Study of 481 640 Deaths. Lancet. 2013;382(9893):685-93.

76. Africa SS. South Africa Demographic and Health Survey 2016: Key Indicator Report. In: Health, editor. Pretoria: Statistics South Africa; 2016. 
77. Swanepoel B, Schutte AE, Cockeran M, Steyn K, Wentzel-Viljoen E. Sodium and Potassium Intake in South Africa: An Evaluation of 24 -Hour Urine Collections in a White, Black, and Indian Population. J Am Soc Hypertens. 2016;10(11):829-37.

78. Homer AR, Fenemor SP, Perry TL, Rehrer NJ, Cameron CM, Skeaff CM, et al. Regular Activity Breaks Combined with Physical Activity Improve Postprandial Plasma Triglyceride, Nonesterified Fatty Acid, and Insulin Responses in Healthy, Normal Weight Adults: A Randomized Crossover Trial. J Clin Lipidol. 2017;11(5):1268-79.

79. Mobasseri M, Yavari A, Najafipoor F, Aliasgarzadeh A, Niafar M. Effect of a LongTerm Regular Physical Activity on Hypertension and Body Mass Index in Type 2 Diabetes Patients. J Sports Med Phys Fitness. 2015;55(1-2):84-90.

80. Donniacuo M, Urbanek K, Nebbioso A, Sodano L, Gallo L, Altucci L, et al. Cardioprotective Effect of a Moderate and Prolonged Exercise Training Involves Sirtuin Pathway. Life Sci. 2019;222:140-47.

81. Adams V, Linke A. Impact of Exercise Training on Cardiovascular Disease and Risk. Biochim Biophys Acta Mol Basis Dis. 2018;1865(4):728-34.

82. Lee DC, Pate RR, Lavie CJ, Sui X, Church TS, Blair SN. Leisure-Time Running Reduces All-Cause and Cardiovascular Mortality Risk. J Am Coll Cardiol. 2014;64(5):472-81.

83. Huskens D, Roest M, Remijn JA, Konings J, Kremers RM, Bloemen S, et al. Strenuous Exercise Induces a Hyperreactive Rebalanced Haemostatic State That Is More Pronounced in Men. Thromb Haemost. 2016;115(06):1109-19.

84. Lippi G, Salvagno GL, Tarperi C, Gelati M, Montagnana M, Danese E, et al. Prothrombotic State Induced by Middle-Distance Endurance Exercise in Middle-Aged Athletes. Semin Thromb Hemost. 2018;44(8):747-55.

85. Akyol O, Akyol S, Chen C-H. Update on Adamts13 and VWF in Cardiovascular and Hematological Disorders. Clin Chim Acta. 2016;463:109-18. 
86. Ljungkvist M, Olofsson H, Funding E, Berntorp E, Zetterberg E. Coagulation Factor VIII Is Vital for Increasing Global Coagulation after Physical Exercise. Haemophilia. 2019;25(2):e86-e93.

87. Paczuski R, Cieślicka M. The Moderate Physical Exercise Significantly Increases Von Willebrand's Factor's Activity and Concentration in the Blood. Pol Ann Med. 2013;20(2):100-05.

88. Wannamethee SG, Lowe GD, Whincup PH, Rumley A, Walker M, Lennon L. Physical Activity and Hemostatic and Inflammatory Variables in Elderly Men. Circulation. 2002;105(15):1785-90.

89. van Loon JE, Sonneveld MA, Praet SF, de Maat MP, Leebeek FWJPo. Performance Related Factors Are the Main Determinants of the Von Willebrand Factor Response to Exhaustive Physical Exercise. Plos One. 2014;9(3):1-8, DOI: 10.1371/journal.pone.0091687.

90. Stakiw J, Bowman M, Hegadorn C, Pruss C, Notley C, Groot E, et al. The Effect of Exercise on Von Willebrand Factor and ADAMTS-13 in Individuals with Type 1 and Type 2b Von Willebrand Disease. J Thromb Haemost. 2008;6(1):90-96.

91. Pillai A, Nayak MB, Greenfield TK, Bond JC, Nadkarni A, Patel V. Patterns of Alcohol Use, Their Correlates, and Impact in Male Drinkers: A Population-Based Survey from Goa, India. Soc Psychiatry Psychiatr Epidemiol. 2013;48(2):275-82.

92. Gonçalves A, Claggett B, Jhund PS, Rosamond W, Deswal A, Aguilar D, et al. Alcohol Consumption and Risk of Heart Failure: The Atherosclerosis Risk in Communities Study. Eur Heart J. 2015;36(15):939-45.

93. Yeung SLA, Jiang C, Cheng KK, Cowling BJ, Liu B, Zhang W, et al. Moderate Alcohol Use and Cardiovascular Disease from Mendelian Randomization. PloS one. 2013;8(7):e68054, DOI: 10.1371/journal.pone.0068054.

94. Blomster JI, Zoungas S, Chalmers J, Li Q, Chow CK, Woodward M, et al. The Relationship between Alcohol Consumption and Vascular Complications and Mortality in Individuals with Type 2 Diabetes. Diabetes Care. 2014;37(5):1353-59. 
95. Pomp ER, Rosendaal FR, Doggen CJ. Alcohol Consumption Is Associated with a Decreased Risk of Venous Thrombosis. Thromb Haemost. 2008;99(1):59-63.

96. Mons U, Müezzinler A, Gellert C, Schöttker B, Abnet CC, Bobak M, et al. Impact of Smoking and Smoking Cessation on Cardiovascular Events and Mortality among Older Adults: Meta-Analysis of Individual Participant Data from Prospective Cohort Studies of the Chances Consortium. BMJ. 2015;350, DOI: 10.1136/bmj.h551.

97. Gellert C, Schöttker B, Müller H, Holleczek B, Brenner H. Impact of Smoking and Quitting on Cardiovascular Outcomes and Risk Advancement Periods among Older Adults. Eur J Epidemiol. 2013;28(8):649-58.

98. Kianoush S, Yakoob MY, AI-Rifai M, DeFilippis AP, Bittencourt MS, Duncan BB, et al. Associations of Cigarette Smoking with Subclinical Inflammation and Atherosclerosis: Elsa-Brasil (the Brazilian Longitudinal Study of Adult Health). J Am Heart Assoc. 2017;6(6), DOI: 10.1161/JAHA.116.005088.

99. McEvoy JW, Nasir K, DeFilippis AP, Lima JA, Bluemke DA, Hundley WG, et al. Relationship of Cigarette Smoking with Inflammation and Subclinical Vascular Disease: The Multi-Ethnic Study of Atherosclerosis. Arterioscler Thromb Vasc Biol. 2015;35(4):1002-10.

100. Al-Awadhi AM, AlFadhli SM, Mustafa NY, Sharma PN. Effects of Cigarette Smoking on Hematological Parameters and Von Willebrand Factor Functional Activity Levels in Asymptomatic Male and Female Arab Smokers. Med Princ Pract. 2008;17(2):14953.

101. Ma Q, Jacobi PM, Emmer BT, Kretz CA, Ozel AB, McGee B, et al. Genetic Variants in Adamts13 as Well as Smoking Are Major Determinants of Plasma Adamts13 Levels. Blood Adv. 2017;1(15):1037-46.

102. Mozaffarian D, Fahimi S, Singh GM, Micha R, Khatibzadeh S, Engell RE, et al. Global Sodium Consumption and Death from Cardiovascular Causes. N Engl J Med. 2014;371(7):624-34. 
103. Ha SK. Dietary Salt Intake and Hypertension. Electrolyte Blood Press. 2014;12(1):718.

104. Kjeldsen SE. Hypertension and Cardiovascular Risk: General Aspects. Pharmacol Res. 2018;129:95-99.

105. Organization WH. Who Issues New Guidance on Dietary Salt and Potassium. WHO: Geneva, Switzerland. 2013.

106. Svetkey LP, McKeown SP, Wilson AF. Heritability of Salt Sensitivity in Black Americans. Hypertension. 1996;28(5):854-58.

107. Seidell JC, Halberstadt J. The Global Burden of Obesity and the Challenges of Prevention. Ann of Nutr Metab. 2015;66(Suppl 2):7-12.

108. Kachur S, Lavie CJ, de Schutter A, Milani RV, Ventura HO. Obesity and Cardiovascular Diseases. Minerva Med. 2017;108(3):212-28.

109. Colosia AD, Palencia R, Khan S. Prevalence of Hypertension and Obesity in Patients with Type 2 Diabetes Mellitus in Observational Studies: A Systematic Literature Review. Diabetes Metab Syndr Obes. 2013;6:327-38.

110. García AG, Núñez GG, Sandoval MEV, Castellanos SG, Aguilar CA. Factors Associated with Early Platelet Activation in Obese Children. Clin Med Res. $2014 ; 12(1-2): 21-26$.

111. Nicol KK, Shelton BJ, Knovich MA, Owen J. Overweight Individuals Are at Increased Risk for Thrombotic Thrombocytopenic Purpura. Am J Hematol. 2003;74(3):170-74.

112. Zanato V, Lombardi AM, Busetto L, Dal Prà C, Foletto M, Prevedello L, et al. Weight Loss Reduces Anti-ADAMTS13 Autoantibodies and Improves Inflammatory and Coagulative Parameters in Obese Patients. Endocrine. 2017;56(3):521-27.

113. Elgar FJ, Pförtner T-K, Moor I, De Clercq B, Stevens GW, Currie C. Socioeconomic Inequalities in Adolescent Health 2002-2010: A Time-Series Analysis of 34 Countries Participating in the Health Behaviour in School-Aged Children Study. Lancet. 2015;385(9982):2088-95. 
114. Conner M, McEachan R, Jackson C, McMillan B, Woolridge M, Lawton R. Moderating Effect of Socioeconomic Status on the Relationship between Health Cognitions and Behaviors. Ann Behav Med. 2013;46(1):19-30.

115. Zarnowiecki D, Ball K, Parletta N, Dollman J. Describing Socioeconomic Gradients in Children's Diets-Does the Socioeconomic Indicator Used Matter? Int J Behav Nutr Phys Act. 2014;11(1), DOI: 10.1186/479-5868-11-44.

116. Darmon N, Drewnowski A. Contribution of Food Prices and Diet Cost to Socioeconomic Disparities in Diet Quality and Health: A Systematic Review and Analysis. Nutr Rev. 2015;73(10):643-60.

117. Beard E, Brown J, West R, Kaner E, Meier P, Michie S. Associations between SocioEconomic Factors and Alcohol Consumption: A Population Survey of Adults in England. PloS one. 2019;14(2):e0209442, DOI: 10.1371/journal.pone.0209442.

118. Lin C-H, Chiang S-L, Yates P, Tzeng W-C, Lee M-S, Chiang L-C. Influence of Socioeconomic Status and Perceived Barriers on Physical Activity among Taiwanese Middle-Aged and Older Women. J Cardiovasc Nurs. 2017;32(4):321-30.

119. Laaksonen M, Rahkonen O, Karvonen S, Lahelma E. Socioeconomic Status and Smoking: Analysing Inequalities with Multiple Indicators. Eur J Public Health. 2005;15(3):262-69.

120. Martin CC. High Socioeconomic Status Predicts Substance Use and Alcohol Consumption in US Undergraduates. Subst Use Misuse. 2019;54(6):1035-43.

121. Ramsay S, Lowe GD, Whincup PH, Rumley A, Morris RW, Wannamethee SG. Relationships of Inflammatory and Haemostatic Markers with Social Class: Results from a Population-Based Study of Older Men. Atherosclerosis. 2008;197(2):654-61.

122. Parsons TJ, Sartini C, Welsh P, Sattar N, Ash S, Lennon LT, et al. Physical Activity, Sedentary Behavior, and Inflammatory and Hemostatic Markers in Men. Med Sci Sports Exerc. 2017;49(3):459-65. 
123. Bongers T, de Bruijne E, Dippel D, De Jong A, Deckers J, Poldermans D, et al. Lower Levels of ADAMTS13 Are Associated with Cardiovascular Disease in Young Patients. Atherosclerosis. 2009;207(1):250-54.

124. Bongers TN, de Maat MP, van Goor M-LP, Bhagwanbali V, van Vliet HH, Gómez García EB, et al. High Von Willebrand Factor Levels Increase the Risk of First Ischemic Stroke: Influence of ADAMTS13, Inflammation, and Genetic Variability. Stroke. 2006;37(11):2672-77.

125. Yarnell J, Sweetnam P, Rumley A, Lowe G. Lifestyle Factors and Coagulation Activation Markers: The Caerphilly Study. Blood Coagul Fibrinolysis. 2001;12(8):72128.

126. Vorster $\mathrm{H}$. The Emergence of Cardiovascular Disease During Urbanisation of Africans. Public Health Nutr. 2002;5(1a):239-43.

127. Turok I, Borel-Saladin J. Is Urbanisation in South Africa on a Sustainable Trajectory? Deve South Afr. 2014;31(5):675-91.

128. Lloyd-Jones D, Adams R, Carnethon M, De Simone G, Ferguson TB, Flegal K, et al. Heart Disease and Stroke Statistics-2009 Update. A Report from the American Heart Association Statistics Committee and Stroke Statistics Subcommittee. Circulation. 2008;119(3):e21-e181. 


\section{Chapter 2}

Methodology 


\section{Study design and participants}

The African Prospective study on the Early Detection and Identification of Cardiovascular disease and Hypertension (African-PREDICT) is a longitudinal study that aims to identify and understand early pathophysiology changes in cardiovascular function, and specific markers or predictors contributing to the development of hypertension and target organ damage (1). The African-PREDICT study (NWU-00001-12-A1) and this sub-study (NWU-00029-19-A1) obtained ethics approval from the Health Research Ethics Committee of the North-West University, and all procedures were in adherence with the institutional guidelines and the Declaration of Helsinki. African-PREDICT is registered on ClinicalTrials.gov (NCT03292094).

Participants were recruited in and around the city of Potchefstroom, in the JB Marks local municipality, North West Province, South Africa (Figure 1). A total of 1202 young healthy black and white individuals, men and women (aged 20-30 years) were included and will be followed every 5 years over a 10-year period. This current study made use of existing baseline data of the African-PREDICT study. We excluded participants with incomplete VWF:Ag and ADAMTS13 data $(n=6)$.

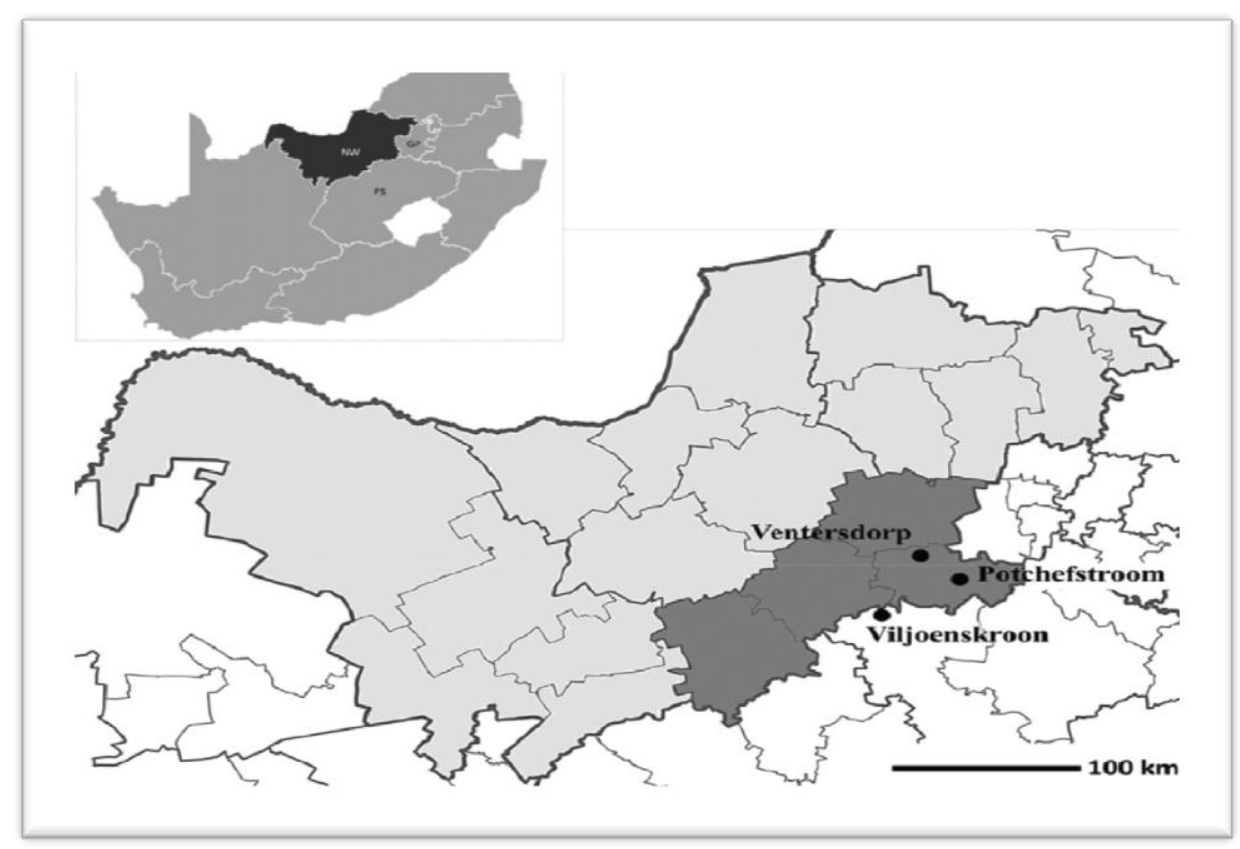

Figure 1: Map of South Africa indicating the city of Potchefstroom in the North-West Province and surrounding areas in which recruitment was conducted (2) 
An individual was defined as healthy when they had normal clinical blood pressure (brachial systolic blood pressure (SBP) $<140$ and diastolic blood pressure (DBP) $<90 \mathrm{mmHg}$; was human immunodeficiency virus (HIV) uninfected; no history of self-reported disease diagnosis or medication for chronic disease; not pregnant or breastfeeding. Participant selection was balanced and stratified into sex, ethnicity (black and white) and socioeconomic status (low, middle, high).

\subsection{Organisational Procedures}

Recruited individuals gave written informed consent and were screened for eligibility for participation in this study. Screening took place within the Hypertension Research and Training Clinic at the Physiology building F11, on the Potchefstroom campus of the NorthWest University or at the participants' workplace. For eligibility, participants had to meet the inclusion criteria indicated in Table 1.

Table 1: Detailed eligibility criteria and justification for the African-PREDICT study

\begin{tabular}{|l|l|}
\hline Exclusion criteria & Justification \\
\hline $\begin{array}{l}\text { 1. Self-reported Indian, Asian, mixed origin } \\
\text { ethnicity }\end{array}$ & $\begin{array}{l}\text { Black populations present with very high } \\
\text { blood pressure compared to other } \\
\text { populations, and is therefore investigated in } \\
\text { this study, the white population is used as a } \\
\text { comparison group. Our focus is thus on } \\
\text { ethnic differences between the black and } \\
\text { white populations. }\end{array}$ \\
\hline $\begin{array}{l}\text { 2. Not permanent resident of Potchefstroom } \\
\text { or surrounding areas or not intending to }\end{array}$ & $\begin{array}{l}\text { Due the longitudinal nature of the study, } \\
\text { researchers make sure that participants can } \\
\text { be followed over the required time period. }\end{array}$ \\
\hline $\begin{array}{l}\text { 3. Inability to read or understand English } \\
\text { 4. Previously diagnosed with Type 1 or } 2 \\
\text { Diabetes Mellitus } \\
\text { 5. Elevated glucose }>5.6\end{array}$ & $\begin{array}{l}\text { Psychological questionnaires formed part of } \\
\text { the larger African-PREDICT study. To } \\
\text { complete these questionnaires English } \\
\text { proficiency was required. }\end{array}$ \\
\hline $\begin{array}{l}\text { Individuals with any known diseases or risk } \\
\text { factors that may influence cardiovascular } \\
\text { health were excluded. }\end{array}$ \\
\hline
\end{tabular}


(confirmed glycated haemoglobin (HbA1c) $\geq 6.5 \%)$

6. HIV or other known infectious disease

7. Fever (ear temperature $>37.5^{\circ} \mathrm{C}$ on the research day)

8. Previously diagnosed liver disease, cancer, tuberculosis or renal disease

9. Microalbuminuria $>30 \mathrm{mg} / \mathrm{ml}$ in spot morning urine or proteinuria

10. Medication use for chronic disease, i.e. antihypertensive, anti-diabetic, antiretroviral or anti-inflammatory medication

11. Self-reported pregnancy or women who breastfeed.

12. Recent surgery or trauma (within the past three months).

13. Self-reported previous history of stroke, angina pectoris or myocardial infarction.

14. Phobia for needles (used during blood sampling).
Due to the known effects of hormones on cardiovascular health, pregnant and lactating women were not included. Pregnancy also changes the plasma levels of many clotting factors and would therefore influence the findings.

Individuals with any known diseases or risk factors that may influence cardiovascular health were excluded.

Since the measurement of biomarkers in blood samples was an important objective of the study, it was required that research participants were able and willing to provide a blood sample. To avoid any anxiety and incidents during blood sampling in individuals with a phobia for needles, such individuals were excluded.

All participants were given feedback by a research nurse in a private room, and referrals for appropriate medical care were made if required. Participants who were eligible for participation were invited to take part in the research study and were provided with a detailed participant information leaflet detailing measurements that were involved. 
A maximum of four participants were accommodated per day to ensure detailed and quality measurements. Participants were required to fast from 10:00 pm the evening before the day of the study and were transported (free of charge) from their homes to the hypertension clinic, arriving at approximately 08:00 am in the morning. Participants were familiarised with the research environment and experimental set-up, and the procedures of the measurements were again explained to them. Written informed consents were then obtained by the research nurse from all participants. After blood sampling, anthropometry, bioimpedance and a set of cardiovascular measurements were done. Participants were provided with a light meal, and, at approximately 01:00 pm, transport was provided to all participants to return home.

\section{Methodology}

\subsection{Questionnaires}

Participants completed a general health and demographic questionnaire with the help of either a research nurse, trained research assistant or postgraduate students. The questionnaire was done one-on-one in the clinic and was completed online on a web-based program and age, sex, ethnicity, alcohol consumption and tobacco use, contraceptive use and socio-economic status (SES) were reported.

The SES was calculated using a point system that was adapted from Kuppuswamy's SES Scale 2010 (3) for a South African environment. The adapted version scored participants in three categories: skill level; education; and household income. Skill level was classified according to the South African Standard Classification of Occupation (SASCO). These three factors were scored as continuous variables, and used to categorise participants into low, middle, and high socio-economic groups. 


\subsection{Cardiovascular measurements}

All cardiovascular measurements were done in temperature controlled and private assessment rooms to ensure participants were comfortable, and to provide the participant with the necessary privacy. Clinic brachial blood pressure measurements were conducted using the Dinamap Procare 100 Vital Signs Monitor (GE Medical Systems, Milwaukee, USA) with an appropriately sized GE Critikon latex-free Dura-Cuff. Prior to the measurement being performed, participants were requested to not have smoked, exercised or eaten at least 30 minutes beforehand and were required to be in a seated resting state with the arm supported at heart level. It was important for the participants to be correctly seated and rested (Figure 2), as talking, crossing legs and unsupported back and arm during blood pressure measurement could raise the blood pressure (4). The first measurement was taken on the left arm after the participant was seated calmly for 5 minutes. Thereafter, blood pressure was taken on the right arm in duplicate with a 5-minute interval in between the measurements. Systolic blood pressure and diastolic blood pressure were captured for each measurement.

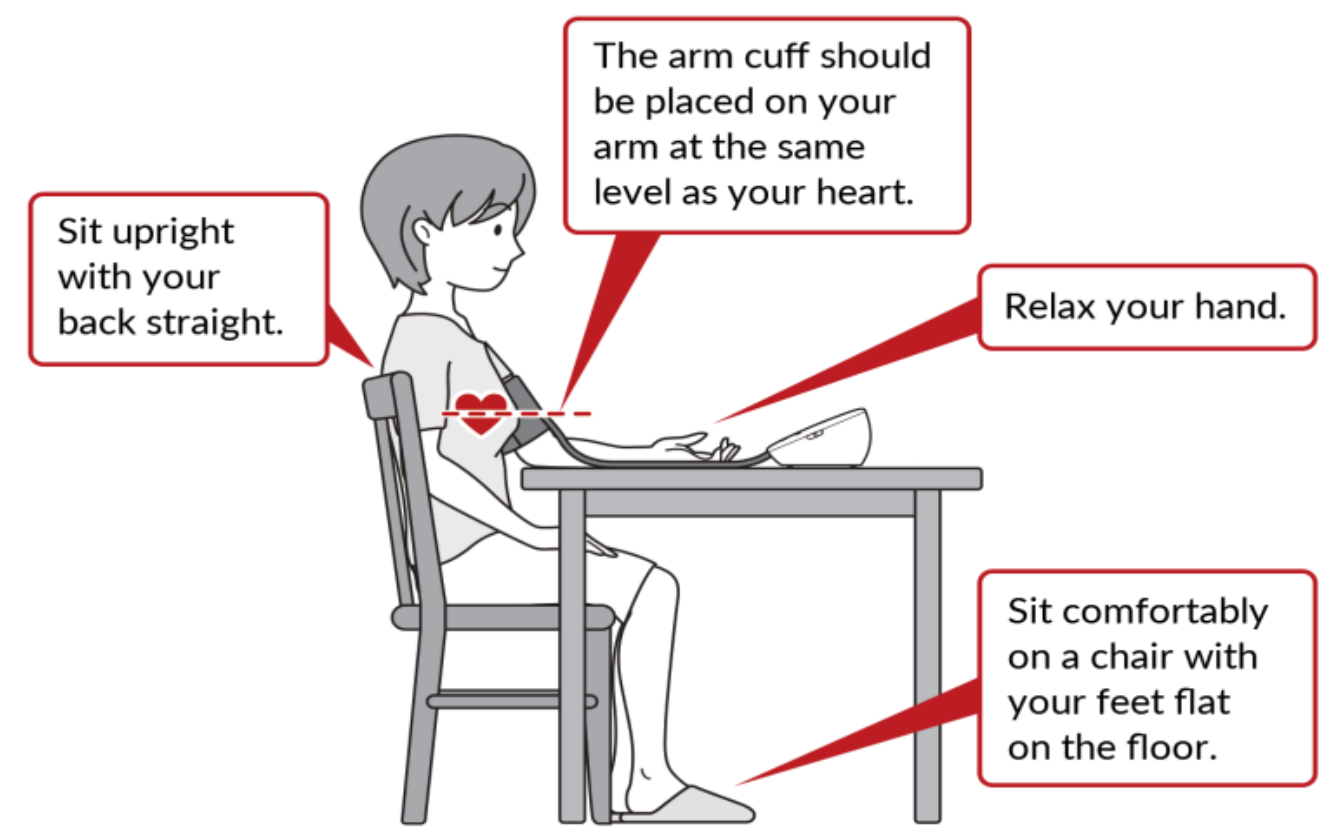

Figure 2: Correct posture for blood pressure measurement. Courtesy of OMRON Healthcare Europe B.V. / Copyright 2019 
The 24-hour blood pressure was measured using an ambulatory blood pressure monitor (ABPM) (Card(X) plore, Meditech, Budapest, Hungary). An appropriately sized cuff was fitted to the participant's non-dominant arm and instructions were given to participants on how to ensure successful inflations across the 24-hour time period. The ABPM apparatus was programmed to measure blood pressure in 30-minute intervals during the day $(06: 00$ to 22:00) and hourly during the night (22:00 to $06: 00)$. An ambulatory diary card, recording information that could influence blood pressure was distributed and completed by participants during the 24-hour duration of the measurements. Over the 24-hour period that ambulatory devices were worn by participants, $87.3 \%$ successful mean inflation rate was achieved for this MHSc study sample.

\subsection{Anthropometric measurements and physical activity}

All anthropometric measurements were done by trained researchers in a private room, with participants wearing minimal clothing to ensure accuracy. Body weight $(\mathrm{kg})$ was measured to the nearest $0.01 \mathrm{~kg}$ using the SECA 813 electronic scale (SECA, Hamburg, Germany), and height $(\mathrm{m})$ was measured using SECA 213 stadiometer (SECA, Hamburg, Germany). Waist circumference $(\mathrm{WC})(\mathrm{cm})$ was measured in triplicate using a non-flexible tape measure (Holtain, Crymych, UK), and recorded to the nearest $0.1 \mathrm{~cm}$. The median of the three recordings was used in subsequent analyses. The body mass index (BMI) was calculated using the standard (weight $(\mathrm{kg}) /$ height $\left(\mathrm{m}^{2}\right)$ ) calculation, and the waist-to-height ratio was calculated using WC $(\mathrm{cm}) /$ height $(\mathrm{cm})$. All measurements were done following the guidelines of the International Society for the Advancement of Kinanthropometry (5). These anthropometric measurements are determinants of obesity, which have been shown to be related to increased plasma levels of vWF and decreased ADAMST13 (6). 


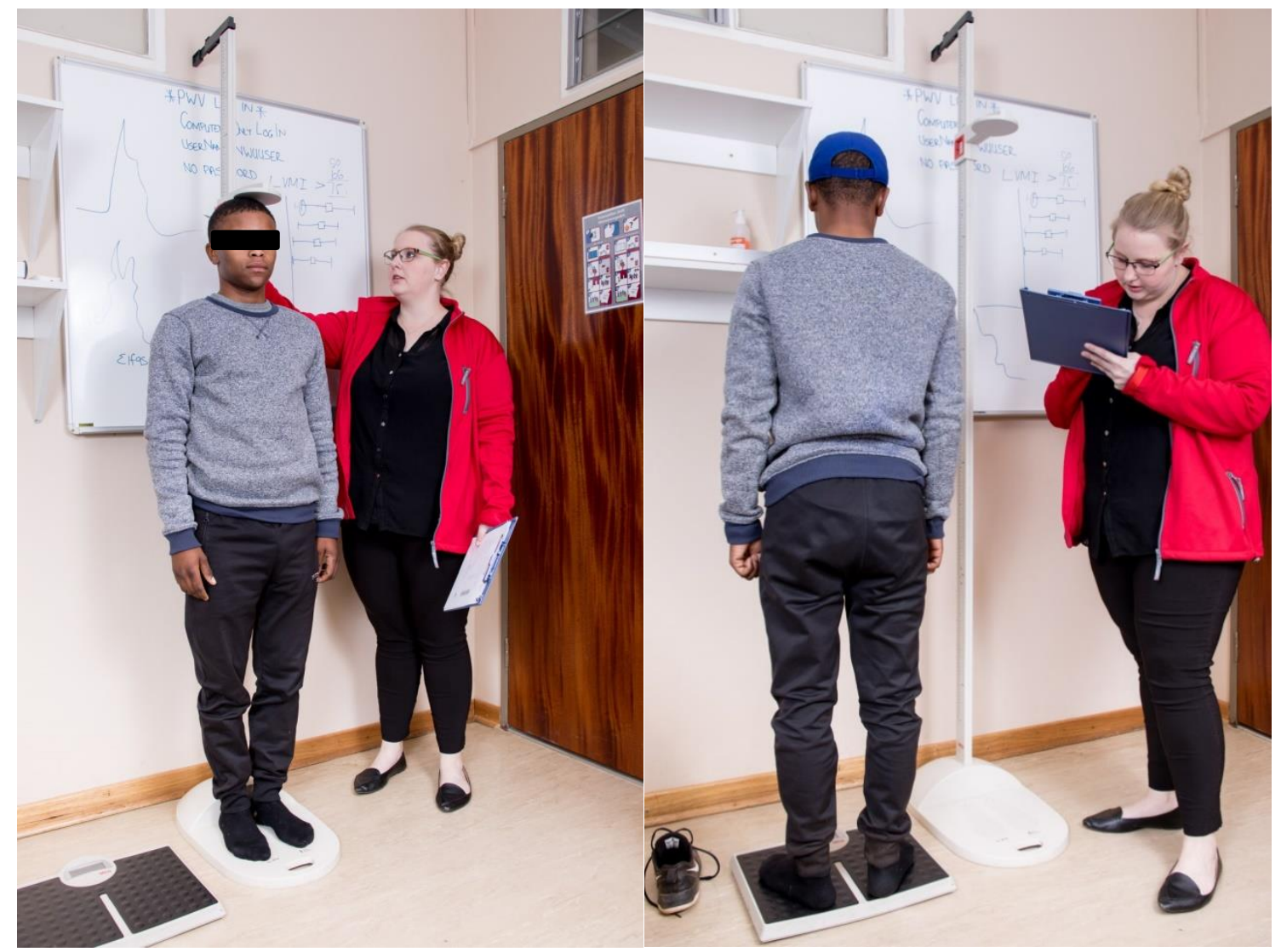

Figure 3: Anthropometric measurements for the African-PREDICT study

To determine physical activity and to capture the changes in heart rate during normal everyday activities, participants were asked to wear an ActiHeart physical activity monitor (CamNtech Ltd, England, UK) for a maximum of 7 consecutive days. This device recorded heart rate, inter-beat-interval as well as physical activity. Data collected was downloaded and cleaned with the relevant ActiHeart software. The recorded activity energy expenditure (AEE) was used as an independent variable, as strenuous physical activity was found to increase vWF levels (7).

\subsection{Biological sampling and biochemical measurements}

Blood samples were taken by a registered nurse with a sterile winged infusion set and syringes from the antebrachial vein into different blood sample tubes; serum, sodium fluoride $(\mathrm{NaF})$, ethylenediaminetetraacetic acid (EDTA), and citrate blood tubes. Once the research nurse had taken the samples, a research assistant, trained in the handling of biological 
samples (using latex gloves), collected the samples in the hypertension clinic and placed the $\mathrm{NaF}$ with some of the EDTA sample tubes in a closed container with ice to minimize glycolysis and other metabolic processes that continue within blood samples after they are collected. Other samples were placed in a closed container with no ice. The samples were taken immediately to the on-site temperature-controlled laboratory. The samples were then centrifuged, and the plasma was aliquoted into cryovials for short- and long term (screw cap) storage in biofreezers at $-80^{\circ} \mathrm{C}$. This was done by trained postgraduate students and a laboratory intern under the supervision of the qualified laboratory manager. All staff and students handling biological samples underwent extensive training by the laboratory manager to reduce any risks to the laboratory students and to ensure quality of results.

Blood groups were determined with a finger prick rapid test using Anti-A; Anti-B and Anti-D monoclonal reagents (ProMab Biotechnologies, Inc., USA) during screening. In the laboratory, full blood count was performed in whole blood samples using Coulter AcT5 diff OV Haematology analyser (Beckman Coulter, Brea, CA, US) on the same day that the blood samples were drawn.

Participants were also asked to collect a 24-hour urine sample on a day that was convenient to them within 7 days after they visited the hypertension clinic, and the day was noted. The first urine of the day was to be discarded and all the urine passed thereafter was collected in the provided container. The participants were asked to store the sample in a cool dark place until a research assistant came to collect it after the 24-hour period. All samples were immediately taken to the onsite laboratory and aliquoted into $1.5 \mathrm{ml}$ cryovials and stored in biofreezers at $-80^{\circ} \mathrm{C}$ until analysis. The protocol for 24 -hour urine collection followed that of the Pan American Health Organization/ World Heal Organization protocol for population level sodium determination in 24-hour urine (8). Incomplete urine collections were defined as a volume less than $300 \mathrm{ml}$ per 24-hour and/or a 24-hour creatinine excretion of $>4 \mathrm{mmol}$ or $<$ $25 \mathrm{mmol}$ in women and $>6 \mathrm{mmol}$ or $<30 \mathrm{mmol}$ in men (9). 
Samples were stored in the biofreezer in the F12 Physiology building until appropriate analyses were performed. All biochemical variables were tested for intra- and inter-assay variability to ensure specificity, sensitivity and reliability. Intra-assay variability should be $<10 \%$, whereas inter-assay variability should be $<20 \%$. For analysis, serum samples were taken out of the biofreezers, and taken into the laboratory by trained postgraduate students or laboratory intern. In the laboratory, samples were defrosted and used in a Cobas Integra 400plus (Roche Basel, Switzerland) to analyse for low-density lipoprotein-cholesterol (LDLC) (intra- and inter-assay variability were $1.5 \%$ and $1.90 \%$, respectively), high-density lipoprotein- cholesterol (HDL-C) (intra- and inter-assay variability were $1.13 \%$ and $1.00 \%$, respectively), total cholesterol (TC) (intra- and inter-assay variability were $0.51 \%$ and $1.90 \%$, respectively), triglycerides (intra- and inter-assay variability were $1.6 \%$ and $1.90 \%$, respectively), and serum high-sensitivity C-reactive protein (hs-CRP) (intra- and inter-assay variability were $1.3 \%$ and $3.5 \%$, respectively). Glucose (intra- and inter-assay variability were $1.8 \%$ and $2.1 \%$, respectively) was measured in fluoride plasma.

Gamma-glutamyltransferase (GGT) was also determined in serum using the Cobas Integra 400plus (Roche, Basel, Switzerland). The intra- and inter-assay variability for GGT were $1.8 \%$ and $1.8 \%$, respectively. GGT is considered to be a biomarker of alcohol use and abuse (10), and moderate alcohol consumption was found to have an influence of the haemostatic profile by decreasing vWF levels $(11,12)$. Serum samples were used to measure a nicotine metabolite called cotinine using the chemiluminescence method on the immulite (Siemens, Erlangen, Germany). Intra- and inter-assay variability for cotinine were $10.7 \%$ and $5.5 \%$, respectively. Cotinine is considered as a biomarker of both passive exposure and active smoking (13). Smoking was found to increase the plasma levels of vWF and ADAMTS13 (14), and therefore, cotinine is one of the independent variable.

Twenty four-hour urinary sodium (intra- and inter-assay variability were $0.29 \%$ and $0.89 \%$, respectively), potassium (intra- and inter-assay variability were $0.29 \%$ and $0.89 \%$, respectively) and chloride (intra- and inter-assay variability were $0.69 \%$ and $1.3 \%$, 
respectively) were measured by means of ion-selective electrode potentiometry on the Cobas Integra $\AA^{\circledR} 400$ plus (Roche, Basel, Switzerland) and creatinine (intra- and inter-assay variability were $1.4 \%$ and $2.5 \%$, respectively) concentrations were measured using the Creatinine Jaffé Gen.2 reagent (Roche, Basel, Switzerland). Daily urinary sodium and potassium excretion $(\mathrm{mmol} / \mathrm{d})$ were calculated by multiplying the sodium, potassium and creatinine concentrations $(\mathrm{mmol} / \mathrm{l})$ of the 24 -hour urine by the total $24 \mathrm{hr}$ volume of urine (in litres) (15). Daily salt intake was estimated from 24-hour urinary sodium excretion by converting sodium in $\mathrm{mmol}$ to $\mathrm{mg}$ : sodium ( $\mathrm{mmol}) \times 23=$ sodium $(\mathrm{mg})$ and then applying the conversion: $1 \mathrm{~g}$ salt (sodium chloride $(\mathrm{NaCl}))=390 \mathrm{mg}$ sodium (15).

Citrated samples were used for the analysis of von Willebrand factor (vWF) antigen, which was determined using an ELISA kit (DAKO, Glostrup, Denmark). Polyclonal rabbit anti-vWF antibody and rabbit anti-vWF-horseradish peroxidase (HRP) antibody (DAKO, Glostrup, Denmark) were used to perform the assay. The 6th International Standard for vWF/FVIII was used to create the standard curve against which the samples were measured. Serum samples were used to measure ADAMTS13 as part of a bead-based multiplex immunoassay, which allows the simultaneous quantification of multiple markers. The intraand inter-assay variability for ADAMTS13 were $1.27 \%$ and $4.33 \%$, respectively. The MILLIPEX MAP Human Cardiovascular Disease Magnetic Bead Panel 2 (Merck Millipore, Darmstadt, Germany) were custom made to include ADAMTS13, growth differentiation factor-15 (GDF-15), myeloperoxidase (MPO), P-selectin, soluble cell adhesion molecule (sCAM), and soluble vascular cell adhesion molecule (sVCAM) related to CVD. These immunoassays were performed on a Luminex $200^{\mathrm{TM}}$ system (Luminex, Austin, TX, US), and a protocol found in the kits was followed to run the analyses. Samples could only be defrosted twice for analyses, and they were stored and destroyed as indicated in the informed consent. 


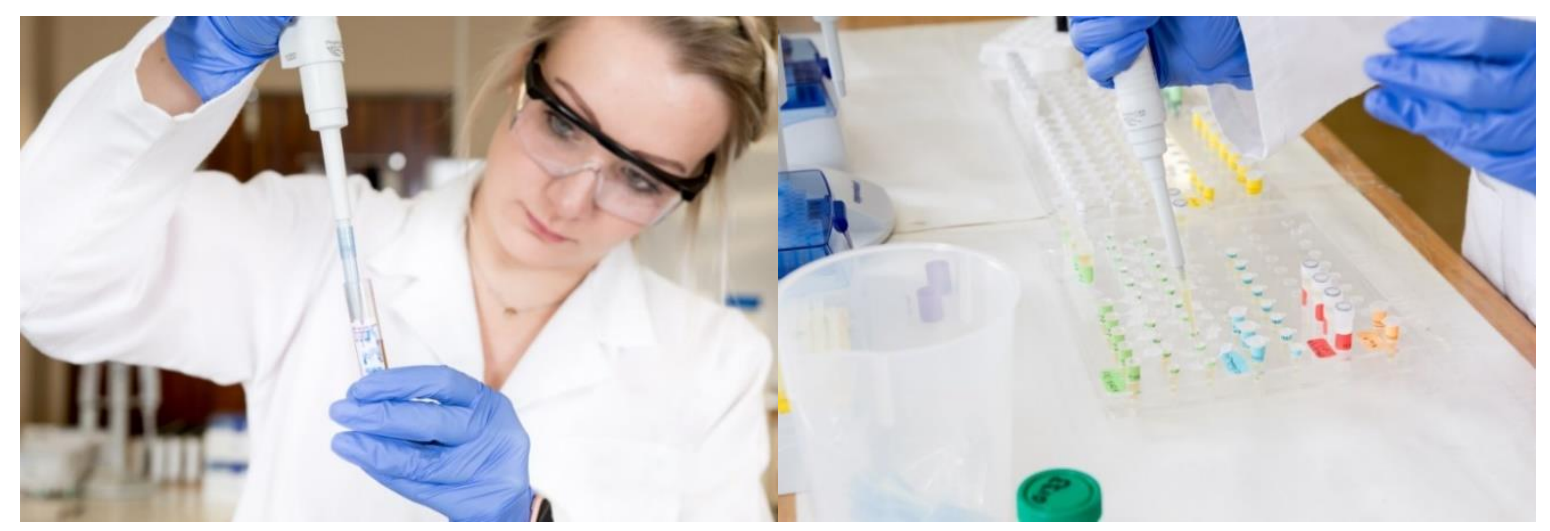

Figure 4: Preparation of the African-PREDICT study blood and spot urine samples

\section{Statistical analyses}

\subsection{Power calculations}

By using the $G^{*}$ Power 3.1.9.2 statistical analysis software (16), an effect size of 0.047 was calculated in a sample group of 600 participants to detect $95 \%$ power at an alpha error probability of 0.05 . Hence, with a total study sample of 1202 participants, this sub-study had sufficient power to address the proposed research objectives.

Table 2: Power analysis report

F tests - Linear multiple regression: Fixed model, $\mathrm{R}^{2}$ deviation from zero

Analysis: Sensitivity: Compute required effect size

$\begin{array}{lll}\text { Input: } & \alpha \text { err prob } & =0.05 \\ & \text { Power (1- } \beta \text { err prob) } & =0.95 \\ & \text { Total sample size } & =600 \\ \text { Output: } & \text { Number of predictors } & =15 \\ & \text { Concentrality parameter } \lambda & =28.4369570 \\ & \text { Numerator } \mathrm{df} & =1.6835334 \\ \text { Denominator } \mathrm{df} & =15 \\ \text { Effect size } \mathrm{f}^{2} & =584 \\ \end{array}$

Statistical analyses were performed using the IBM SPSS Statistics, Version 25 (IBM Corporation, Armonk, New York). 
All variables were tested for normality using the Kolmogorov-Smirnov test and Shapiro-Wilk test, as well as graphical methods (histograms and q-q plots). In the case of non-Gaussian distribution, a logarithmic transformation was performed for each skewed variable and retested for normality. Normally distributed variables were reported as mean and standard deviation, and logarithmically transformed variables were presented by the geometric mean and 5th and 95th percentiles.

Interactions of ethnicity was tested for the relationship between plasma levels of vWF and ADAMTS13 and health behaviours (physical activity, alcohol consumption, smoking, salt intake, obesity and SES).

Chi-square test was used to compare categorical variables, and the variables were presented as frequencies and proportions. Independent T-tests were used to compare continuous variables between black and white participants and were reported as mean \pm standard deviation if the variables followed a normal distribution, or geometric mean with 5th and 95th percentiles for log transformed data.

Multivariable-adjusted linear regression was performed to determine whether plasma levels of VWF and ADAMTS13, as dependent variables are associated with the aforementioned health behaviours, as main independent variables.

Bivariate correlations of the depended variables and health behaviours with a range of potential covariates were performed, to determine which variables to include in our final regression models.

The detailed statistical procedures followed are reported in the methods section of Chapter 3.

\section{Data handling}

The African-PREDICT study uses the REDCap (Research Electronic Data Capture, see http://project-redcap.org) system to capture all data elements (17). The Data Manager was appointed and trained to oversee REDCap. When using this system all laboratory 
specimens, evaluation forms, reports, data and other records are identified only by the participant number to maintain subject confidentiality. Only the Data Mananger, Head of the hypertension clinic and Principal Investigator have access to information linking participant numbers to participant names. Apart from the REDCap system, data are also backed up on password protected hard drives and all paper and computerised records are kept in a secured area. Clinical information will not be released without the participant's written permission except as necessary for cleaning, monitoring, and statistical analysis by the authorised study team members or when the participant's well-being is at risk.

\section{Ethical Considerations}

The risks to participants for participating in this study falls within the category of medium risk, and the possible risks related to the collection of the baseline data, was discussed and approved in previous HREC applications. Participants benefited directly from participation in the African-PREDICT since measurement results were made available to them.

Minimal risk is involved in this sub-study since the data that will be used has already been gathered, and appropriate measures have been kept in place by the African-PREDICT study to ensure privacy and confidentiality of all participants. There is limited information on the

role that lifestyle or health behaviours play in the plasma concentration of VWF and ADAMTS13, therefore the participants and South African population at large will indirectly benefit from the knowledge this study will provide.

\section{Contribution of MHSc student}

As a MHSc student, I was involved in the follow-up research measurements of the AfricanPREDICT study and performed the following activities:

- Laboratory work: I was responsible for blood and urine samples preparation and processing. I collected the samples from the hypertension clinic, centrifuged the blood samples, aliquoted samples into appropriate cryovials, and stored them in bio- 
freezers. I was also responsible for labelling the cryovials and cases in which the samples were stored in. Furthermore, I was involved in the biochemical analyses of these samples.

- Data collection in the hypertension clinic: I was involved in obtaining pulse wave analysis and pulse wave velocity using Sphygmorcor XCEL device and electrocardiogram (data not included in this sub-study). I also contributed in obtaining clinic blood pressure readings using the Dinamap Procare 100 Vital Signs Monitor and 24-Hour ambulatory blood pressure, as well as physical activity measurements, using the $\operatorname{Card}(\mathrm{X})$ plore and Acti-heart devices, respectively.

- Data capturing: I was also responsible for downloading and capturing of the data of the 24 hour BP and biochemical analyses.

- Data analyses: I attended SPSS training and performed all analyses for the manuscript. 


\section{References}

1. Schutte AE, Gona PN, Delles C, Uys AS, Burger A, Mels CM, et al. The African Prospective Study on the Early Detection and Identification of Cardiovascular Disease and Hypertension (African-Predict): Design, Recruitment and Initial Examination. Eur J Prev Cardiol. 2019;26(5):458-70.

2. Botha M, Siebert S, Van den Berg J, Ellis S, Greyvenstein B. Diversity Patterns of Selected Predaceous Arthropod Groups in Maize Fields and Margins in South African Highveld Grassland: Predaceous Arthropods of Maize Agro-Ecosystems. Agric For Entomol. 2018;20:461-75.

3. Patro BK, Jeyashree K, Gupta PK. Kuppuswamy's Socioeconomic Status Scale 2010—the Need for Periodic Revision. Indian J Pediatr. 2012;79(3):395-96.

4. Peters GL, Binder SK, Campbell N. The Effect of Crossing Legs on Blood Pressure: A Randomized Single-Blind Cross-over Study. Blood Press Monit. 1999;4(2):97-101.

5. Marfell-Jones MJ, Stewart A, De Ridder J. International Standards for Anthropometric Assessment, International Society for the Advancement of Kinanthropometry. New Zealand: Wellington; 2012.

6. García AG, Núñez GG, Sandoval MEV, Castellanos SG, Aguilar CA. Factors Associated with Early Platelet Activation in Obese Children. Clin Med Res. $2014 ; 12(1-2): 21-26$.

7. Huskens D, Roest M, Remijn JA, Konings J, Kremers RM, Bloemen S, et al. Strenuous Exercise Induces a Hyperreactive Rebalanced Haemostatic State That Is More Pronounced in Men. Thromb Haemost. 2016;115(06):1109-19.

8. Pan American Health Organization. Protocol for Population Level Sodium Determination in 24-Hour Urine Samples. Washington, DC: PAHO; 2010. Available at: http://www. https://www.paho.org/hq/dmdocuments/2013/24h-urine-Protocoleng.pdf. 
9. Stolarz-Skrzypek K, Kuznetsova T, Thijs L, Tikhonoff V, Seidlerová J, Richart T, et al. Fatal and Nonfatal Outcomes, Incidence of Hypertension, and Blood Pressure Changes in Relation to Urinary Sodium Excretion. JAMA. 2011;305(17):1777-85.

10. Peterson K. Biomarkers for Alcohol Use and Abuse. Alcohol Res Health. 2005;28(1):30-37.

11. Stote K, Tracy R, Taylor P, Baer D. The Effect of Moderate Alcohol Consumption on Biomarkers of Inflammation and Hemostatic Factors in Postmenopausal Women. Eur J Clin Nutr. 2016;70(4):470-74.

12. Toda M, Totoki T, Nakamura C, Yasuma T, D'Alessandro-Gabazza CN, MifujiMoroka R, et al. Low Dose of Alcohol Attenuates Pro-Atherosclerotic Activity of Thrombin. Atherosclerosis. 2017;265:215-24.

13. Whincup PH, Gilg JA, Emberson JR, Jarvis MJ, Feyerabend C, Bryant A, et al. Passive Smoking and Risk of Coronary Heart Disease and Stroke: Prospective Study with Cotinine Measurement. BMJ. 2004;329(7459):200-05.

14. Al-Awadhi AM, Jadaon MM, Alsayegh FA, AI-Sharrah SK. Smoking, Von Willebrand Factor and ADAMTS-13 in Healthy Males. Scand J Clin Lab Invest. 2012;72(8):61418.

15. Control CfD, Prevention. Sodium Reduction Toolkit: A Global Opportunity to Reduce Population-Level Sodium Intake. 2013.

16. Faul F, Erdfelder E, Lang A-G, Buchner A. G* Power 3: A Flexible Statistical Power Analysis Program for the Social, Behavioral, and Biomedical Sciences. Behav Res Methods. 2007;39(2):175-91.

17. Harris PA, Taylor R, Thielke R, Payne J, Gonzalez N, Conde JG. Research Electronic Data Capture (Redcap)—a Metadata-Driven Methodology and Workflow Process for Providing Translational Research Informatics Support. J Biomed Inform. 2009;42(2):377-81 . 


\title{
Chapter 3
}

\author{
Manuscript
}




\section{THROMBOSIS RESEARCH}

\section{Author Instructions}

\section{Article structure}

The article should be divided into clearly defined sections (Introduction, Material and Methods, Results, Discussion, Conclusion and Appendices). Each subsection should be given a brief heading, which should be on its own separate line.

\section{Essential title page information}

- Title. Should be concise and informative. Avoid abbreviations and formulae where possible.

- Author names and affiliations. All authors' given name(s) and family name(s) should be clearly indicated, checking that all names are accurately spelled. Author's affiliations should be presented addresses (where the actual work was done) below the names.

- Corresponding author. A corresponding author's name, email address and permanent address should be stated. It should be ensured that contact details are kept up to date by the corresponding author.

- Word count should be provided in the title page, and a word count of the text should include Tables and Legends. The Abstract and Reference list should be excluded. 


\section{Abstract}

A concise and factual abstract is required. It should not exceed 250 words and structured abstracts are encouraged and should use the following headings: Introduction, Materials and Methods, Results and Conclusions.

\section{Keywords}

A maximum of 6 keywords should be provided, avoiding general and plural terms. Only abbreviations firmly established in the field may be eligible.

\section{Abbreviations}

A list of all abbreviations must be provided after the keywords.

\section{Acknowledgements}

Should be stated in a separate section at the end of the article before the references, and therefore, should not be included in the title page.

\section{References}

There are no strict requirements on reference formatting at submission. References can be in any style or format as long as the style is consistent. Where applicable, author(s) name(s), journal title/ book title, chapter title/article title, year of publication, volume number/book chapter and the article number or pagination must be present. Use of DOI is highly encouraged.

\section{Tables and Figures}

It should be ensured that the figures and the tables included in the single file are placed next to the relevant text in the manuscript, rather than at the bottom or the top of the file. The corresponding caption should be placed directly below the figure or table. 


\title{
กWU $\mathbf{N W}^{\circledast}$ Hypertension in Africa Research Team
}

\section{The association of von Willebrand factor and its cleaving protease (ADAMTS13) with health behaviours in young black and white adults: The African-PREDICT study}

\author{
Nonkululeko H Navise ${ }^{\mathrm{a}}$, Leandi Lammertyn ${ }^{\mathrm{ab}}$, Gontse G Mokwatsi ${ }^{\mathrm{ab}}$, Aletta E \\ Schutte ${ }^{a b}$
}

${ }^{a}$ Hypertension in Africa Research Team (HART), North-West University, Potchefstroom, South Africa;

${ }^{b}$ MRC Unit for Hypertension and Cardiovascular Disease, North-West University, Potchefstroom, South Africa

\section{Corresponding author:}

Prof Aletta E Schutte

Hypertension in Africa Research Team (HART), North-West University, Private Bag X6001, Potchefstroom, 2520, South Africa, E-mail: Alta.Schutte@nwu.ac.za, Tel: +27 18299 2444, Fax: +27 182852432

Word count: 4830

Manuscript prepared for submission to Thrombosis Research 


\section{Abstract}

Introduction: Von Willebrand factor (VWF) plays an important role in maintaining normal haemostasis, and together with its cleaving protease, ADAMTS13, has been associated with increased risks of cardiovascular diseases. To reduce cardiovascular risks imposed by these markers from young ages knowledge on health behaviours that may affect their concentrations would be essential. We therefore, determined whether circulating vWF antigen and ADAMTS13 associate with health behaviours in young healthy adults.

Materials and Methods: We included 602 black and 594 white adults aged 20-30 years and used questionnaires for socio-economic status (SES), tobacco and alcohol use data. The VWF:Ag was measured from citrated samples and ADAMTS13, cotinine and GGT from serum. Salt intake was estimated from 24-hour urine and body mass index (BMI) was calculated.

Results: Black adults had higher vWF:Ag and lower ADAMTS13 levels compared to whites (all $\mathrm{p}<0.001$ ). In multiple regression analyses in the total group, vWF:Ag associated positively with BMI $(p=0.037)$, while ADAMTS13 associated negatively with BMI $(p=0.016)$ and cotinine $(p=0.029)$; and positively with gamma-glutamyl transferase (GGT) $(p=0.002)$. When exploring within each ethnic group, vWF:Ag associated positively with estimated salt intake ( $p=0.043$ ) only in the black group. In the white group, vWF:Ag associated positively with BMI $(p=0.023)$, while ADAMTS13 associated positively with GGT $(p=0.003)$ and negatively with cotinine $(\mathrm{p}=0.041)$.

Conclusion: Young black adults may have an increased thrombotic risk due to higher vWF and lower ADAMTS13. Ethnic-specific associations between vWF:Ag and ADAMTS13 with salt intake, obesity, and smoking may have implications for public health initiatives to improve cardiovascular outcomes.

Keywords: ethnicity, haemostasis, smoking, alcohol, salt, obesity 
Abbreviations

ABPM

ADAMTS13

AEE

African-PREDICT

$\mathrm{Ag}$

BMI

CVD

FVIII

GGT

GDF

HDL-C

HIV

HRP

hs-CRP

LDL-C

MPO

n

$\mathrm{NaCl}$

NAFLD

SAMRC

SARChl

sCAM

SES

SVCAM

TTP

vWF
Ambulatory blood pressure monitor

A Disintegrin And Metalloproteinase with a ThromboSpondin type 1 motif, member 13

Activity energy expenditure

African Prospective study on the Early Detection and Identification of Cardiovascular Disease and Hypertension

Antigen

Body mass index

Cardiovascular diseases

Factor VIII

Gamma-glutamyl transferase

Growth differentiation factor

High-density lipoprotein cholesterol

Human immunodeficiency virus

Horseradish peroxidase

High-sensitivity C-reactive protein

Low-density lipoprotein cholesterol

Myeloperoxidase

Number of participants

Sodium chloride

Non-alcoholic fatty liver disease

South African Medical Research Council

South African Research Chairs Initiative

Soluble cell adhesion molecule

Socio-economic status

Soluble vascular cell adhesion molecule

Thrombotic thrombocytopenic purpura

von Willebrand factor 
Chapter 3

WC

Waist circumference 


\section{Introduction}

Thrombotic events are one of the leading causes of morbidity and mortality globally $(1,2)$. Since thrombosis is intricately involved in the occurrence of ischaemic stroke and myocardial infarction, it is not unexpected that the prothrombotic factor, von Willebrand factor (vWF), is an independent risk factor involved in the pathogenesis of cardiovascular diseases (CVD) (35). The vWF is a large multimeric glycoprotein that plays an important role in primary haemostasis by inducing platelet adhesion and aggregation at sites of vascular injury, and by acting as a carrier for factor VIII (FVIII), protecting it from proteolytic degradation (6-8). It is also considered to be a marker of endothelial function (9). The activity of vWF is regulated by ADAMTS13 (A Disintegrin And Metalloproteinase with a ThromboSpondin type 1 motif, member 13), a metalloprotease belonging to the ADAMTS family. ADAMTS13 cleaves the large vWF multimers into smaller less haemostatically active fragments $(10,11)$. Reduced ADAMTS13 levels result in the accumulation of large vWF multimers, thereby promoting thrombosis. Plasma levels and activity of both vWF and ADAMTS13 are independent risk factors for CVD (4). High VWF and low ADAMTS13 plasma levels were found to be associated with an increased risk of coronary heart disease, myocardial infarction, and ischemic stroke $(12,13)$.

Plasma levels of vWF are determined by both genetic and environmental factors. One such genetic determinant is an individual's blood group, where individuals with non-O blood groups ( $A, B$ and $A B$ ) have higher levels of vWF compared to those with blood group-O (1416). Other determining factors include age (17), the use of oral contraceptives and pregnancy $(4,18)$. Variation in vWF levels is also seen in different ethnic groups with black individuals having higher plasma vWF compared to their white counterparts (19-22).

With regard to ADAMTS13, some studies have found no association with blood group (15, 23), while others reported ADAMTS13 levels to be lower in individuals with non-O blood groups compared to group $\mathrm{O}(24,25)$. The incidence of thrombotic thrombocytopenic 
purpura (TTP), which is associated with severe ADAMTS13 deficiency, was found to be greater among blacks compared to other ethnic groups (26). This finding suggests an ethnic difference in ADAMTS13 however, limited information is available on this matter.

Modifiable lifestyle factors including alcohol consumption, sedentary behaviour, and smoking have also been shown to contribute to the variation in plasma levels of both vWF and ADAMTS13 (27-29), which opens up an opportunity to reduce CVD and thrombosis risk by incorporating healthier lifestyles. It would be important to reduce cardiovascular risk already from young age onwards, but limited information is available on the role of lifestyle factors on VWF and ADAMTS13 in healthy youth. Taking into account the shift towards unhealthy lifestyle practices by the youth (30), we investigated the associations between vWF and ADAMTS13 with health behaviours (including socio-economic status, physical activity, alcohol consumption, smoking, salt intake and obesity) in young healthy black and white adults. We also determined whether vWF and ADAMTS13 concentrations differ in women, according to hormonal contraception used.

\section{Materials and Methods}

\section{Study Population}

This study forms part of the African Prospective study on the Early Detection and Identification of Cardiovascular Disease and Hypertension (African-PREDICT) (31). We recruited participants $(n=1202)$ on a voluntary basis from Potchefstroom and surrounding areas. Black $(n=606)$ and white $(n=596)$ apparently healthy individuals between the ages of 20-30 years, with a screening clinic blood pressure of $<140$ and $90 \mathrm{mmHg}$, human immunodeficiency virus (HIV) uninfected, who had no previous self-reported diagnosis or using medication for chronic disease, not pregnant and not breast feeding were included in the study. We excluded participants with incomplete vWF:Ag and ADAMTS13 data $(n=6)$. The Health Research Committee of the North-West University (NWU-0009-19-S1) approved 
this sub-study, and all procedures were in compliance with the institutional guidelines and the declaration of Helsinki. All participants gave written informed consent.

\section{Data collection}

\section{Questionnaires}

Participants completed a General Health and Demographic Questionnaire with the help of a trained researcher, in which smoking, alcohol consumption, the use of contraceptives and demographics were reported. Socioeconomic status (SES) was derived from three categories including skill level, education, and household income. Points were awarded to each category and used to determine whether a participant fell within a low, middle or high SES. The classification of SES was adapted from Patro et al (32).

\section{Anthropometric and physical activity measurements}

Weight (SECA 813 Electronic Scales, SECA, Hamburg, Germany), height (SECA 213 Portable Stadiometer, SECA, Hamburg, Germany), and waist circumference (WC) (Lufkin Steel Anthropometric Tape (W606 PM), Lufkin, Apex, USA) were measured using standardised methods and calibrated instruments (33). We calculated body mass index (BMI) and waist-to-height ratio. Each participant was fitted with an accelerometry device (ActiHeart, CamNtech Ltd., Cambridge, UK) that was worn on the chest and recorded heart rate and activity continuously for a maximum of 7 consecutive days. From this daily activity, energy expenditure (AEE) was calculated.

\section{Cardiovascular measurements}

Clinic blood pressure measurements were conducted using the Dinamap Procare 100 Vital Signs Monitor (GE Medical Systems, Milwaukee, USA) according to standard guidelines. Two measurements were taken on each arm and we used the second reading taken on the left arm in this study. 
We used $\operatorname{Card}(\mathrm{X})$ plore ambulatory blood pressure monitor (ABPM) devices (MediTech, Budapest, Hungary) for collection of 24-hour blood pressure measurements, programmed to take recordings every 30 minutes during the day (06:00 to $22: 00)$ and every hour during the night (22:00 to $06: 00)$. The ABPM was fitted to each participant at approximately the same time every morning, using an appropriately sized cuff. The participants in this study had a mean successful inflation rate of $87.3 \%$.

\section{Biological sampling}

Participants were required to fast from 22:00 of the evening prior to the study day. Blood samples were taken with a sterile winged infusion set and syringes from the antebrachial vein. Participants were required to collect a 24-hour urine sample, within 7-days after they visited the hypertension clinic. All samples were immediately taken to the onsite laboratory, prepared and aliquoted into cryovials for storage in biofreezers at $-80^{\circ} \mathrm{C}$ until analysis.

\section{Biochemical measurements}

The Cobas Integra 400 Roche Clinical System (Roche Diagnostics, Indianapolis, IN, USA) was used to determine serum total cholesterol, high-density lipoprotein cholesterol (HDL-C), low-density lipoprotein cholesterol (LDL-C), triglycerides, gamma-glutamyl transferase (GGT), and high-sensitivity C-reactive protein (hs-CRP). Serum samples were also used to measure cotinine using the chemiluminescence method on the Immulite (Siemens, Erlangen, Germany). Glucose was measured in fluoride plasma. We used the following equation to estimate daily salt intake: (34)

Estimated $\mathrm{NaCl}(\mathrm{g} /$ day $)=\frac{\left(24 \mathrm{~h} \text { Urinary } \mathrm{Na}\left(\frac{\mathrm{mmol}}{\mathrm{L}}\right) \times \text { Urinary volume }(\mathrm{L})\right) \times 58.44}{1000}$

Blood groups were determined with a finger prick rapid test using Anti-A; Anti-B and Anti-D monoclonal reagents (ProMab Biotechnologies, Inc., USA) during screening. A full blood 
count was performed in whole blood samples using A Coulter AcT5 diff OV Haematology analyser (Beckman Coulter, Brea, CA, US).

Citrated samples were used for the analysis of vWF antigen (vWF:Ag), using a sandwich enzyme-linked immunosorbent assay. Polyclonal rabbit anti-vWF antibody and rabbit antivWF-horseradish peroxidase (HRP) antibody (DAKO, Glostrup, Denmark) were used to perform the assay. The 6th International Standard for vWF/FVIII was used to create the standard curve against which the samples were measured. Serum samples were used to measure ADAMTS13 as part of a bead-based multiplex immunoassay, which allows the simultaneous quantification of multiple markers on a Luminex $200^{\mathrm{TM}}$ system (Luminex, Austin, TX, US). The MILLIPEX MAP Human Cardiovascular Disease Magnetic Bead Panel 2 (Merck Millipore, Darmstadt, Germany) was custom made to include ADAMTS13, growth differentiation factor-15 (GDF-15), myeloperoxidase (MPO), P-selectin, soluble cell adhesion molecule (sCAM), and soluble vascular cell adhesion molecule (sVCAM).

\section{Statistical analyses}

We used IBM® SPSS $\AA^{\circ}$ Statistics, Version 25 software (IBM Corporation, Armonk, New York) for all statistical analyses. Variables were tested for normality by visual inspection (histograms and q-q plots) and skewness and kurtosis coefficients. Variables that were not normally distributed were log-transformed (including vWF:Ag, GGT, glucose, cotinine, $\mathrm{NaCl}$, LDL-C, triglycerides, hs-CRP). We performed interaction testing to test the interaction of ethnicity on the association of VWF and ADAMTS13 with health behaviours using multiple regression analyses. We used Independent T-tests and Chi-square tests to compare means and proportions between black and white individuals. Pearson and partial (adjusted for age, sex and ethnicity) correlations were used to determine associations between vWF and ADAMTS13 with health behaviours. We used multiple regression analyses to confirm associations independent of potential confounders. In addition to lifestyle factors, the following covariates were included in the multiple regression analysis: age, sex, ethnicity and 
blood groups. To establish differences in haemostatic markers according to hormonal contraceptive use, we compared VWF and ADAMTS13 concentrations between women using no contraception versus those using the contraceptive pill or the injection by employing analysis of covariance, while adjusting for age and BMI.

\section{Results}

We found significant interactions of ethnicity on the correlation between vWF:Ag and estimated salt intake $(p=0.001)$. Ethnicity also showed interactions on the correlations between BMI $(p=0.021)$, SES score $(p=0.021)$, GGT $(p=0.008)$ and salt intake $(p<0.001)$ with ADAMTS13. Based on these interactions and the findings of previous studies on ethnic differences in VWF:Ag plasma levels $(19,35)$, we divided the study population according to ethnicity.

The characteristics of the study population are presented in Table 1. Black participants presented with higher vWF:Ag and lower ADAMTS13 (all p<0.001) plasma levels compared to white participants. A large percentage (58.7\%) of black participants had a low SES while $49.5 \%$ of white participants had a high SES. White participants presented with a higher BMI $(p<0.001)$, larger waist circumference $(p<0.001)$, and lower activity energy expenditure $(p<0.001)$ compared to their black counterparts. Regarding liver enzymes, black participants presented with higher concentrations of GGT $(p<0.001)$ compared to white participants. 
Table 1. Characteristics of the study population

\begin{tabular}{|c|c|c|c|c|}
\hline & $\begin{array}{c}\text { Total group } \\
(n=1196)\end{array}$ & $\begin{array}{c}\text { Black } \\
(n=602)\end{array}$ & $\begin{array}{c}\text { White } \\
(n=594)\end{array}$ & $\mathbf{P}^{*}$ \\
\hline \multicolumn{4}{|l|}{ Blood groups n/total (\%) } & 0.51 \\
\hline Group O & $466 / 1038(44.9)$ & $260 / 549(47.4)$ & $206 / 489(42.1)$ & \multirow[t]{2}{*}{0.091} \\
\hline Group non-O & $572 / 1038$ & $289 / 549(52.6)$ & $283 / 489$ (57.9) & \\
\hline \multicolumn{5}{|l|}{ SES class n/total (\%) } \\
\hline Lower & 473/1196 (39.5) & $354 / 602(58.7)$ & $119 / 594(20.0)$ & \multirow{3}{*}{$<0.001$} \\
\hline Middle & $345 / 1196(28.8)$ & $164 / 602(27.3)$ & $181 / 594(30.5)$ & \\
\hline Higher & $378 / 1196(31.6)$ & $84 / 602(14.0)$ & $294 / 594(49.5)$ & \\
\hline \multicolumn{5}{|l|}{ Body composition } \\
\hline $\mathrm{BMI}, \mathrm{kg} / \mathrm{m}^{2}$ & $24.5(18.0 ; 35.5)$ & $24.0(17.6 ; 35.5)$ & $25.1(18.9 ; 35.5)$ & $<0.001$ \\
\hline Weight, kg & $71.3 \pm$ & 66.2 & $76.5 \pm 18.4$ & $<0.001$ \\
\hline Height, $\mathrm{cm}$ & 168 & 164 & 173 & $<0.001$ \\
\hline WC, cm & & $77 . \varepsilon$ & 82.5 & $<0.001$ \\
\hline Waist-to-hip ratio & $0.79 \pm 0.08$ & 0.78 & $0.80 \pm 0.08$ & $<0.001$ \\
\hline$B S A, m^{2}$ & $1.82 \pm 0.24$ & $1.73 \pm 0.20$ & $1.90 \pm 0.25$ & $<0.001$ \\
\hline \multicolumn{5}{|l|}{ Blood pressure } \\
\hline Clinic SBP, & & $\overline{117}$ & 116 & 0.15 \\
\hline Clini & & 79. & 77.7 & $<0.001$ \\
\hline 24-hour SBP, n & 117 & 116 & $118 \pm 9.82$ & $<0.001$ \\
\hline 24-hour DBP, $r$ & 68.7 & 68.8 & 68.6 & 0.44 \\
\hline \multicolumn{5}{|l|}{ Biochemical measurements } \\
\hline vWF:Ag, \% & 84.0 & 93.9 & 75.0( & $<0.001$ \\
\hline $\mathrm{TS} 13, \mathrm{ng} / \mathrm{ml}$ & 137 & 133 & 1422 & $<0.001$ \\
\hline $\mathrm{e}, \mathrm{mmol} / \mathrm{L}$ & 4.0 & 1.03 & 4.25 & $<0.001$ \\
\hline $\mathrm{mmol} / \mathrm{L}$ & 3.57( & 3.33( & $3.38(2$ & $<0.001$ \\
\hline LDL & 2.26 & ;3.71) & $2.45(1$. & $<0.001$ \\
\hline $\mathrm{HDLC}, \mathrm{mmol} / \mathrm{L}$ & 1.08( & $8 ; 1.83)$ & $1.09(0.57 ; 2.02)$ & 0.84 \\
\hline Trigl & 0.72 & $0.64(0$ & $0.80(0$. & $<0.001$ \\
\hline C-re & 0 ०० & $1.02(($ & $0.78(0$ & 0.002 \\
\hline \multicolumn{5}{|l|}{ Lifestyle factors } \\
\hline GGT, U/L & 18.2 & ;66.2) & $14.9(5$ & $<0.001$ \\
\hline Cotinine, $\mathrm{nc}$ & 3.59 & $4.02(1$ & $3.20(1.00 ; 308)$ & 0.080 \\
\hline Estimated salt intake, g/day & 7.63 & 3;21.4) & $7.35(2$. & 0.096 \\
\hline $\mathrm{AEE}, \mathrm{kCal} / \mathrm{kg}$ & 5.9 & 6.52 & 5.37 & $<0.001$ \\
\hline Alcohol intake, n/total (\%) & $662 / 1188(55.7)$ & $331 / 595(55.6)$ & $331 / 593(55.8)$ & 0.95 \\
\hline Smoking, n/total (\%) & $284 / 1$ & $153 / 6$ & $131 / 59$ & 0.17 \\
\hline \multicolumn{5}{|l|}{ Total hormonal contraceptives } \\
\hline Contraceptive & 154 & $35 /$ & $119 / 3$ & $<0.001$ \\
\hline Contracepti & $99 / 6$ & $92 / 303(30.4)$ & $7 / 310(2.30)$ & $<0.001$ \\
\hline Contraceptive implant n/total (\%) & $24 / 256(9.40)$ & $19 / 118(16.1)$ & $5 / 138(3.60)$ & 0.001 \\
\hline \multicolumn{5}{|c|}{$\begin{array}{l}\text { Abbreviations: SES - socio-economic status; BMI - body mass index; WC - waist circumference; BSA } \\
\text { - body surface area; SBP - systolic blood pressure; DBP - diastolic blood pressure; vWF - von } \\
\text { Willebrand factor; ADAMTS13 - a disintegrin and metalloproteinase with a thrombospondin type } 1 \\
\text { motif, member 13; GGT - gamma-glutamyl transferase; LDLC - low density lipoprotein cholesterol; } \\
\text { HDLC - high density lipoprotein; AEE - activity energy expenditure. }{ }^{*} \text { P value for comparing black vs } \\
\text { white groups. Values are expressed as arithmetic mean } \pm \text { standard deviation or geometric mean (5th to } \\
95 \text { th percentile interval) for logarithmically transformed variables, or number of participants and } \\
\text { percentages }(\%) \text { and } 0<0.05 \text { was considered sianificant. }\end{array}$} \\
\hline
\end{tabular}


Firstly, we determined whether VWF:Ag is related to ADAMTS13 in the total sample, and as expected we found a negative correlation $(r=-0.11 ; p<0.001)$ (Figure 1).

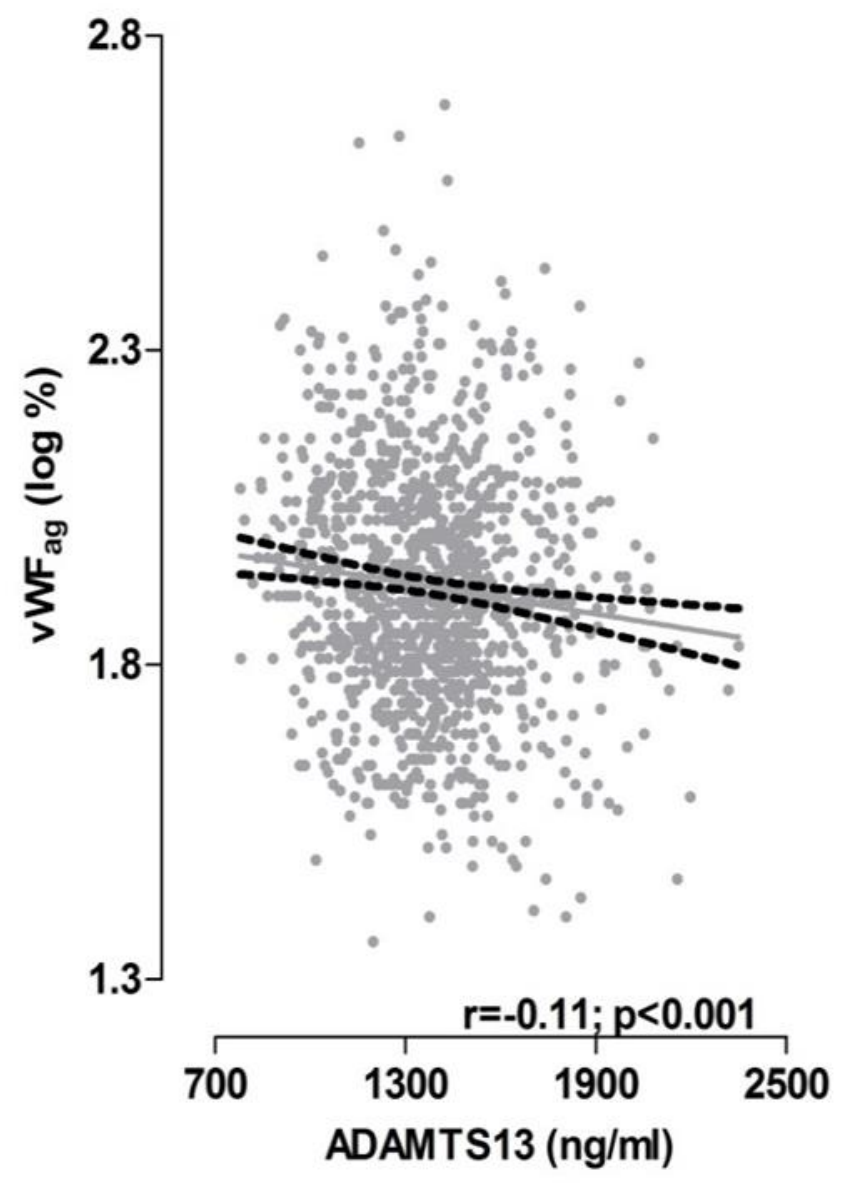

Figure 1. Linear regression analyses between vWF:Ag and ADAMTS13 levels in the total group.

Solid and dashed lines represent the regression line and $95 \% \mathrm{Cl}$ boundaries, respectively. Abbreviations: vWF:Ag - von Willebrand factor antigen; ADAMTS13 - a disintegrin and metalloproteinase with a thrombospondin type 1 motif, member 13.

To address our aim, we explored the correlations of vWF:Ag and ADAMTS13 with health behaviours using Pearson correlations (Figure 2). The vWF:Ag associated negatively with SES score $(r=-0.13 ; p<0.001)$ and positively with GGT $(r=0.07 ; p=0.017)$, while ADAMTS13 associated positively with SES score $(r=0.10 ; p=0.001)$ and negatively with BMI $(r=-0.06$; $\mathrm{p}=0.044)$. 

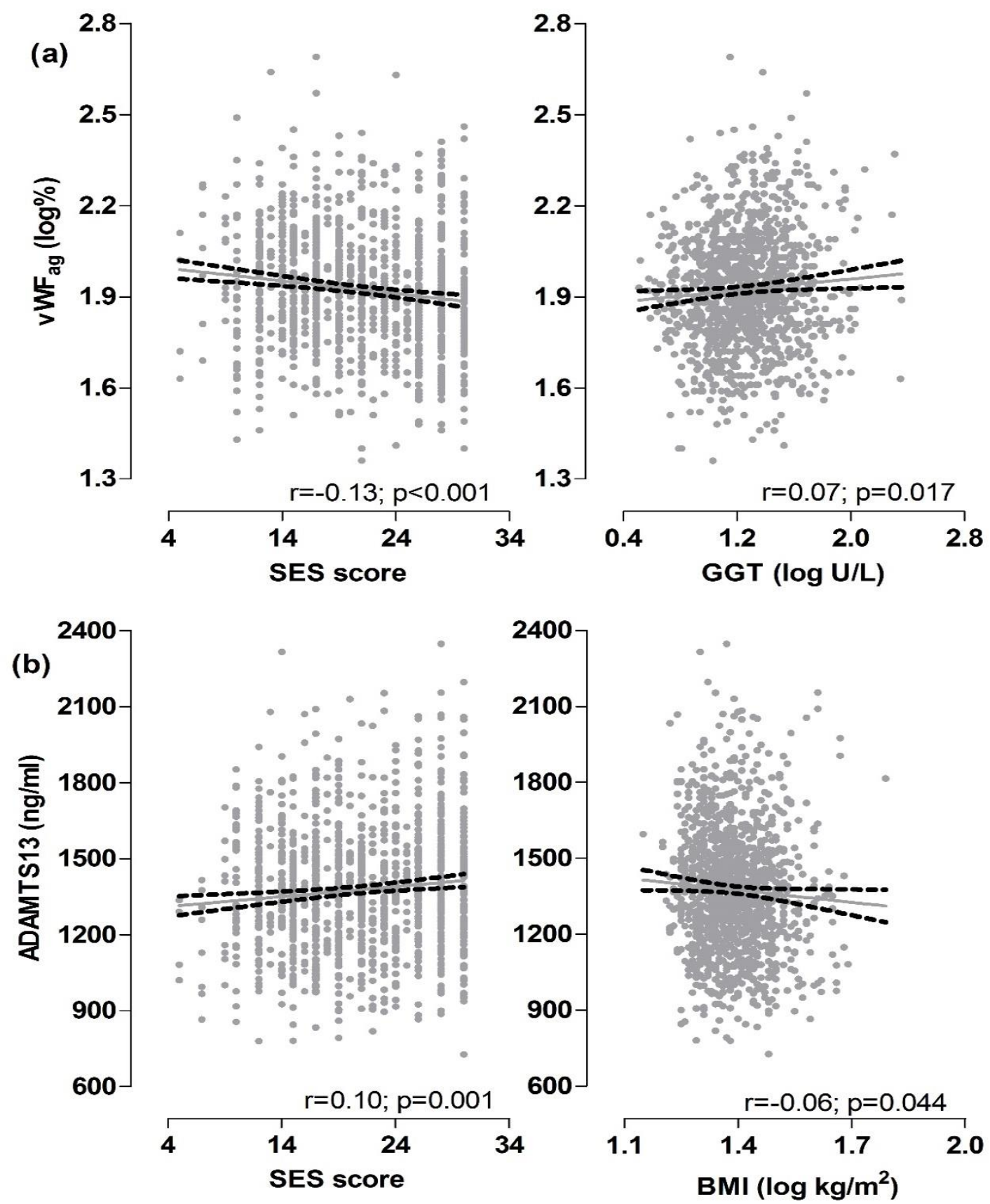

Figure 2. Linear regression analyses in the total group between (a) VWF:Ag and SES score and GGT; and (b) ADAMTS13 and SES score and BMI. Solid and dashed lines represent the regression line and $95 \% \mathrm{Cl}$ boundaries, respectively. Abbreviations: vWF:Ag - von Willebrand factor antigen; SES score - socioeconomic score; GGT gamma-glutamyl transferase; ADAMTS13 - a disintegrin and metalloproteinase with a thrombospondin type 1 motif, member 13; BMI - body mass index. 
In addition, multivariate regression analyses were performed in the total group with health behaviours as main independent variables (Table 2). The vWF:Ag associated with black ethnicity $(\beta=-0.25 ; p<0.001)$ and non-O blood group $(\beta=-0.30 ; p<0.001)$ and positively with BMI $(\beta=0.09 ; p=0.037)$, while ADAMTS13 associated positively with white ethnicity $(\beta=0.23$; $p<0.001)$ and GGT $(\beta=0.14 ; p=0.002)$, and negatively with BMI $(\beta=-0.10 ; p=0.016)$ and cotinine $(\beta=-0.09 ; p=0.029)$.

Table 2. Multiple regression analysis of vWF:Ag and ADAMTS13 with health behaviours in the total group

\begin{tabular}{|c|c|c|c|c|}
\hline & von Willebrand Fa & & ADAMTS13, ng/ml & \\
\hline & $\beta(95 \% \mathrm{Cl})$ & $p$ & $\beta(95 \% \mathrm{Cl})$ & $\mathbf{p}$ \\
\hline Adjusted $\mathrm{R}^{2}$ & $0.15 ; \quad P<0.001$ & & $0.05 ; \quad P<0.001$ & \\
\hline Age, years & $0.08(-0.004 ; 0.16)$ & 0.062 & $0.002(-0.09 ; 0.09)$ & 0.96 \\
\hline Sex, (women/men) & $-0.03(-0.12 ; 0.05)$ & 0.42 & $0.06(-0.03 ; 0.15)$ & 0.18 \\
\hline Ethnicity (black/white) & $-0.25(-0.34 ;-0.17)$ & $<0.001$ & $0.23(0.13 ; 0.32)$ & $<0.001$ \\
\hline Blood group (non-O/O) & $-0.30(-0.37 ;-0.22)$ & $<0.001$ & $-0.002(-0.08 ; 0.08)$ & 0.95 \\
\hline BMI, $\mathrm{kg} / \mathrm{m}^{2}$ & $0.09(0.005 ; 0.17)$ & 0.037 & $-0.10(-0.19:-0.02)$ & 0.016 \\
\hline SES score & $-0.08(-0.17 ; 0.02)$ & 0.11 & $-0.00(-0.10 ; 0.10)$ & 1.00 \\
\hline AEE, $\mathrm{kCal} / \mathrm{kg}$ & $0.005(-0.02 ; 0.03)$ & 0.72 & $0.001(-0.03 ; 0.03)$ & 0.92 \\
\hline $\mathrm{GGT}, \mathrm{ng} / \mathrm{ml}$ & $-0.04(-0.12 ; 0.05)$ & 0.41 & $0.14(0.05 ; 0.23)$ & 0.002 \\
\hline Cotinine, $\mathrm{ng} / \mathrm{ml}$ & $-0.02(-0.10 ; 0.06)$ & 0.62 & $-0.09(-0.18 ;-0.009)$ & 0.029 \\
\hline Salt intake, g/day & $0.05(-0.03 ; 0.12)$ & 0.26 & $-0.04(-0.12 ; 0.04)$ & 0.29 \\
\hline $\begin{array}{l}\text { Abbreviations: vWF:Ag } \\
\text { metalloproteinase with a } \\
\text { score - socio-economi } \\
\text { glutamyltransferase; } \mathrm{Na}\end{array}$ & $\begin{array}{l}\text { - von Willebrano } \\
\text { hrombospondin ty } \\
\text { status score; A } \\
\text { - sodium chloride }\end{array}$ & $\begin{array}{l}\text { antige } \\
\text { tif, men } \\
\text { ctivity } \\
5 \text { was c }\end{array}$ & $\begin{array}{l}\text { ADAMTS13 - a } \\
\text { r 13; BMI - body m } \\
\text { rgy expenditure; C } \\
\text { idered significant }\end{array}$ & $\begin{array}{l}\text { grin and } \\
\text { lex; SES- } \\
\text { gamma- }\end{array}$ \\
\hline
\end{tabular}


We further performed ethnic-specific single regression analyses between VWF:Ag or ADAMTS13 plasma levels with health behaviours (Supplementary Table S1). In the black group, VWF:Ag associated negatively with cotinine $(r=-0.08 ; p=0.047)$ and self-reported smoking $(r=-0.08 ; p=0.046)$, while ADAMTS13 associated negatively with BMl $(r=-0.15$; $p<0.001)$. In the white group ADAMTS13 associated positively with GGT $(r=0.18 ; p<0.001)$.

In multivariable-adjusted regression analyses in the black group (Table 3), vWF:Ag associated with non-O blood group $(\beta=-0.23 ; p<0.001))$ and positively with salt intake $(\beta=0.12 ; p=0.043)$. In the white group vWF:Ag also associated with non-O blood group ( $\beta=-$ 0.36; $p<0.001)$, and positively with BMI $(\beta=0.14 ; p=0.023)$, while ADAMTS13 associated positively with male sex $(\beta=0.15 ; p=0.026)$ and $G G T(\beta=0.22 ; p=0.003)$ and negatively with cotinine $(\beta=-0.14 ; p=0.041)$. 
Table 3. Multiple regression analysis of vWF:Ag and ADAMTS13 with health behaviours

\begin{tabular}{|c|c|c|c|c|}
\hline & \multicolumn{4}{|c|}{ von Willebrand Factor ${ }_{a g}, \%$} \\
\hline & \multicolumn{2}{|c|}{ Black $(n=602)$} & \multicolumn{2}{|c|}{ White $(n=594)$} \\
\hline & $\beta(95 \% \mathrm{Cl})$ & $\mathbf{p}$ & $\beta(95 \% \mathrm{Cl})$ & $\mathbf{p}$ \\
\hline Adjusted $\mathrm{R}^{2}$ & $0.05 ; p=0.003$ & & $0.14 ; p<0.001$ & \\
\hline Age, years & $0.09(-0.03 ; 0.21)$ & 0.13 & $0.09(-0.04 ; 0.21)$ & 0.19 \\
\hline Sex, (women/men) & $0.03(-0.10 ; 0.16)$ & 0.64 & $-0.11(-0.23 ; 0.008)$ & 0.068 \\
\hline Blood group, (non-O/O) & $-0.23(-0.34 ;-0.12)$ & $<0.001$ & $-0.36(-0.46 ;-0.26)$ & $<0.001$ \\
\hline BMI, $\mathrm{kg} / \mathrm{m}^{2}$ & $0.05(-0.07 ; 0.18)$ & 0.41 & $0.14(0.02 ; 0.27)$ & 0.023 \\
\hline SES score & $-0.05(-0.18 ; 0.08)$ & 0.45 & $-0.09(-0.23 ; 0.06)$ & 0.23 \\
\hline $\mathrm{AEE}, \mathrm{kCal} / \mathrm{kg}$ & $0.001(-0.04 ; 0.04)$ & 0.95 & $0.00(-0.04 ; 0.04)$ & 0.99 \\
\hline GGT, U/L & $-0.02(-0.14 ; 0.11)$ & 0.81 & $-0.06(-0.18 ; 0.07)$ & 0.37 \\
\hline Cotinine, $\mathrm{ng} / \mathrm{ml}$ & $-0.06(-0.17 ; 0.06)$ & 0.34 & $-0.002(-0.12 ; 0.11)$ & 0.97 \\
\hline Salt intake, g/day & $0.12(0.004 ; 0.23)$ & 0.043 & $-0.02(-0.13 ; 0.08)$ & 0.66 \\
\hline
\end{tabular}

\begin{tabular}{|c|c|c|c|c|}
\hline \multicolumn{5}{|c|}{ ADAMTS13, ng/ml } \\
\hline & \multicolumn{2}{|c|}{ Black $(n=602)$} & \multicolumn{2}{|c|}{ White $(n=594)$} \\
\hline & $\beta(95 \% \mathrm{Cl})$ & p & $\beta(95 \% \mathrm{Cl})$ & p \\
\hline Adjusted $\mathrm{R}^{2}$ & $0.02 ; p=0.14$ & & $0.04 ; p=0.012$ & \\
\hline Age, years & $-0.04(-0.15 ; 0.08)$ & 0.51 & $0.06(-0.09 ; 0.20)$ & 0.43 \\
\hline Sex, (women/men) & $-0.07(-0.20 ; 0.05)$ & 0.26 & $0.15(0.02 ; 0.29)$ & 0.026 \\
\hline Blood group, (non-O/O) & $-0.03(-0.14 ; 0.08)$ & 0.60 & $0.04(-0.08 ; 0.16)$ & 0.52 \\
\hline $\mathrm{BMI}, \mathrm{kg} / \mathrm{m}^{2}$ & $-0.17(-0.29 ;-0.05)$ & 0.007 & $-0.13(-0.27 ; 0.11)$ & 0.070 \\
\hline SES score & $-0.03(-0.16 ; 0.10)$ & 0.60 & $0.02(-0.15 ; 0.18)$ & 0.86 \\
\hline $\mathrm{AEE}, \mathrm{kCal} / \mathrm{kg}$ & $-0.02(-0.06 ; 0.02)$ & 0.30 & $0.03(-0.02 ; 0.08)$ & 0.24 \\
\hline GGT, U/L & $0.06(-0.06 ; 0.18)$ & 0.31 & $0.22(0.08 ; 0.36)$ & 0.003 \\
\hline Cotinine, $\mathrm{ng} / \mathrm{ml}$ & $-0.06(-0.17 ; 0.06)$ & 0.33 & $-0.14(-0.27 ;-0.006)$ & 0.041 \\
\hline Salt intake, g/day & $-0.06(-0.17 ; 0.04)$ & 0.25 & $-0.03(-0.15 ; 0.10)$ & 0.69 \\
\hline
\end{tabular}

Abbreviations: BMI - body mass index; SES-score - socio-economic status score; AEE - actiivity energy expenditure; GGT - gamma-glutamyl transferase; $\mathrm{NaCl}$ - sodium chloride; ADAMTS13 - a disintegrin and metalloproteinase with a thrombospondin type 1 motif, member 13 . $P<0.05$ was considered significant.

Since it is known that the liver enzyme, GGT can be a marker of oxidative stress and nonalcoholic fatty liver disease (NAFLD) in addition to being a marker of alcohol consumption $(36,37)$, we performed sensitivity analyses in which GGT was replaced by self-reported alcohol consumption to determine whether the association found between ADAMTS13 and GGT represented alcohol consumption. Self-reported alcohol consumption did not associate 
with ADAMTS13 in the total $\left(R^{2}=0.05 ; \beta=0.01 ; p=0.79\right)$ or white group $\left(R^{2}=0.04 ; \beta=-0.03\right.$; $\mathrm{p}=0.66)$.

Finally, due to previous reports suggesting that hormonal contraception may influence vWF and ADAMTS13 levels (4), we compared VWF:Ag and ADAMTS13 concentrations within each ethnic group between women using no hormonal contraceptives, using oral contraceptives or an injection (Table S2). Neither vWF:Ag nor ADAMTS13 levels differed between women using no contraceptives and those using the different hormonal contraceptives.

\section{Discussion}

In our study investigating young healthy black and white adults, black individuals presented with an increased thrombotic risk evidenced by higher vWF:Ag and lower plasma levels of its cleaving protease, ADAMTS13, when compared to their white counterparts. We found that these haemostatic markers associated independently with lifestyle and health behaviours. In the total group of 1196 participants, VWF:Ag was positively associated with a marker of obesity (BMI), whereas ADAMTS13 associated negatively with obesity - highlighting obesity as a potential important contributor affecting the equilibrium in VWF:Ag and ADAMTS13 concentrations, already in young healthy individuals. ADAMTS13 further associated positively with the liver enzyme, GGT, and negatively with cotinine. When viewing contraceptive use, no significant variation was found in vWF:Ag and ADAMTS13 levels between women using hormonal contraceptives and those who did not.

The variation in VWF:Ag levels observed between black and white individuals is consistent with the literature (19-22). In the ARIC study - including 15407 (27\% black) participants aged 45-64 years in the United States, black men and women were found to have a fourtimes higher stroke rate than their white counterparts, and this was most apparent in the youngest group (38). In the same study, vWF levels were higher in the black individuals and were found to be independently associated with incidence of stroke in both black and white 
individuals. Regarding ADAMTS13, a deficiency thereof causes TTP which is reported to be more common in black populations (26). In a study by Sonneveld et al., low ADAMTS13 was also associated with stroke (39). To improve health outcomes, it would be important to maintain a favourable vWF and ADAMTS13 balance by making lifestyle changes known to have an effect on these haemostatic markers.

Indeed, we found that certain health behaviours - particularly obesity, potentially alcohol consumption, smoking and salt intake to be related to vWF:Ag and/or ADAMTS13 levels. Obesity is a known risk factor for ischemic stroke (40), due to its prothrombotic effects by influencing haemostatic and inflammatory factors by disrupting the endothelium (41). Obesity has also been associated with early endothelial damage which resulted in an increase in circulating VWF (42). We observed a positive association between vWF:Ag and obesity in the total group, which is in accordance with a recent study by Atiq et al. (43) that investigated the association between vWF:Ag and BMI in patients suffering from von Willebrand disease. These results suggest that in the young African-PREDICT population, there may already be early endothelial activation in those with elevated adiposity that increase these individuals' thrombotic risk. We also found ADAMTS13 to be inversely related to obesity, and this result is supported by a study in which weight loss resulted in elevated ADAMST13 levels, by decreasing anti-ADAMTS13 antibodies (44). These findings highlight that weight management programmes have the potential of improving the VWF:Ag and ADAMTS13 equilibrium, and if applied from young ages this may have long-term beneficial effects.

Salt intake is an important health behaviour related to hypertension and CVD, especially in the black population, (45) as black populations are known to be more salt sensitive compared to whites, due to higher renal sodium retention (46). This ethnic difference in haemostatic relationships with salt intake is noteworthy and requires further investigation. It is unclear how retained sodium is mechanistically involved in raised vWF:Ag levels. In a study by Dmitrieva et al. (3) a high salt intake was shown to influence the haemostasis by increasing the production of vWF by endothelial cells in a cell culture. In the same study 
vWF levels were also found to increase with salt intake in humans which aligns with our finding. Salt sensitivity in black populations thus, does not only predispose these individuals to a risk for raised blood pressure, but may potentially also affect platelet adhesion and clot formation. Therefore, our finding supports the need for policies and strategies to reduce salt intake.

With regards to tobacco use, we found no relationship with vWF:Ag levels, but ADAMTS13 showed an independent inverse relationship with tobacco use. This finding is in accordance with Ma et al. (28) who reported an association of smoking with low ADAMTS13 levels in a healthy European-ancestry population. In this population, smoking was associated with a 3.6\% decrease in ADAMTS13. Tobacco use is a known risk factor of thrombosis, and contributes to thrombus formation by altering the haemostatic process via endothelial dysfunction $(47,48)$. In a recent meta-analysis, smokers were also found to have an increased risk of stroke compared to non-smokers (49) depending on the number of cigarettes smoked per day. These findings, together with our results, bring forth awareness on the beneficial effects of smoking cessation and support the global initiatives to prevent the youth from initiating tobacco use and to stop smoking from young ages onwards.

Interestingly, we found a potential beneficial positive relationship between ADAMTS13 and GGT. The liver enzyme, GGT is strongly and consistently associated with the metabolic syndrome, stroke and other CVD $(50,51)$. Our finding is thus unexpected and not corroborated by previous reports where an inverse association between ADAMTS13 and GGT were reported in 432 men and woman, of mean age 54.8 and 56.4 years, respectively (52). We originally regarded GGT as a marker of alcohol consumption. However, as GGT is also an alternative marker of oxidative stress (37) and NAFLD (36), we performed sensitivity analyses by substituting GGT with self-reported alcohol use (no/yes). The relationship between ADAMTS13 and self-reported alcohol consumption was not significant, suggesting that GGT likely represented other conditions such as oxidative stress. The finding is challenging to interpret as self-reported alcohol intake may also be unreliable as people tend 
to under-report their drinking behaviour. It remains unclear why elevated GGT would associate with increased ADAMTS13 levels.

With regard to the influences of hormonal contraceptive use on vWF and ADAMTS13 levels, there are inconsistent reports in the literature. In our study, we found no marked effect of hormonal contraceptives on VWF:Ag and ADAMTS13 levels. Our findings are in agreement with a study that investigated the effects of combined oral contraceptives in 55 healthy women aged 18-34 years (53). In this study, vWF:Ag concentrations did not differ between women who used contraceptives and the controls. By contrast, in a study including 1018 women aged 18-49 years, Andersson et al. (4) found women using oral contraceptives to have higher vWF and lower ADAMS13 levels. It remains unclear why inconsistent findings are reported, but based on either the white or black women in our study, there were no clear differences in either vWF:Ag or ADAMTS13.

In addition to the associations with health behaviours, our study also confirmed that individuals with non-O blood groups have higher vWF:Ag levels compared to those with group O type, irrespective of ethnicity. It is well established that humans with the O-blood group have lower vWF concentrations due to increased clearance of VWF from plasma in comparison to $A, B$ and $A B$ blood groups $(14-16,54)$. We did not find an association between ADAMTS13 and blood groups, which is in agreement with previous studies in healthy populations $(15,23)$. However, two studies have reported lower ADAMTS13 levels in non-O blood group compared to group $\mathrm{O}(24,54)$. In both studies the findings were in a healthy control group, one in a young population with a mean age of 20 years and the other in an older population of mean age 55 years. Further research is therefore needed to determine if ethnic differences exist regarding ADAMTS13.

Our findings should be reported while taking the strengths and limitations into account. This study design is cross-sectional and precluded us from determining cause and effect. The strengths are that we included a large young healthy population with a detailed phenotype. 
The black and white population allowed us to evaluate ethnic differences in haemostatic proteins and a detailed range of health behaviours.

In conclusion, in a young healthy population we found higher levels of vWF:Ag and lower levels of ADAMTS13 in black compared to white adults. Overall obesity is adversely associated with vWF and ADAMTS13, whereas an ethnic-specific positive association was found between vWF and salt intake in the black group and an inverse association between ADAMTS13 and smoking in the white group. Collectively our findings strongly support population-based strategies to reduce obesity, smoking, and salt intake as these interventions may also have direct beneficial consequences on thrombotic risk. Our results therefore, support cardioprotective population-based strategies to improve lifestyle and health behaviours.

\section{Acknowledgements}

The authors are grateful towards all individuals participating voluntarily in the study. The dedication of the support and research staff as well as students at the Hypertension Research and Training Clinic at the North-West University are all duly acknowledged. The research funded in this manuscript is part of an ongoing research project financially supported by the South African Medical Research Council (SAMRC) with funds from National Treasury under its Economic Competitiveness and Support Package; the South African Research Chairs Initiative (SARChl) of the Department of Science and Technology and National Research Foundation (NRF) of South Africa (GUN 86895); SAMRC with funds received from the South African National Department of Health, GlaxoSmithKline R\&D (Africa Non-Communicable Disease Open Lab grant), the UK Medical Research Council and with funds from the UK Government's Newton Fund; as well as corporate social investment grants from Pfizer (South Africa), Boehringer-Ingelheim (South Africa), Novartis (South Africa), the Medi Clinic Hospital Group (South Africa) and in kind contributions of Roche Diagnostics (South Africa). Any opinion, findings, and conclusions or recommendations 
expressed in this material are those of the authors, and therefore, the NRF does not accept any liability in this regard.

\section{Conflict of interest}

All authors declare no conflict of interest. 


\section{References}

1. Kim AS, Johnston SC. Temporal and Geographic Trends in the Global Stroke $\begin{array}{llll}\text { Epidemic. } & \text { Stroke. 2013;44(6 suppl } 1): s 123-s 25, \quad \text { DOI: }\end{array}$ 10.1161/STROKEAHA.111.000067.

2. Roth GA, Johnson C, Abajobir A, Abd-Allah F, Abera SF, Abyu G, et al. Global, Regional, and National Burden of Cardiovascular Diseases for 10 Causes, 1990 to 2015. J Am Coll Cardiol. 2017;70(1):1-25, DOI: 10.1016/j.jacc.2017.04.052.

3. Dmitrieva NI, Burg MB. Secretion of Von Willebrand Factor by Endothelial Cells Links Sodium to Hypercoagulability and Thrombosis. Proc Natl Acad Sci U S A. 2014;111(17):6485-90, DOI: 10.1073/pnas.1404809111.

4. Andersson HM, Siegerink B, Luken BM, Crawley JT, Algra A, Lane DA, et al. High VWF, Low ADAMTS13, and Oral Contraceptives Increase the Risk of Ischemic Stroke and Myocardial Infarction in Young Women. Blood. 2012;119(6):1555-60, DOI: 10.1182/blood-2011-09-380618.

5. Shahidi M. Thrombosis and Von Willebrand Factor. Adv Exp Med Biol. 2017;906:285-306, DOI: 10.1007/5584_2016_122.

6. Lenting PJ, Denis CV. Platelet Von Willebrand Factor: Sweet Resistance. Blood. 2013;122(25):4006-07, DOI: 10.1182/blood-2013-10-533174.

7. Sonneveld MA, de Maat MP, Leebeek FW. Von Willebrand Factor and ADAMTS13 in Arterial Thrombosis: A Systematic Review and Meta-Analysis. Blood Rev. 2014;28(4):167-78, DOI: 10.1016/j.blre.2014.04.003.

8. Ruggeri ZM. The Role of Von Willebrand Factor in Thrombus Formation. Thromb Res. 2007;120(Suppl 1):s5-s9, DOI: 10.1016/j.thromres.2007.03.011.

9. Wiseman S, Marlborough F, Doubal F, Webb DJ, Wardlaw J. Blood Markers of Coagulation, Fibrinolysis, Endothelial Dysfunction and Inflammation in Lacunar Stroke Versus Non-Lacunar Stroke and Non-Stroke: Systematic Review and MetaAnalysis. Cerebrovasc Dis. 2014;37(1):64-75, DOI: 10.1159/000356789. 
10. Kelwick R, Desanlis I, Wheeler GN, Edwards DR. The ADAMTS (a Disintegrin and Metalloproteinase with Thrombospondin Motifs) Family. Genome Biol. 2015;16(1):113, DOI: 10.1186/s13059-015-0676-3.

11. Lancellotti S, Basso M, De Cristofaro R. Proteolytic Processing of Von Willebrand Factor by ADAMTS13 and Leukocyte Proteases. Mediterr J Hematol Infect Dis. 2013;5(1), DOI: 10.4084/MJHID.2013.058.

12. Maino A, Siegerink B, Lotta L, Crawley J, le Cessie S, Leebeek F, et al. Plasma ADAMTS-13 Levels and the Risk of Myocardial Infarction: An Individual Patient Data Meta-Analysis. J Thromb Haemost. 2015;13(8):1396-404, DOI: 10.1111/jth.13032.

13. Sonneveld MA, Franco OH, Ikram MA, Hofman A, Kavousi M, de Maat MP, et al. Von Willebrand Factor, ADAMTS13, and the Risk of Mortality: The Rotterdam Study. Arterioscler Thromb Vasc Biol. 2016;36(12):2446-51, DOI: 10.1161/atvbaha.116.308225.

14. Song J, Chen F, Campos M, Bolgiano D, Houck K, Chambless LE, et al. Quantitative Influence of ABO Blood Groups on Factor VIII and Its Ratio to Von Willebrand Factor, Novel Observations from an Aric Study of 11,673 Subjects. PloS one. 2015;10(8):e0132626, DOI: 10.1371/journal.pone.0132626.

15. Wang Z, Dou M, Du X, Ma L, Sun P, Cao H, et al. Influences of ABO Blood Group, Age and Gender on Plasma Coagulation Factor VIII, Fibrinogen, Von Willebrand Factor and ADAMTS13 Levels in a Chinese Population. PeerJ. 2017;5, DOI: 10.7717/peerj.3156.

16. Asuquo JI, Okafor IM, Usanga EA, Idongesit I. Von Willebrand Factor Antigen Levels in Different $\mathrm{ABO}$ Blood Groups in a Nigerian Population. Int J Biomed Lab Sci. $2014 ; 1: 24-28$.

17. Conlan MG, Folsom AR, Finch A, Davis C, Sorlie P, Marcucci G, et al. Associations of Factor VIII and Von Willebrand Factor with Age, Race, Sex, and Risk Factors for Atherosclerosis. Thromb Haemost. 1993;70(3):380-85. 
18. Sánchez-Luceros A, Meschengieser SS, Marchese C, Votta R, Casais P, Woods Al, et al. Factor VIII and Von Willebrand Factor Changes During Normal Pregnancy and Puerperium. Blood Coagul Fibrinolysis. 2003;14(7):647-51, DOI: 10.1097/00001721$200310000-00005$.

19. Miller C, Dilley A, Richardson L, Craig Hooper W, L. Evatt B. Population Differences in Von Willebrand Factor Levels in African American Women. Am J Hematol. 2001;67(2):125-29, DOI: 10.1002/ajh.1090.

20. Sukhu K, Poovalingam V, Mahomed R, Giangrande PF. Ethnic Variation in Von Willebrand Factor Levels Can Influence the Diagnosis of Von Willebrand Disease. Clin Lab Haematol. 2003;25(4):247-49, DOI: 10.1046/j.1365-2257.2003.00523.x.

21. Miller C, Haff E, Platt S, Rawlins P, Drews C, Dilley A, et al. Measurement of Von Willebrand Factor Activity: Relative Effects of ABO Blood Type and Race. J Thromb Haemost. 2003;1(10):2191-97, DOI: 10.1046/j.1538-7836.2003.00367.x.

22. Payne AB, Miller CH, Hooper WC, Lally C, Austin HD. High Factor VIII, Von Willebrand Factor, and Fibrinogen Levels and Risk of Venous Thromboembolism in Blacks and Whites. Ethn Dis. 2014;24(2):169-74.

23. Alpoim PN, Gomes KB, Godoi LC, Rios DR, Carvalho MG, Fernandes AP, et al. ADAMTS13, FVIII, Von Willebrand Factor, ABO Blood Group Assessment in Preeclampsia. Clin Chim Acta. 2011;412(23-24):2162-66, DOI: 10.1016/j.cca.2011.07.030.

24. Mannucci PM, Capoferri C, Canciani MTJBjoh. Plasma Levels of Von Willebrand Factor Regulate ADAMTS-13, Its Major Cleaving Protease. $\mathrm{Br} \mathrm{J}$ Haematol. 2004;126(2):213-18, DOI: 10.1111/j.1365-2141.2004.05009.x.

25. Rios DR, Fernandes AP, Figueiredo RC, Guimaraes DA, Ferreira CN, e Silva ACS, et al. Relationship between ABO Blood Groups and Von Willebrand Factor, ADAMTS13 and Factor VIII in Patients Undergoing Hemodialysis. J Thromb Thrombolysis. 2012;33(4):416-21, DOI: 10.1007/s11239-012-0719-5. 
26. Terrell DR, Motto DG, Kremer Hovinga JA, Lämmle B, George JN, Vesely SK. Blood Group $\mathrm{O}$ and Black Race Are Independent Risk Factors for Thrombotic Thrombocytopenic Purpura Associated with Severe ADAMTS13 Deficiency. Transfusion. 2011;51(10):2237-43, DOI: 10.1111/j.1537-2995.2011.03125.x.

27. Parsons TJ, Sartini C, Welsh P, Sattar N, Ash S, Lennon LT, et al. Physical Activity, Sedentary Behavior, and Inflammatory and Hemostatic Markers in Men. Med Sci Sports Exerc. 2017;49(3):459-65, DOI: 10.1249/MSS.0000000000001113.

28. Ma Q, Jacobi PM, Emmer BT, Kretz CA, Ozel AB, McGee B, et al. Genetic Variants in ADAMTS13 as Well as Smoking Are Major Determinants of Plasma ADAMTS13 Levels. Blood Adv. 2017;1(15):1037-46, DOI: 10.1182/bloodadvances.2017005629.

29. Mukamal KJ, Jadhav PP, D’Agostino RB, Massaro JM, Mittleman MA, Lipinska I, et al. Alcohol Consumption and Hemostatic Factors: Analysis of the Framingham Offspring Cohort. Circulation. 2001;104(12):1367-73, DOI: 10.1161/hc3701.096067.

30. Reddy SP, Resnicow K, James S, Funani IN, Kambaran NS, Omardien RG, et al. Rapid Increases in Overweight and Obesity among South African Adolescents: Comparison of Data from the South African National Youth Risk Behaviour Survey in 2002 and 2008. Am J Public Health. 2012;102(2):262-68, DOI: 10.2105/AJPH.2011.300222.

31. Schutte AE, Gona PN, Delles C, Uys AS, Burger A, Mels CM, et al. The African Prospective Study on the Early Detection and Identification of Cardiovascular Disease and Hypertension (African-Predict): Design, Recruitment and Initial Examination. Eur J Prev Cardiol. 2019;26(5):458-70, DOI: $10.1177 / 2047487318822354$.

32. Patro BK, Jeyashree K, Gupta PK. Kuppuswamy's Socioeconomic Status Scale 2010—the Need for Periodic Revision. Indian J Pediatr. 2012;79(3):395-96, DOI: 10.1007/s12098-011-0517-7. 
33. Marfell-Jones MJ, Stewart A, De Ridder J. International Standards for Anthropometric Assessment, International Society for the Advancement of Kinanthropometry. New Zealand: Wellington; 2012.

34. Dickinson BD, Havas S. Reducing the Population Burden of Cardiovascular Disease by Reducing Sodium Intake: A Report of the Council on Science and Public Health. Arch Intern Med. 2007;167(14):1460-68, DOI: 10.1001/archinte.167.14.1460.

35. Miller CH, Dilley A, Richardson L, Hooper WC, Evatt BL. Population Differences in Von Willebrand Factor Levels Affect the Diagnosis of Von Willebrand Disease in African-American Women. Am J Hematol. 2001;67(2):125-29, DOI: 10.1002/ajh.1090.

36. Banderas DZ, Escobedo J, Gonzalez E, Liceaga MG, Ramirez JC, Castro MG. Gamma-Glutamyl Transferase: A Marker of Nonalcoholic Fatty Liver Disease in Patients with the Metabolic Syndrome. Eur J Gastroenterol Hepatol. 2012;24(7):80510, DOI: 10.1097/MEG.0b013e328354044a.

37. Torino C, Mattace-Raso F, van Saase JL, Postorino M, Tripepi GL, Mallamaci F, et al. Oxidative Stress as Estimated by Gamma-Glutamyl Transferase Levels Amplifies the Alkaline Phosphatase-Dependent Risk for Mortality in ESKD Patients on Dialysis. Oxid Med Cell Longev. 2016;2016, DOI: 10.1155/2016/8490643.

38. Huxley RR, Bell EJ, Lutsey PL, Bushnell C, Shahar E, Rosamond W, et al. A Comparative Analysis of Risk Factors for Stroke in Blacks and Whites: The Atherosclerosis Risk in Communities Study. Ethn Health. 2014;19(6):601-16, DOI: $10.1080 / 13557858.2013 .857765$.

39. Sonneveld MA, de Maat MP, Portegies ML, Kavousi M, Hofman A, Turecek PL, et al. Low ADAMTS13 Activity Is Associated with an Increased Risk of Ischemic Stroke. Blood. 2015;126(25):2739-46, DOI: 10.1182/blood-2015-05-643338.

40. Mitchell AB, Cole JW, McArdle PF, Cheng YC, Ryan KA, Sparks MJ, et al. Obesity Increases Risk of Ischemic Stroke in Young Adults. Stroke. 2015;46(6):1690-92, DOI: 10.1161/strokeaha.115.008940. 
41. Blokhin IO, Lentz SR. Mechanisms of Thrombosis in Obesity. Curr Opin Hematol. 2013;20(5):437-44, DOI: 10.1097/MOH.0b013e3283634443.

42. Giordano P, Del Vecchio GC, Cecinati V, Delvecchio M, Altomare M, De Palma F, et al. Metabolic, Inflammatory, Endothelial and Haemostatic Markers in a Group of Italian Obese Children and Adolescents. Eur J Pediatr. 2011;170(7):845-50, DOI: 10.1007/s00431-010-1356-7.

43. Atiq F, Fijnvandraat K, van Galen KPM, Laros-Van Gorkom BAP, Meijer K, de Meris $\mathrm{J}$, et al. BMI Is an Important Determinant of VWF and FVIII Levels and Bleeding Phenotype in Patients with Von Willebrand Disease. Am J Hematol. 2019;94(8), DOI: 10.1002/ajh.25499.

44. Zanato V, Lombardi AM, Busetto L, Dal Prà C, Foletto M, Prevedello L, et al. Weight Loss Reduces Anti-ADAMTS13 Autoantibodies and Improves Inflammatory and Coagulative Parameters in Obese Patients. Endocrine. 2017;56(3):521-27, DOI: 10.1007/s12020-016-1059-6.

45. Mozaffarian D, Fahimi S, Singh GM, Micha R, Khatibzadeh S, Engell RE, et al. Global Sodium Consumption and Death from Cardiovascular Causes. N Engl J Med. 2014;371(7):624-34, DOI: 10.1056/NEJMoa1304127.

46. Bochud M, Staessen JA, Maillard M, Mazeko MJ, Kuznetsova T, Woodiwiss A, et al. Ethnic Differences in Proximal and Distal Tubular Sodium Reabsorption Are Heritable in Black and White Populations. J Hypertens. 2009;27(3):606-12, DOI: 10.1097/HJH.0b013e32832104b1.

47. Kianoush S, Yakoob MY, AI-Rifai M, DeFilippis AP, Bittencourt MS, Duncan BB, et al. Associations of Cigarette Smoking with Subclinical Inflammation and Atherosclerosis: Elsa-Brasil (the Brazilian Longitudinal Study of Adult Health). J Am Heart Assoc. 2017;6(6), DOI: 10.1161/JAHA.116.005088.

48. Barua RS, Ambrose JA. Mechanisms of Coronary Thrombosis in Cigarette Smoke Exposure. Arterioscler Thromb Vasc Biol. 2013;33(7):1460-67, DOI: 10.1161/atvbaha.112.300154. 
49. Pan B, Jin X, Jun L, Qiu S, Zheng Q, Pan M. The Relationship between Smoking and Stroke: A Meta-Analysis. Medicine. 2019;98(12), DOI: 10.1097/MD.0000000000014872.

50. Lee DS, Evans JC, Robins SJ, Wilson PW, Albano I, Fox CS, et al. Gamma Glutamyl Transferase and Metabolic Syndrome, Cardiovascular Disease, and Mortality Risk: The Framingham Heart Study. Arterioscler Thromb Vasc Biol. 2007;27(1):127-33, DOI: 10.1161/01.Atv.0000251993.20372.40.

51. Yang W, Kim CK, Kim DY, Jeong HG, Lee SH. Gamma-Glutamyl Transferase Predicts Future Stroke: A Korean Nationwide Study. Ann Neurol. 2018;83(2):375-86, DOI: 10.1002/ana.25158.

52. Enooku K, Kato R, Ikeda H, Kurano M, Kume $\mathrm{Y}$, Yoshida $\mathrm{H}$, et al. Inverse Correlations between Serum ADAMTS13 Levels and Systolic Blood Pressure, Pulse Pressure, and Serum C-Reactive Protein Levels Observed at a General Health Examination in a Japanese Population: A Cross-Sectional Study. Clin Chim Acta. 2013;421:147-51, DOI: 10.1016/j.cca.2013.03.012.

53. Larsen JB, Bor MV, Hvas A-M. Combined Oral Contraceptives Do Not Influence Von Willebrand Factor Related Biomarkers Despite an Induced Acute Phase Response. Thromb Res. 2015;135(1):208-11, DOI: 10.1016/j.thromres.2014.11.007.

54. Liu X, Chen X, Yang J, Guo R. Association of ABO Blood Groups with Von Willebrand Factor, Factor VIII and ADAMTS-13 in Patients with Lung Cancer. Oncol Lett. 2017;14(3):3787-94, DOI: 10.3892/ol.2017.6619. 


\section{Supplementary data}

Table S1. Single linear regression analysis of VWF:Ag and ADAMTS13 with health behaviours

\begin{tabular}{|c|c|c|c|c|}
\hline & \multicolumn{4}{|c|}{ von Willebrand Factor $_{a g}, \%$} \\
\hline & \multicolumn{2}{|c|}{ Black $(n=602)$} & \multicolumn{2}{|c|}{ White $(n=594)$} \\
\hline & $\mathbf{r}$ & $\mathbf{p}$ & $\mathbf{r}$ & $\mathbf{p}$ \\
\hline BMI, $\mathrm{kg} / \mathrm{m}^{2}$ & 0.05 & 0.21 & 0.07 & 0.085 \\
\hline SES score & -0.03 & 0.61 & 0.61 & 0.26 \\
\hline $\mathrm{AEE}, \mathrm{kCal} / \mathrm{kg}$ & -0.04 & 0.40 & 0.04 & 0.34 \\
\hline $\mathrm{GGT}, \mathrm{ng} / \mathrm{ml}$ & 0.01 & 0.80 & -0.02 & 0.63 \\
\hline Alcohol consumption, \% & -0.05 & 0.26 & -0.01 & 0.85 \\
\hline Cotinine, $\mathrm{ng} / \mathrm{ml}$ & -0.08 & 0.047 & 0.001 & 0.98 \\
\hline Smoking, \% & -0.08 & 0.046 & 0.03 & 0.46 \\
\hline Salt intake, g/day & 0.10 & 0.060 & -0.07 & 0.17 \\
\hline
\end{tabular}

\begin{tabular}{lcccc} 
& \multicolumn{4}{c}{ ADAMTS13, $\mathbf{n g} / \mathbf{m l}$} \\
\cline { 2 - 5 } & \multicolumn{2}{c}{ Black (n=602) } & \multicolumn{2}{c}{ White $(\mathbf{n = 5 9 4 )}$} \\
\cline { 2 - 5 } & $\mathbf{r}$ & $\mathbf{p}$ & $\mathbf{r}$ & $\mathbf{p}$ \\
\hline $\mathrm{BMl}, \mathrm{kg} / \mathrm{m}^{2}$ & -0.15 & 0.001 & -0.003 & 0.93 \\
SES score & -0.05 & 0.21 & 0.08 & 0.052 \\
$\mathrm{AEE}, \mathrm{kCal} / \mathrm{kg}$ & -0.04 & 0.41 & 0.001 & 0.98 \\
$\mathrm{GGT}, \mathrm{ng} / \mathrm{ml}$ & 0.004 & 0.92 & 0.18 & $<\mathbf{0 . 0 0 1}$ \\
Alcohol consumption, \% & 0.03 & 0.46 & -0.02 & 0.71 \\
Cotinine, $\mathrm{ng} / \mathrm{ml}$ & -0.03 & 0.47 & -0.06 & 0.13 \\
Smoking, \% & -0.01 & 0.82 & -0.07 & 0.11 \\
Salt intake, g/day & -0.06 & 0.22 & 0.03 & 0.52 \\
\hline
\end{tabular}

Abbreviations: vWF:Ag - von Willebrand factor antigen; ADAMTS13 - a disintegrin and metalloproteinase with a thrombospondin type 1 motif, member 13; BMI - body mass index; SES score - socio-economic status score; AEE - activity energy expenditure; GGT - gamma-glutamyl transferase; $\mathrm{NaCl}$ - sodium chloride. $\mathrm{P}<0.05$ was considered significant 
Table S2. Analysis of covariance of vWF:Ag and ADAMTS13 levels according to hormonal contraceptive use in all women and separately in black and white women

\begin{tabular}{lcccc} 
& $\begin{array}{c}\text { No } \\
\text { contraceptive }\end{array}$ & $\begin{array}{c}\text { Contraceptive } \\
\text { pill }\end{array}$ & $\begin{array}{c}\text { Contraceptive } \\
\text { injection }\end{array}$ & p \\
\hline Total & $(\mathbf{n}=\mathbf{3 4 0})$ & $(\mathbf{n}=\mathbf{1 5 1})$ & $(\mathbf{n = 9 6 )}$ & \\
vWF:Ag $(\%)$ & $1.93 \pm 0.01$ & $1.92 \pm 0.02$ & $1.96 \pm 0.02$ & 0.21 \\
ADAMTS13 $(\mathrm{ng} / \mathrm{ml})$ & $1362 \pm 13.4$ & $1368 \pm 20.2$ & $1373 \pm 25.4$ & 0.92 \\
Black & $(\mathbf{n}=\mathbf{1 6 0})$ & $(\mathbf{n}=\mathbf{3 3})$ & $(\mathbf{n}=90)$ & \\
vWF:Ag $(\%)$ & $1.97 \pm 0.02$ & $2.02 \pm 0.04$ & $1.97 \pm 0.02$ & 0.31 \\
ADAMTS13 $(\mathrm{ng} / \mathrm{ml})$ & $1336 \pm 17.9$ & $1302 \pm 39.5$ & $1349 \pm 24.0$ & 0.59 \\
White & $(\mathbf{n}=\mathbf{1 8 0})$ & $(\mathbf{n}=\mathbf{1 1 8})$ & $(\mathbf{n}=6)$ & \\
vWF:Ag $(\%)$ & $1.89 \pm 0.01$ & $1.89 \pm 0.02$ & - & 0.94 \\
ADAMTS13 $(\mathrm{ng} / \mathrm{ml})$ & $1383 \pm 19.6$ & $1396 \pm 24.3$ & - & 0.69 \\
\hline
\end{tabular}

Adjusted for age and body mass index.

Abbreviation: vWF:Ag - von Willebrand factor antigen; ADAMTS13 - a disintegrin and metalloproteinase with a thrombospondin type 1 motif, member 13. Values are expressed as mean \pm standard error of the mean, $p<0.05$ was considered significant 


\section{Chapter 4}

Summary of main findings and conclusion 


\section{Introduction}

In this summative chapter, the main findings of the study are interpreted and compared to relevant literature. The original hypotheses will be accepted or rejected, a conclusion will be drawn, and recommendations will be made for future research studies.

\section{Summary of the main findings}

This study aimed to determine whether circulating von Willebrand factor antigen (vWF:Ag) and ADAMTS13 concentrations are associated with lifestyle behaviours in young healthy black and white adults, namely physical activity, alcohol consumption, smoking, obesity, salt intake and socio-economic status (SES).

Hypothesis 1: vWF:Ag will be higher and ADAMTS13 will be lower in black individuals compare to whites.

Indeed, our study confirmed this hypothesis. We therefore accept the first hypothesis as the black group presented with higher levels of vWF:Ag and lower levels of ADAMTS13 when compared to their white counterparts. Our findings on vWF:Ag confirm reports from Miller et al. (1) on a study carried out on American women, who found vWF:Ag to be higher in black women compared to their white counterparts. In addition, our results are also in agreement with a South African study by Sukhu et al. (2) who also reported higher vWF:Ag levels in black individuals when compared to whites and Indians. With regards to ADAMTS13, limited studies are available on ethnic differences of circulating ADAMTS13 concentrations. Our study is among the first to confirm significantly lower ADAMTS13 levels in young healthy black compared to white individuals. Despite the limited information on ADAMTS13, Terrel et al. (3) reported that black individuals have a higher incidence of TTP which is caused by ADAMTS13 deficiency, and this formed the basis for our original hypothesis. The authors suggested that genetic diversity that characterises ethnicity plays an important role in plasma levels of VWF and ADAMTS13, and we believe that understanding the effects of 
ethnicity on these two markers may have implications in understanding the thrombotic risks observed in black populations (4).

Hypothesis 2: Black participants will have higher levels of smoking, alcohol consumption, salt intake, obesity, and lower levels of physical activity and SES compared to white participants.

With regards to smoking levels, alcohol use and estimated salt intake we found no differences between the black and white group. White participants presented with a higher body mass index when compared to black individuals, whereas blacks were more active with higher physical activity levels than whites. As hypothesised, a greater number of black participants had a low SES while the majority of whites had high SES. We therefore, partially accept our second hypothesis.

Our findings on obesity and physical activity contradict previous findings. Firstly, a study by Arroyo-Johnson and Mincey (5) found black children between the ages of 9-12 years as well as adults aged 20 years and over to have a higher obesity prevalence compared to their white counterparts in the United States. Secondly, a study by Armstrong et al. (6) in a young population aged 12-29 years, white males were found to have higher and black females to have a lower self-reported physical activity. In addition, minority ethnicity (black) and low income were associated with low physical activity. By contrast, in a South African study including 7348 learners aged 8-14 years, black learners were found to have higher physical activity levels compared to white learners (7). Upon thorough investigation, information on ethnicity and lifestyle behaviours are not consistent in the literature, and differences seem to depend largely on socio-demographic aspects (8-11). It is also clear that conditions in countries such as the United States are not necessarily directly applicable to South African populations where there are major differences in culture, tradition, economy, healthcare and social environment. 
Hypothesis 3: vWF:Ag will be positively and ADAMTS13 will be negatively associated with smoking; obesity; alcohol consumption; and salt intake

To address this hypothesis, the content will be discussed based on specific results found:

\section{The associations of vWF:Ag with obesity and estimated salt intake}

In our young population, VWF:Ag was positively associated with obesity in the total and white group, and with estimated salt intake only in the black group. We therefore partially accept the third hypothesis. Our findings on obesity coincided with findings of a recent study by Atiq et al. (12) who found a positive association between vWF:Ag and BMI in patients with von Willebrand disease. In a study including 79 obese and 64 non-obese children aged 5-10 years, obese children presented with higher vWF:Ag compared to non-obese children (13). Regarding salt intake, Andersson et al. (14), using data from the ARIC study, found elevated plasma sodium concentration to be related to high vWF levels in humans. The authors also showed that high extracellular sodium chloride levels stimulate the production and secretion of vWF by human umbilical vein endothelial cells. This may explain and support our findings in the black group, as black individuals are known to be salt sensitive and to have increased sodium retention in the kidneys (15).

\section{The associations of ADAMTS13 with obesity, smoking and gamma-glutamyl transferase (GGT).}

ADAMTS13 indeed associated negatively with obesity in the total group and as well as smoking in the total and white group, we therefore partially accept the third hypothesis. Since we did not find any association between ADAMTS13 and estimated salt intake, we partially reject the third hypothesis. In a previous study, obese patients were found to have anti-ADAMTS13 antibodies which interferes with ADAMTS13 activity, leading to its deficiency (16). This finding provides a possible mechanism in which obesity may decrease ADAMTS13 levels. With regard to smoking, a study by Ma et al. (17) reported lower ADAMTS13 levels in smokers compared to non-smokers. Furthermore, we also found 
ADAMTS13 to associate positively with GGT in the white group, which we initially considered as a marker of alcohol use. However, after performing sensitivity analysis with self-reported alcohol use, the association with ADAMTS13 was lost. Seeing that selfreported data are subjective and may be unreliable (18), it could be that alcohol use was under-reported in this population and therefore, the association was lost. In addition high levels of GGT is also known as a marker of oxidative stress (19), thereby possibly reflecting an association due to oxidative stress in this group. GGT upregulate the expression of the anti-oxidant glutathione which plays a major role in the protection against oxidative stress (20). This protective effect of GGT may explain the positive association we observed between ADAMTS13 and GGT concentration.

\section{Hypothesis 4: vWF:Ag will be negatively and ADAMTS13 will be positively associated with physical activity and SES.}

We did not find any associations between the two markers of haemostasis (VWF:Ag and ADAMTS13) with physical activity and SES. We therefore, reject our fourth hypothesis. Our hypothesis was based on previous studies, including the $20^{\text {th }}$ year follow-up of the British Regional Heart Study (21), including 3810 elderly men aged 60-70 years from 24 British towns. Plasma levels of VWF were found to be inversely associated with physical activity. In another study, ADAMTS13 was shown to increase after excessive physical activity (22). The mean physical activity in our study was lower compared to this study, and this may explain the lack of association.

Regarding SES, in a previous study, low childhood social class, education and adult SES were associated with high vWF levels in white participants (23). In the same study, results in black individuals were less consistent and lowest adult social class was associated with slightly higher vWF levels. In our study population, the distribution of SES was not equal between the black and white individuals, whereby a greater number of black individuals had lower SES while a high number of whites had higher SES. But, also in our total group there 
was a lack of association between VWF and SES. It is unclear why we were unable to confirm previous findings, but we aim to follow the participants from the study over time, and will re-evaluate these associations in a longitudinal fashion.

\section{Strengths and limitations}

- One of the limitations of this study is that we only investigated two markers of haemostasis, and therefore we could not determine or conclude on the thrombotic risk profile of the black or white participants.

- Our study population consisted of individuals from Potchefstroom and surrounding areas in the North West province, and therefore, our population may not represent the general population of South Africa.

- The cross-sectional nature of our study did not allow us to determine the causal relationship between the two markers and health behaviours.

- A strength of our study is the large sample size $(n=1196)$ with good statistical power and a fair distribution in the number of black $(n=602)$ and white $(n=594)$ individuals.

- Our bi-ethnic population enabled us to determine ethnic differences in the circulating plasma levels of VWF:Ag and ADAMTS13, and how these markers are potentially associated with health behaviours that may explain ethnic differences in cardiovascular outcome.

- We conducted measurements in a controlled environment, and we used gold standard methods to obtain our data.

- The use of the VWF:Ag assay alone, may limit the interpretation of results. Investigating the propeptide:Ag ratio as well as FVIII levels, and or vWF activity may provide a better description of the role of vWF. 


\section{Recommendations}

- In addition to vWF and ADAMTS13, it would be important to investigate a more detailed array of haemostatic markers to obtain a better understanding of ethnic differences in thrombotic risk.

- To better understand the impact imposed by health behaviours on the haemostatic markers, intervention studies assessing the impact of modifying lifestyle and health behaviours on haemostatic markers in order to minimise thrombotic risk should be carried out.

- In our study, an association between ADAMTS13 and sex was observed. It is recommended that future studies with greater sample sizes investigate the influence of sex on the plasma levels of ADAMTS13 and potentially other haemostatic makers especially ADAMTS13.

- We postulated that GGT may be involved in the protection against oxidative stress and therefore, it is recommended that future studies focus on the association of oxidative stress and VWF/ADAMTS13.

\section{Final conclusion}

In our bi-ethnic population, black individuals presented with higher vWF:Ag and lower ADAMTS13 levels compared to whites. The vWF:Ag associated positively with estimated salt intake in the black group and with obesity in the white group, whereas ADAMTS13 associated positively with GGT and negatively with obesity and smoking in the white group. Our findings suggest that ethnic differences contribute to the variation in plasma levels of these two markers and that from young ages, lifestyle and health behaviours already play a role in health risk determination. Therefore, smoking cessation, and reducing obesity and fat/sugar/salt intake while being physically active seem to be the cornerstone in health strategies to prevent and treat cardiovascular disease. 


\section{References}

1. Miller C, Dilley A, Richardson L, Craig Hooper W, L. Evatt B. Population Differences in Von Willebrand Factor Levels in African American Women. Am $\mathrm{J}$ Hematol. $2001 ; 67(2): 125-29$.

2. Sukhu K, Poovalingam V, Mahomed R, Giangrande PF. Ethnic Variation in Von Willebrand Factor Levels Can Influence the Diagnosis of Von Willebrand Disease. Clin Lab Haematol. 2003;25(4):247-49.

3. Terrell DR, Motto DG, Kremer Hovinga JA, Lammle B, George JN, Vesely SK. Blood Group $\mathrm{O}$ and Black Race Are Independent Risk Factors for Thrombotic Thrombocytopenic Purpura Associated with Severe ADAMTS13 Deficiency. Transfusion. 2011;51(10):2237-43.

4. Fall AO, Proulle V, Sall A, Mbaye A, Ba PS, Diao M, et al. Risk Factors for Thrombosis in an African Population. Clin Med Insights Blood Disord. 2014;7:1-6.

5. Arroyo-Johnson C, Mincey KD. Obesity Epidemiology Worldwide. Gastroenterol Clin North Am. 2016;45(4):571-79.

6. Armstrong S, Wong CA, Perrin E, Page S, Sibley L, Skinner A. Association of Physical Activity with Income, Race/Ethnicity, and Sex among Adolescents and Young Adults in the United States: Findings from the National Health and Nutrition Examination Survey, 2007-2016. JAMA Pediatr. 2018;172(8):732-40.

7. Van Biljon A, McKune A, DuBose K, Kolanisi U, Semple S. Physical Activity Levels in Urban-Based South African Learners: A Cross-Sectional Study of 7348 Participants. S Afr Med J. 2018;108(2):126-31.

8. Lincoln KD, Abdou CM, Lloyd D. Race and Socioeconomic Differences in Obesity and Depression among Black and Non-Hispanic White Americans. J Health Care Poor Underserved. 2014;25(1):257-75.

9. Kuntz B, Lampert T. Socioeconomic Factors and Obesity. Dtsch Arztebl nt. $2010 ; 107(30): 517-22$. 
10. Hankonen N, Heino MTJ, Kujala E, Hynynen S-T, Absetz P, Araújo-Soares V, et al. What Explains the Socioeconomic Status Gap in Activity? Educational Differences in Determinants of Physical Activity and Screentime. BMC Public Health. 2017;17(1), DOI: 10.1186/s12889-016-3880-5.

11. Lord S, Manlhiot C, Tyrrell PN, Dobbin S, Gibson D, Chahal N, et al. Lower Socioeconomic Status, Adiposity and Negative Health Behaviours in Youth: A CrossSectional Observational Study. BMJ Open. 2015;5(5), DOI: 10.1136/bmjopen-2015008291.

12. Atiq F, Fijnvandraat K, van Galen KP, Laros-Van Gorkom BA, Meijer K, de Meris J, et al. BMI Is an Important Determinant of VWF and FVIII Levels and Bleeding Phenotype in Patients with Von Willebrand Disease. Am J Hematol. a2019;94(8):E201-E05.

13. García AG, Núñez GG, Sandoval MEV, Castellanos SG, Aguilar CA. Factors Associated with Early Platelet Activation in Obese Children. Clin Med Res. $2014 ; 12(1-2): 21-26$.

14. Dmitrieva NI, Burg MB. Secretion of Von Willebrand Factor by Endothelial Cells Links Sodium to Hypercoagulability and Thrombosis. Proc Natl Acad Sci U S A. 2014;111(17):6485-90.

15. Bochud M, Staessen JA, Maillard M, Mazeko MJ, Kuznetsova T, Woodiwiss A, et al. Ethnic Differences in Proximal and Distal Tubular Sodium Reabsorption Are Heritable in Black and White Populations. J Hypertens. 2009;27(3):606-12.

16. Lombardi AM, Fabris R, Scarda A, Zanato V, Dal Prà C, Scarparo P, et al. Presence of Anti-ADAMTS13 Antibodies in Obesity. Eur J Clin Invest. 2012;42(11):1197-204.

17. Ma Q, Jacobi PM, Emmer BT, Kretz CA, Ozel AB, McGee B, et al. Genetic Variants in ADAMTS13 as Well as Smoking Are Major Determinants of Plasma ADAMTS13 Levels. Blood Adv. 2017;1(15):1037-46.

18. Althubaiti A. Information Bias in Health Research: Definition, Pitfalls, and Adjustment Methods. J Multidiscip Healthc. 2016;9:211-17. 
19. Torino C, Mattace-Raso F, van Saase JL, Postorino M, Tripepi GL, Mallamaci F, et al. Oxidative Stress as Estimated by Gamma-Glutamyl Transferase Levels Amplifies the Alkaline Phosphatase-Dependent Risk for Mortality in ESKD Patients on Dialysis. Oxid Med Cell Longev. 2016;2016, DOI: 10.1155/2016/8490643.

20. Zhang H, Forman HJ. Redox Regulation of Gamma-Glutamyl Transpeptidase. Am J Respir Cell Mol Biol. 2009;41(5):509-15.

21. Wannamethee SG, Lowe GD, Whincup PH, Rumley A, Walker M, Lennon L. Physical Activity and Hemostatic and Inflammatory Variables in Elderly Men. Circulation. 2002;105(15):1785-90.

22. van Loon JE, Sonneveld MA, Praet SF, de Maat MP, Leebeek FWJPo. Performance Related Factors Are the Main Determinants of the Von Willebrand Factor Response to Exhaustive Physical Exercise. Plos One. 2014;9(3):1-8, DOI: 10.1371/journal.pone.0091687.

23. Pollitt RA, Kaufman JS, Rose KM, Diez-Roux AV, Zeng D, Heiss G. Early-Life and Adult Socioeconomic Status and Inflammatory Risk Markers in Adulthood. Eur J Epidemiol. 2007;22(1):55-66. 
Appendices 


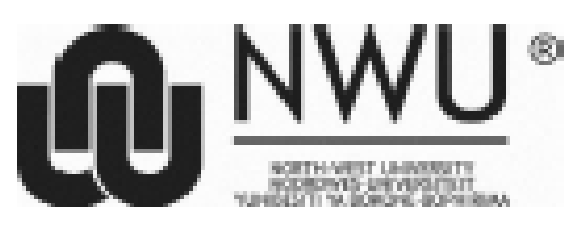

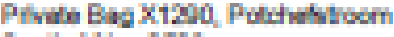 \\ Bouli Arlea 2585 \\ Th: 018 Mot1110h \\ Fax 018 whtoto \\ Wat hipomemiden \\ Mesurth Ethks For-letury Cumm the \\ Th ois

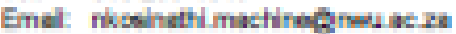

02 May 2019

\title{
ETHICS APPROVAL LETTER OF STUDY
}

Eased on approwal by the Noth West Universty Health Research Etrics Committee (NWU-HREC) on 0205/2019, the NWu Healh Research Ethlse Committee hereby approves your study as Indcated below. Thls Imples that the North-West Unversty Research Etics Regulatory Committee (WWU-RERC) grants its permiselon that, provided the spedal condtions speciled below are met and pending any other authorisation that may be necessary, the study may be Initiated, using the eitics number below.

Study tite: The association of von Willebrand tactor and lis cleaving protesae, ADAMTS13, with health behaviours In young biack and white adulte: The Afrlean-PREDicT study.

Study LeaderiSupervisor (Frinclpal Inveetlgator)/Researcher: Pro' AE schutte student NH Havlae

Ethlca number:

\begin{tabular}{|l|l|l|l|l|l|l|l|l|l|l|l|l|l|l|}
\hline $\mathbf{N}$ & $\mathbf{W}$ & $\mathbf{U}$ & - & 0 & 0 & 0 & 2 & $\mathbf{5}$ & - & 1 & $\mathbf{9}$ & - & $\mathbf{A}$ & 1 \\
\hline
\end{tabular}

Applleaton Type: single study

commencenent date: $0205 / 2019$

Explry date: 31062020

Fisk:

HInImal

Approval of the atudy is initlally provided for a year, after which continuation of the study ls dependent on recelpt and revlew of an annual (or as otherwhe atipulated) monitoring report and the concomiltant liseulng of a letter of contlnuabion.

spectal ln procese condltions of the reaearch for approval (if applicable):

General oondtore:

While this ethics apovovil is sublect to al declavatbns, undertakings and agreements hoorporated and syned in the applcadion fom, the following general tems and conations wiv apply

- The study leadersupensor (principle hiestgatoryesearcher must report in the prescribed format to the NWHFEC:

- amualy ( $\alpha$ as othenwe requested) on the montoing of the sualy, whereby a letter of conthuation Wil be prowled, and upon completton of the study, and

- wthout any delay in case of ary adverse event or indient (or any matter that interuphs sound ethlal Dhalples) oung the coure of the study.

- The approval apples sictiy to the proposal as stipulated in the appication fom. Should any amenoments to the proposal be deemed necesary dury the course of the study, the sudy leaderhesearcher must apply for approval or these amendments at the WWHHREC, prior to Implementation. Should there be any dewations fom the study proposal without the necessary aporoval of such amenoments, the ethics approval is immedatey and automadkaly forteited.

- Annualy a number of sudies may be randony selected for an external audt.

- The dale of approval inolcates the nst date that the study may be started.

- In the hteres or ethical responsibity the WU-RERC and WWHAREC resenes the rght to:

- request access to any hotomaton or data at any the dung the couse or atter completon of the stivgy:

- to ask Auther questions, seek adothonal infomation, require futher modkatbon or montor the conouct of your research or the intomed consent process?

- whoraw or postpone accovol it

- any unethlal pornciples or practices of the sudy are revealed or suspected, 
- If becomes apparent that any relevant infomaton was wheld fom the MWH-hREC or that intomation has been talse or mbrepresented;

- submisolon of the arrual (or otherwise stpulated montoing report, the requied anenaments or repoting of advese events or holoents was not done ha tiney manner and accuratey and/or - new institional rules, national legislabion or intemational conentions deem it necessay.

- WMHAEC can be contacted for further hromaton or any report templates va Ethus. HRECAgolvonwuac.za or $016200120 \%$.

The NWU-HREC would llke to remain at your service as sctentst and researcher, and whes you well with your study. Plese do not hestate to confact the NWU-HFEC or the WWU-FERC for any further enquirles or requests for assistance.

Yours sincerely

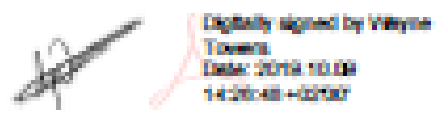

Prot Wayne Tower

Chalperson NWU Haalh Research Ethlcs Committee

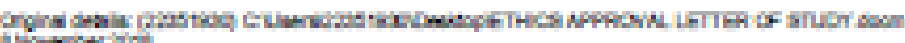
ins ristini

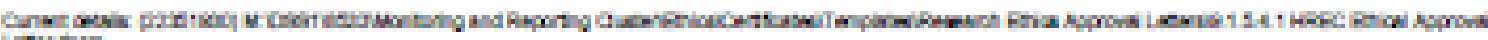
manter

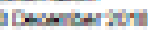

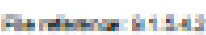


20088310:Nonkus_Turnitin_draft_NHN.docx

\begin{tabular}{|c|c|c|c|c|}
\hline \multicolumn{5}{|l|}{ ORIGINAUTY REPORT } \\
\hline $14 \%$ & $\begin{array}{l}10 \% \\
\text { INTERNET SOURCES }\end{array}$ & $\begin{array}{c}14 \% \\
\text { PUBLICATIONS }\end{array}$ & $\begin{array}{l}15 \% \\
\text { STUDENT }\end{array}$ & \\
\hline \multicolumn{5}{|l|}{ PRINARY SOURCES } \\
\hline \multicolumn{5}{|c|}{$\begin{array}{l}\text { Yolandi Breet, Hugo W. Huisman, Ruan Kruger, } \\
\text { Johannes M. van Rooyen, Lebo F. Gafane- } \\
\text { Matemane, Lisa J. Ware, Aletta E. Schutte. } \\
\text { "Pulse pressure amplification and its relationship } \\
\text { with age in young, apparently healthy black and } \\
\text { white adults: The African-PREDICT study", } \\
\text { International Journal of Cardiology, } 2017 \\
\text { Publication }\end{array}$} \\
\hline
\end{tabular}

2 Wessel L. Du Toit, Aletta E. Schutte, Catharina M. C. Mels. "The relationship of blood pressure with uric acid and bilirubin in young lean and overweight/obese men and women: the AfricanPREDICT study", Journal of Human

Hypertension, 2019

Publication

3 Submitted to North West University Student Paper

5 repository.nwu.ac.za 
6 "Abstracts", Journal of Thrombosis and Haemostasis, 2015.

7 "ABSTRACTS OF THE XXIV CONGRESS OF THE INTERNATIONAL SOCIETY ON THROMBOSIS AND HAEMOSTASIS", Journal of Thrombosis and Haemostasis, 2013. Publication

8 "Abstracts", Research and Practice in Thrombosis and Haemostasis, 2017 Publication

9 Gontse Gratitude Mokwatsi, Aletta Elisabeth Schutte, Catharina Martha Cornelia Mels, Ruan Kruger. "Morning blood pressure surge in young black and white adults: The African-PREDICT Study", Journal of Human Hypertension, 2018 Publication

10 Rens de Groot, Ajoy Bardhan, Nalisha Ramroop, David A. Lane, James T. B. Crawley. "Essential role of the disintegrin-like domain in ADAMTS13 function", Blood, 2009 Publication 
12 Sunelle A. Barnard, Wayne Smith, Catharina M.C. Mels, Shani Botha, Aletta E. Schutte.

"Bioavailable IGF-1 is beneficially associated with biomarkers of endothelial function in young healthy adults: The African-PREDICT study", Growth Hormone \& IGF Research, 2018 Publication

13 Leandi Lammertyn, Aletta E. Schutte, Marlien Pieters, Rudolph Schutte. "D-dimer relates positively with increased blood pressure in black South Africans: The SABPA study", Thrombosis Research, 2014 


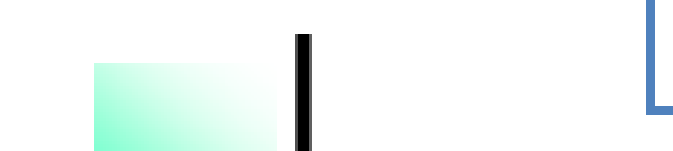

ProCom language consultancy

Professional Communicators and Language Specialists

DATE : 22 NOVEMBER, 2019

1106 ZETHUSHOF, 620 PARK STREET

0083 ARCADIA

$-27641001099,+263778915424$

Jeremutalogmilcem

\section{CERTIFICATE OF ENGLISH LANGUAGE EDITING}

\section{To whom it may concern}

This is to certify that thesis paper with the provisional title 'The association of von Willebrand factor and its cleaving protease (ADAMTS13) with health behaviours in young black and white adults: The African-PREDICT study" has been edited for language by ProCom Language Consultancy. Neither the research content nor the authors' intentions were altered in any way during the editing process.

ProCom Language Consultancy guarantees the quality of English language in this paper, provided our editor's suggestions are accepted and further changes made to the paper are referred back to our editing team.

$$
\text { gisesera }
$$

Mutangadura J. (Dr.) Author Services-ProCom Language Services

Director: Mutangadura J. (DRS, BA Hons, MALSP: UZ, DTech: TUT, PhD: UNISA). 